\title{
Simulation of organics in the atmosphere: evaluation of EMACv2.54 with the Mainz Organic Mechanism (MOM) coupled to the ORACLE (v1.0) submodel
}

\author{
Andrea Pozzer ${ }^{1}$, Simon F. Reifenberg ${ }^{1}$, Vinod Kumar ${ }^{1}$, Bruno Franco ${ }^{2}$, Domenico Taraborrelli ${ }^{3}$, \\ Sergey Gromov ${ }^{1}$, Sebastian Ehrhart ${ }^{1}$, Patrick Jöckel ${ }^{4}$, Rolf Sander ${ }^{1}$, Veronica Fall ${ }^{5}$, Simon Rosanka ${ }^{3}$, \\ Vlassis Karydis ${ }^{3}$, Dimitris Akritidis ${ }^{6}$, Tamara Emmerichs ${ }^{3}$, Monica Crippa ${ }^{7}$, Diego Guizzardi ${ }^{7}$, Johannes \\ W. Kaiser ${ }^{8}$, Lieven Clarisse ${ }^{2}$, Astrid Kiendler-Scharr ${ }^{3}$, Holger Tost ${ }^{9}$, and Alexandra Tsimpidi ${ }^{3,10}$ \\ ${ }^{1}$ Atmospheric Chemistry Department, Max Planck Institute for Chemistry, Mainz, Germany \\ ${ }^{2}$ Université libre de Bruxelles (ULB), Spectroscopy, Quantum Chemistry and Atmospheric Remote Sensing (SQUARES), \\ Brussels, Belgium \\ ${ }^{3}$ Institute of Energy and Climate Research, IEK-8: Troposphere, Forschungszentrum Jülich GmbH, 52428 Jülich, Germany \\ ${ }^{4}$ Deutsches Zentrum für Luft- und Raumfahrt (DLR), Institut für Physik der Atmosphäre, Oberpfaffenhofen, Germany \\ ${ }^{5}$ Illinois-Indiana Sea Grant, University of Illinois, Champaign, IL, USA \\ ${ }^{6}$ Department of Meteorology and Climatology, School of Geology, Aristotle University of Thessaloniki, Thessaloniki, Greece \\ ${ }^{7}$ European Commission, Joint Research Centre, Ispra (VA), Italy \\ ${ }^{8}$ Satellite-based Climate Monitoring Unit, Deutscher Wetterdienst (DWD), Offenbach am Main, Germany \\ ${ }^{9}$ Institute for Atmospheric Physics, Johannes Gutenberg University, Mainz, Germany \\ ${ }^{10}$ National Observatory of Athens, Inst. for Environmental Research and Sustainable Development, Athens, 15236, Greece
}

Correspondence: andrea.pozzer@mpic.de

\begin{abstract}
An updated and expanded representation of organics in the chemistry general circulation model EMAC (ECHAM5/MESSy for Atmospheric Chemistry) has been evaluated. First, the comprehensive Mainz Organic Mechanism (MOM) in the submodel MECCA (Module Efficiently Calculating the Chemistry of the Atmosphere) was activated with explicit degradation of organic species up to five carbon atoms and a simplified mechanism for larger molecules. Second, the ORACLE submodel (version 1.0) considers now condensation on aerosols for all organics in the mechanism. Parameterizations for aerosol yields are used only for the lumped species that are not included in the explicit mechanism. The simultaneous usage of MOM and ORACLE allows an efficient estimation, not only of the chemical degradation of the simulated volatile organic compounds, but also of the contribution of organics to the growth and fate of (organic) aerosol, with a complexity of the mechanism largely increased compared to EMAC simulations with more simplified chemistry. The model evaluation presented here reveals that the $\mathrm{OH}$ concentration is well reproduced globally, while significant biases for observed oxygenated organics are present. We also investigate the general properties of the aerosols and their composition, showing that the more sophisticated and process-oriented secondary aerosol formation does not degrade the good agreement of previous model configurations with observations at the surface, allowing further research in the field of gas-aerosol interactions.
\end{abstract}




\section{Introduction}

Volatile Organic Compounds (VOCs) play a pivotal role in the atmosphere by constraining the total oxidant level and serve as precursors of ozone $\left(\mathrm{O}_{3}\right)$, carbon dioxide $\left(\mathrm{CO}_{2}\right)$ and aerosols (Heald and Kroll, 2020). Due to the complexity of the chemistry of VOCs, a comprehensive and explicit representation thereof is mostly still missing in global and regional model simulations (Heald et al., 2005). To capture this full complexity, model simulations would become rather computationally expensive and slow in performance. However, missing this complexity also substantially limits the current understanding of the budget of secondary pollutants, e.g., $\mathrm{O}_{3}$ and aerosols. The challenges are twofold: 1) to understand and include the chemical degradation pathways, and 2) to also represent all other influencing processes (e.g. deposition, multiphase chemistry) in already complex global/regional models.

A chemical mechanism that stands out for size and detailed oxidation of many important VOCs is the Mainz Organic Mechanism (MOM, Sander et al., 2019). MOM represents the chemistry of alkanes, alkenes, terpenes (isoprene and monoterpenes) and monocyclic aromatics. The mechanism has been employed to study the impact of isoprene $\mathrm{OH}-$ recycling above pristine tropical forests (Taraborrelli et al., 2012), oxidation of monoterpenes as a source of $\mathrm{HO}_{2}$ (Hens et al., 2014; Mallik et al., 2018) and the influence of aromatics on tropospheric ozone (Taraborrelli et al., 2021). Furthermore, MOM has been used with extensions in order to simulate product yields of $\beta$-caryophyllene oxidation (van Eijck et al., 2013), the oxidation of alkyl amines and formamide as source of HNCO (Rosanka et al., 2020), the atmospheric losses of stabilised Criegee intermediates (Vereecken et al., 2017), and the most recent $\mathrm{OH}$-recycling mechanisms in isoprene oxidation (Novelli et al., 2020). Yet, a full evaluation of the VOC distribution predicted by MOM in a global numerical model has not been published.

Furthermore, a more detailed chemical mechanism, which reduces the number of lumped species of larger VOCs, allows an explicit coupling of the VOC chemistry with an interactive aerosol phase partitioning and an organic compound ageing, without losing the chemical identity of the organic compounds. Previous studies (e.g. Farina et al. (2010); Tsimpidi et al. (2016)), which treat the organic aerosol with the help of a volatility basis set (VBS) (Donahue et al., 2011), usually use lumped species to represent tracers with similar volatility and age structure (e.g. O:C ratio, e.g. Ng et al. (2010)) therefore without any chemical identity or detailed degradation scheme.

In this study we present a simulation and an evaluation of the ECHAM/MESSy Atmospheric Chemistry (EMAC) general circulation model (Jöckel et al., 2010, 2016) with a complex organic chemical mechanism (MOM, Sander et al., 2019), accounting not only for the gas phase chemistry, but also for the losses via uptake/condensation into aerosols (via the ORACLE submodel) and cloud droplets (via the SCAV submodel). As the EMAC model has been largely evaluated in the past and for most of the components there were no significant changes, we focus on the evaluation of organic tracers and aerosols. Most importantly, general properties of the aerosols (such as aerosol optical depth (AOD) and particulate concentration below 2.5 $\mu \mathrm{g} \mathrm{m}^{-3}$ ) will be discussed, as these could be strongly affected. Furthermore, changes to the global hydroxyl radical distribution influenced by the new chemistry adopted in this study are discussed.

A comparison for VOCs with the MIM chemical mechanism developed by Pöschl et al. (2000) that has been evaluated by Pozzer et al. (2007) and used previously (Jöckel et al., 2006, 2016) is not shown here as in such mechanism (i) most of organics 
are either lumped, e.g. methyl vinyl ketone (MVK) and methancrolein (MACR), or missing, e.g. aromatics and monoterpenes; (ii) primary species common to MIM and MOM would be influenced only by the different sinks (mainly $\mathrm{OH}$ ), and a detail description of $\mathrm{OH}$ budget is presented here; (iii) the model bias with respect to secondary species, e.g. oxygenated VOCs, has been linked to a mis-representation or lack thereof processes like in-cloud chemistry (Rosanka et al., 2021b; Franco et al., 2021). Therefore any comparison of VOC simulations between MOM and MIM would not give any additional information on the model-observation discrepancy and aid any future model improvement.

The model set-up is presented in Sect. 2, followed by the description of the observational dataset used for the evaluation (Sect. 3), which is then presented for different tracers and aerosol components. This model evaluation is the basis for future studies on complex organic chemistry with EMAC.

\section{Model configuration}

EMAC is a numerical chemistry and climate simulation system that includes submodels describing tropospheric and middleatmosphere processes and their interaction with oceans, land, and human influences (Jöckel et al., 2016). It uses the second version of the Modular Earth Submodel System (MESSy2) to link multi-institutional computer codes. The core atmospheric model is the 5th generation European Centre Hamburg general circulation model (ECHAM5 Roeckner et al., 2006). For the present study, we applied EMAC (ECHAM5 version 5.3.02, MESSy version 2.54.0) in the T63L31-resolution, i.e. with a spherical triangular truncation of T63 (corresponding to a quadratic Gaussian grid of approx. $1.8^{\circ}$ by $1.8^{\circ}$ in latitude and longitude) and 31 vertical hybrid pressure levels up to $10 \mathrm{hPa}$, with roughly 22 levels in the troposphere. The dynamics have been weakly nudged (Jeuken et al., 1996; Jöckel et al., 2006) towards the ERA-interim data (Berrisford et al., 2011) of the European Centre for Medium-Range Weather Forecasts (ECMWF) to reproduce the actual day-to-day meteorology in the troposphere. In this study we simulated two years (2009-2010), with the first year used as spin-up time.

The anthropogenic emissions are based on the Emissions Database for Global Atmospheric Research (EDGARv4.3.2 Crippa et al., 2018), vertically distributed following Pozzer et al. (2009). These prescribed emissions are included in the model via the OFFEMIS submodel (Kerkweg et al., 2006b). The biogenic emissions of Non-Methane Volatile Organic Compounds (NMVOC) are calculated on-line using the Model of Emissions of Gases and Aerosol from Nature (MEGANv2.04, Guenther et al., 2006, 2012). Lightning $\mathrm{NO}_{\mathrm{x}}$ production is based on the parametrization of Grewe et al. (2001), while the algorithm of Yienger (1995) is used for soil $\mathrm{NO}_{\mathrm{x}}$ emissions, as described in detail in Jöckel et al. (2016).

Biomass burning emissions are calculated daily online based on dry matter burned from observations and fire type (Kaiser et al., 2012). The emission factors for different tracers and fire types are taken from Andreae (2019) and Akagi et al. (2011). The ONEMIS submodel (Kerkweg et al., 2006b) calculates natural emission fluxes of sea-salt (Guelle et al., 2001) and of dust (Klingmüller et al., 2018; Astitha et al., 2012). Oceanic emissions and deposition are calculated online with the AIRSEA submodel (Pozzer et al., 2006; Fischer et al., 2012; Lana et al., 2011) for DMS, $\mathrm{CH}_{3} \mathrm{COCH}_{3}, \mathrm{CH}_{3} \mathrm{OH}, \mathrm{C}_{5} \mathrm{H}_{8}, \mathrm{HCN}$, and $\mathrm{CH}_{3} \mathrm{CN}$ (a net sink for $\mathrm{CH}_{3} \mathrm{OH}, \mathrm{HCN}$, and $\mathrm{CH}_{3} \mathrm{CN}$, a net source for the others). $\mathrm{For}_{2}-\mathrm{C}_{3}$ alkanes and alkenes, the oceanic offline emissions from Inness et al. (2012) have been adopted. 
https://doi.org/10.5194/gmd-2021-295

Preprint. Discussion started: 29 September 2021

(c) Author(s) 2021. CC BY 4.0 License.

(c) (1)

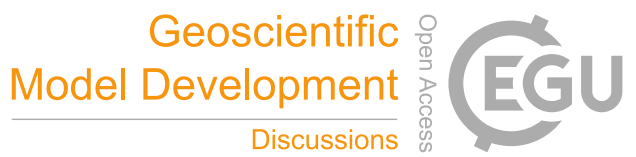

In Table 1 the total emissions are listed for all primary species emitted in the model.

Table 1: . Emissions of primary emitted species for the year 2010 used in this study. The units are in $\operatorname{Tg}(\operatorname{species}) \mathrm{yr}^{-1}$ with the exception of $\mathrm{NO}_{\mathrm{x}}$, in $\mathrm{Tg}(\mathrm{N}) \mathrm{yr}^{-1}$

\begin{tabular}{|c|c|c|c|c|}
\hline Tracer & extended name & Anthropogenic & Natural/Biogenic & Biomass Burning \\
\hline $\mathrm{BC}$ & Black Carbon & 4.34 & & 1.84 \\
\hline $\mathrm{OC}$ & Organic Carbon & 11.05 & & 15.53 \\
\hline $\mathrm{SO} 2$ & Sulfur Dioxide & 99.35 & & 1.95 \\
\hline NOx & nitrogen oxides & 34.50 & 6.09 & 3.98 \\
\hline $\mathrm{CO}$ & carbon monoxide & 537.16 & 106.84 & 289.51 \\
\hline NH3 & ammonia & 57.67 & & 4.07 \\
\hline $\mathrm{C} 2 \mathrm{H} 6$ & ethane & 9.00 & 1.32 & 2.91 \\
\hline $\mathrm{C} 3 \mathrm{H} 8$ & propane & 10.50 & 1.46 & 0.52 \\
\hline $\mathrm{HCN}$ & hydrogen cyanide & & 2.13 & \\
\hline $\mathrm{CH} 3 \mathrm{CN}$ & acetonitrile & & & 1.03 \\
\hline NC4H10 & n-butane & 9.90 & & 0.12 \\
\hline IC4H10 & i-butane & 4.20 & & 0.04 \\
\hline MEK & methyl ethyl ketone & 1.00 & 0.18 & 0.45 \\
\hline $\mathrm{CH} 3 \mathrm{CHO}$ & acetaldehyde & 2.00 & 15.35 & 2.80 \\
\hline $\mathrm{CH} 3 \mathrm{COCH} 3$ & acetone & 1.10 & 35.84 & 1.29 \\
\hline $\mathrm{CH} 3 \mathrm{CO} 2 \mathrm{H}$ & acetic acid & 6.52 & 3.45 & 13.20 \\
\hline $\mathrm{CH} 3 \mathrm{OH}$ & methanol & 9.71 & 105.54 & 6.32 \\
\hline $\mathrm{HCOOH}$ & formic acid & 3.56 & 3.45 & 2.32 \\
\hline $\mathrm{CH} 3 \mathrm{COCO} 2 \mathrm{H}$ & pyruvic Acid & & 0.36 & \\
\hline $\mathrm{HCHO}$ & methanal,formaldehyde & 4.50 & 5.17 & 4.15 \\
\hline $\mathrm{C} 2 \mathrm{H} 4$ & ethene & 5.40 & 24.55 & 3.55 \\
\hline C3H6 & propene & 4.26 & 15.76 & 3.01 \\
\hline $\mathrm{C} 2 \mathrm{H} 2$ & acetylene & 5.40 & & 0.23 \\
\hline BUT1ENE & 1-butene & 1.46 & 6.23 & 0.07 \\
\hline TBUT2ENE & 1,2-dimethylethylene & 1.46 & & 0.05 \\
\hline CBUT2ENE & 2-butene & 1.46 & & 0.20 \\
\hline MEPROPENE & methylpropene & 1.46 & & 0.20 \\
\hline BENZENE & benzene & 5.82 & & 1.42 \\
\hline TOLUENE & toluene & 7.80 & 0.35 & 0.83 \\
\hline
\end{tabular}




\begin{tabular}{|c|c|c|c|}
\hline LXYL & xylenes & 7.24 & \\
\hline LTMB & trimethylbenzenes & 0.95 & \\
\hline PHENOL & phenol & 1.70 & \\
\hline STYRENE & styrene & 1.87 & \\
\hline EBENZ & ethylbenzene & 1.91 & \\
\hline LHAROM & other aromatics & 3.22 & \\
\hline C5H8 & isoprene & & 463.89 \\
\hline APINENE & $\alpha$-pinene & & 33.18 \\
\hline BPINENE & $\beta$-pinene & & 18.71 \\
\hline CARENE & 3-carene & & 6.94 \\
\hline SABINENE & sabinene & & 7.13 \\
\hline CAMPHENE & camphene & & 3.20 \\
\hline $\mathrm{MBO}$ & methyl butenol & & 1.36 \\
\hline LTERP & lumped other terpenes & & 31.86 \\
\hline LALK4 & lumped pentanes & 15.1 & \\
\hline LALK5 & lumped higher alkanes & 21.2 & \\
\hline OLE2 & lumped higher alkenes & 8.20 & \\
\hline DMS & Dimethyl sulfide & & 57.96 \\
\hline
\end{tabular}

Dry deposition and sedimentation are estimated by DDEP and SEDI submodel (Kerkweg et al., 2006a), while wet deposition is simulated by the SCAV submodel (Tost et al., 2006). The dissolution of species in the liquid phase mechanism was augmented by including liquid-gas equilibrium for all additional organics present in the mechanism with a Henry's law constant (solubility) above $10^{3} \mathrm{~mol} \mathrm{~L}^{-1} \mathrm{~atm}^{-1}$. For less soluble species, wet scavenging is not expected to be important (Crutzen and Lawrence, 2000). The Henry's law constants of most oxygenated VOCs of atmospheric relevance are unknown and estimation methods still quite uncertain (Wang et al., 2017). As the hydroxyl (and hydroperoxyl) group affects the solubility in water the most, the Henry's law constants of polyols from the compilation by Sander (2015) are taken as proxies.

In the chemistry submodel MECCA, we used the Mainz Organic Mechanism (MOM, Sander et al., 2019), with roughly 600 species and 1600 reactions. It originates from a reduced isoprene oxidation mechanism (Taraborrelli et al., 2009), which has been updated with recent kinetic data and expanded with efficient mechanisms of OH-recycling under low-NO conditions (Taraborrelli et al., 2012; Nölscher et al., 2014). The oxidation mechanism for $\alpha$-pinene and $\beta$-pinene is based on the MCM (E. Jenkin et al., 2000) with modifications according to the theoretical work of L. Vereecken (Vereecken et al., 2007; Capouet et al., 2008; Nguyen et al., 2009; Vereecken and Peeters, 2012). The degradation of monocyclic aromatics follows the MCM (Jenkin et al., 2003; Bloss et al., 2005) but with some modifications for the chemistry of phenols (Cabrera-Perez et al., 2016). The complete mechanism used in this study is part of the electronic supplement. 
Aerosol microphysics and gas/aerosol partitioning are calculated by the Global Modal-aerosol eXtension (GMXe) aerosol module (described by Pringle et al., 2010a, b). GMXe simulates the distribution of aerosol within interacting lognormal modes (in a similar approach to that of Vignati et al., 2004; Mann et al., 2010). The lognormal modes span four size categories (nucleation $(<5 \mathrm{~nm}$ radius), Aitken $(5-50 \mathrm{~nm})$, accumulation $(50-500 \mathrm{~nm})$, and coarse $(>500 \mathrm{~nm})$ ), and are divided into a hydrophilic (4) and a hydrophobic (3) modes. The GMXe model has been extensively evaluated (Pozzer et al., 2012a, b; Tost and Pringle, 2012; Karydis et al., 2016).

Organic Aerosol (OA) formation is simulated by the submodel ORACLE (Tsimpidi et al., 2014, , v.1.0), where logarithmically spaced saturation concentration bins are used to describe the organic aerosol components based on their volatility. For the formation of primary (POA) and secondary (SOA) organic aerosol from the emissions and photochemical oxidation of semivolatile and intermediate volatility organic compounds the setup of Tsimpidi et al. (2016) is used. However, the SOA formation from the oxidation of the volatile organic compounds (VOC) in ORACLE has been modified to accommodate the photochemical production of components explicitly calculated by the MOM chemical mechanism. The effective saturation concentration of all the species present in the MECCA submodel is calculated based on their elemental composition (number of carbon, oxygen, nitrogen, and sulfur atoms), following the molecular corridor approach (Li et al., 2016) and the study by Donahue et al. (2011). In Figure 1, the volatility versus the molar mass is shown for all tracers present in the model, ranging from high volatility - low molar mass to low volatility - high molar mass. These calculations result in 199 tracers which, under atmospheric conditions, can partition to the aerosol phase forming SOA (i.e., with a volatility lower than $3.2 \times 10^{3} \mu \mathrm{g} \mathrm{m}^{-3}$ ), while the other 396 tracers are considered too volatile for any condensation on aerosol particles. Additionally, the enthalpy of vaporization for the same condensing species has been estimated based on the study by Epstein et al. (2010). In addition to the 199 tracers, 11 additional "lumped species" for different oxidation levels of pentanes, higher alkanes, higher alkenes and terpenes have been added. Then, ORACLE calculates the partitioning of these organic species between the gas and particle phases by assuming a bulk equilibrium, and by further assuming that all organic compounds form a pseudo-ideal solution. The aerosol size distribution is determined by distributing the change in aerosol mass after the bulk equilibrium into each size mode using a weighting factor (Tsimpidi et al., 2014).

The aerosol optical properties are calculated with the submodel AEROPT (Dietmüller et al., 2016), which is based on the scheme by Lauer et al. (2007) and makes use of predefined lognormal modes (i.e., the mode width $\sigma$ and the mode mean radius have to be taken into account). Lookup tables with the extinction coefficient, the single scattering albedo, and the asymmetry factor for the shortwave, and extinction coefficient for the longwave part of the spectrum are pre-calculated with the help of Mie theory-based explicit radiative transfer calculations (see Pozzer et al., 2012a; Dietmüller et al., 2016). The aerosol compounds explicitly considered for their refractve indices are organic carbon, black carbon, dust, sea salt, water-soluble compounds (WASO, i.e. all other water soluble inorganic ions, e.g.: $\mathrm{NH}_{4}^{+}, \mathrm{SO}_{4}^{2-}, \mathrm{HSO}_{4}^{-}, \mathrm{NO}_{3}^{-}$), and aerosol water $\left(\mathrm{H}_{2} \mathrm{O}\right)$. 


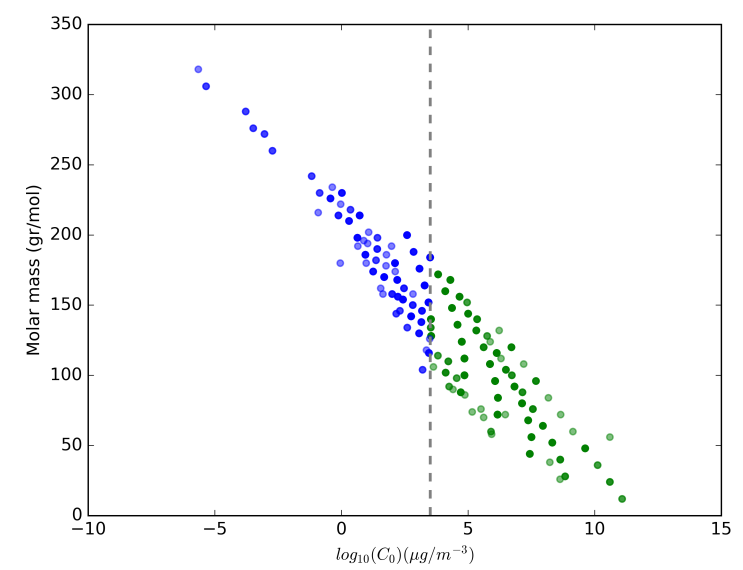

Figure 1. Saturation mass concentrations at $298 \mathrm{~K}$ (Li et al., 2016) versus molar mass of organic tracers in EMAC. The blue dots represent those included in ORACLE, i.e., organic tracers which, under atmospheric conditions, are allowed to condense explicitly on aerosols, the green dots represent those organic tracers always in the gas phase. The dashed line represents the maximum volatility considered in ORACLE (i.e. $3.2 \times 10^{3} \mu \mathrm{g} \mathrm{m}^{-3}$ ) for the VOC oxidation products.

\section{Observational data}

\subsection{Aircraft measurements}

130 We used the database of aircraft measurements of trace gases produced by Emmons et al. (2000). It is based on observations from numerous aircraft campaigns that took place during the period 1990-2001 to create observational-based climatologies of chemical species relevant to tropospheric chemistry. Although these measurements cover only limited time periods and regions, they provide valuable information about the vertical distribution of the analysed trace gases. Note that the field campaigns used in this evaluation have been extended, also including observations after the year 2000, such as those from the TOPSE and

TRACE-P campaigns.

In addition to the Emmons et al. (2000) database, we also included the aircraft measurements for organic aerosols presented by Heald et al. (2011). This dataset includes organic aerosol measurements from 17 aircraft campaigns during the period 2001-2009. Here, similar to Emmons et al. (2000), we consider the aircraft campaigns representative for the period and the regions, i.e., as an observational-based climatology. Therefore, we compared these data with the model results for the year 2010, yielding an improved evaluation of the vertical distribution of the organic aerosols in the troposphere. 


\subsection{Station measurements}

\subsubsection{NOAA-INSTAAR}

Data from the National Oceanic and Atmospheric Administration (NOAA) Institute of Arctic and Alpine Research (INSTAAR) Global Monitoring program were also used in this study. The network consists of 44 background stations from the NOAA Global Greenhouse Gases Reference Network (GGGRN) (Pollmann et al., 2008), where pairs of whole air samples are collected weekly and shipped to a central laboratory for analyses. For this study, we considered measurements of ethane, propane, isoand n-butane from this network.

\subsubsection{EPA}

The Clean Air Markets Division of the U.S. Environmental Protection Agency (EPA) operates the Clean Air Status and Trends Network (CASTNET), with a total of 97 stations. Here, we include weekly filter pack data from 81 stations for $\mathrm{SO}_{4}^{2-}, \mathrm{NO}_{3}^{-}$, $\mathrm{NH}_{4}^{+}, \mathrm{Na}^{+}, \mathrm{Mg}^{2+}, \mathrm{Ca}^{2+}, \mathrm{K}^{+}$and $\mathrm{Cl}^{-}$for the year 2010. The data can be downloaded at www.epa.gov/castnet, last access on December 10, 2020.

\subsubsection{IMPROVE}

In order to evaluate the simulated regional background $\mathrm{OA}$ concentrations, we use monthly averaged $\mathrm{PM}_{2.5} \mathrm{OA}$ measurements during the year 2010 from the Interagency Monitoring of Protected Visual Environments (IMPROVE) program (http://views.cira.colostate.edu/fed, last access on September 21, 2021). IMPROVE is a cooperative measurement effort in the United States designed to characterize current visibility and aerosol conditions in scenic areas (primarily National Parks and Forests). This network includes 198 monitoring sites that are representative of the regional haze conditions over North America. IMPROVE collocated samplers collect 24 hour samples every three days.

\subsubsection{EMEP}

The co-operative programme for monitoring and evaluation of the long-range transmission of air pollutants in Europe (EMEP) is a scientifically-based and policy-driven programme under the Convention on Long-range Transboundary Air Pollution for international co-operation to solve transboundary air pollution problems. We use data from 42 stations, although the number of stations providing sufficient data for a certain species ranges from 22 to 42 (see Table 5). As Teflon filters are used predominantly, depending on the respective station, the concentrations of particulate nitrate can be systematically underestimated (Ames and Malm, 2001). The data were obtained from the EBAS database (http://ebas.nilu.no/, last access on September 21, 2021) and stations not providing full coverage of monthly mean values for the year 2010 were excluded from the analysis. 


\subsubsection{EANET}

The Acid Deposition Monitoring Network in East Asia (EANET) regularly monitors acid deposition as from January 2001. Thirteen countries participate currently in this effort, submitting data from a total of 54 sites. We use monthly averaged aerosol concentrations from 15 to 25 stations, with the data obtained from the Network Center for EANET, at https://monitoring. eanet.asia/document/public/index, last access on September 21, 2021. It is worth mentioning that EANET does not include OA observations. The simulated $\mathrm{PM}_{2.5}$ OA over East Asia is evaluated against collected short-term measurement data as summarized by Jo et al. (2013).

\subsection{Remote sensing observations}

\subsubsection{MOPITT}

The MOPITT (Measurement of Pollution in the Troposphere) is a sensor onboard the NASA's Terra satellite. We use the MOPO3JM version 8 product of MOPITT which provides monthly mean gridded column integrated CO, vertical profiles of $\mathrm{CO}$ mixing ratios at ten regularly spaced pressure levels from the surface up to $100 \mathrm{hPa}$ as well as the corresponding averaging kernels (Deeter et al., 2019). The MOPO3JM product is based on the joint near-infrared (NIR) and thermal-infrared (TIR) retrievals of CO. We apply the MOPITT averaging kernels on the EMAC CO profiles according to equation 1 to ensure the same level of smoothing as that in the MOPO3JM product.

$x_{r t v}=A x_{\text {true }}+(I-A) x_{a}$

Here, $x_{\text {true }}$ is the EMAC profile, $x_{a}$ is the a priori profile, $A$ is the averaging kernel matrix and $I$ represents an identity matrix.

\subsubsection{MODIS}

The MODerate resolution Imaging Spectroradiometer (MODIS) sensor is also located on the Terra satellite. Here, AOD550 data (i.e., Aerosol Optical Depth at $550 \mathrm{~nm}$ ) from the MODIS Level 3 (Col. 6.11) gridded product are used at a spatial resolution of $1^{\circ} \times 1^{\circ}$. The data are available through the Atmosphere Archive \& Distribution System (LAADS) (https://ladsweb.modaps.eosdis.nasa.gov/, last access on September 21, 2021). Here the Deep Blue algorithm (Hsu et al., 2004) was used for the aerosol AOD.

\subsubsection{IASI}

Global observations of a suite of VOCs are retrieved from the thermal infrared measurements of the nadir-viewing IASI (Infrared Atmospheric Sounding Interferometer) instruments (Clerbaux et al., 2009). The VOC dataset exploited here consists of total columns of methanol, acetone, formic and acetic acids, and PAN, retrieved near-globally on a daily basis from the IASI/Metop-A observations with the aid of the ANNI (Artificial Neural Network for IASI) v3 retrieval framework. This neural network-based retrieval approach does not rely on a priori information of the total column and, hence, the products can be 
used directly for unbiased comparisons with model data (see Franco et al., 2018; Whitburn et al., 2016). The satellite products are filtered for measurements affected by clouds and poor retrieval performance. The uncertainties on the individual retrieved column can be large, but are considerably reduced by averaging numerous observations, as done in this study by comparing annual averages. A full description of the ANNI framework, the characterization of the VOC products, and comparisons of the satellite data with independent measurements can be found in Franco et al. $(2018,2019,2020)$ and references therein. For both, IASI and the model, daily gridded averages were constructed at the spatial resolution of the model grid. To have similar temporal coverage over the year between model and satellite observations, the EMAC daily averages were masked when the corresponding IASA data were missing for the same day and location.

\subsubsection{AERONET}

The AOD observations have been obtained from the global AErosol RObotic NETwork (AERONET Holben et al., 1998; Dubovik et al., 2000). The cloud-screened quality-assured Level 2 AOD data used in this study were obtained from the website http://aeronet.gsfc.nasa.gov/cgi-bin/combined_data_access_new (last access on September 21, 2021) including AOD daily averages.

\subsection{Pseudo observations}

Global annual averages of fine particulate matter with an aerodynamic diameter below $2.5 \mu \mathrm{m}\left(\mathrm{PM}_{2.5}\right)$ have been obtained from Hammer et al. (2020). In this dataset, a combination of satellite observed AOD, numerical model, and ground-based $\mathrm{PM}_{2.5}$ measurements were used to estimate $\mathrm{PM}_{2.5}$ on a global scale at high resolution.

\section{Results}

215 In Table 2, the comparison of the model results with the aircraft campaign data from Emmons et al. (2000) is presented for selected tracers. In general the model reproduces the main features observed, as more than $82 \%$ of the simulated values are within a factor of 2 compared to the observations for all species. Nevertheless, for some species (such as the alkene $\mathrm{C}_{4} \mathrm{H}_{6}$ ), a clear underestimation is seen, cohering with former results (Pozzer et al., 2006).

\subsection{CO}

Figure 2 shows the seasonal (MAM: March, April, May; JJA: June, July, August; SON: September, October, November; DJF: December, January and February) mean modified EMAC and MOPITT CO vertical column densities (VCD). Here, we term it as "modified" EMAC VCDs because MOPITT averaging kernels are applied on the simulated CO profiles to account for the sensitivity of MOPITT. To highlight the difference in spatial patterns of EMAC and MOPITT, we also show the absolute bias in the bottom panel.

225 We note that the spatial patterns are in good agreement between simulation and observations. In particular, the elevated CO background in the outflow regions (over oceans) in the northern hemisphere is well represented during boreal winter (DJF) 
https://doi.org/10.5194/gmd-2021-295

Preprint. Discussion started: 29 September 2021

(C) Author(s) 2021. CC BY 4.0 License.

(c) (i)

\begin{tabular}{lcccccccc}
\hline Species & N.points & MM & MSTD & OM & OSTD & MM/OM & PF2 & RMSE \\
\hline $\mathrm{CO}$ & 457 & 90.41 & 32.63 & 94.86 & 72.11 & 1.03 & 100.0 & 63.991 \\
$\mathrm{C}_{2} \mathrm{H}_{4}$ & 454 & 25.16 & 139.23 & 45.93 & 175.49 & 1.06 & 89.2 & 110.05 \\
$\mathrm{C}_{2} \mathrm{H}_{6}$ & 473 & 539.19 & 320.22 & 826.09 & 544.14 & 0.70 & 100.0 & 409.24 \\
$\mathrm{C}_{3} \mathrm{H}_{6}$ & 332 & 6.25 & 63.13 & 13.70 & 53.09 & 0.40 & 93.6 & 32.64 \\
$\mathrm{C}_{3} \mathrm{H}_{8}$ & 472 & 94.96 & 123.26 & 164.99 & 225.57 & 0.89 & 93.2 & 149.02 \\
$\mathrm{CH}_{3} \mathrm{COCH}$ & 246 & 520.61 & 274.71 & 608.50 & 310.84 & 0.92 & 97.9 & 291.65 \\
$\mathrm{CH}_{3} \mathrm{OH}$ & 37 & 595.76 & 369.59 & 913.86 & 373.06 & 0.66 & 100.0 & 426.52 \\
$\mathrm{CH}_{3} \mathrm{OOH}$ & 366 & 210.71 & 190.79 & 376.80 & 321.19 & 0.66 & 96.7 & 251.34 \\
$\mathrm{HCHO}$ & 213 & 198.08 & 377.76 & 192.24 & 299.65 & 1.44 & 84.5 & 235.36 \\
$\mathrm{HCOOH}$ & 53 & 32.67 & 7.05 & 58.92 & 43.55 & 0.87 & 96.2 & 49.41 \\
$\mathrm{CH}_{3} \mathrm{COOH}$ & 53 & 13.50 & 7.08 & 51.08 & 28.31 & 0.34 & 100.0 & 46.51 \\
$\mathrm{HNO}_{3}$ & 416 & 151.33 & 188.49 & 162.15 & 285.72 & 1.25 & 82.4 & 237.42 \\
$\mathrm{H}_{2} \mathrm{O}$ & 411 & 634.08 & 611.96 & 745.48 & 875.21 & 1.09 & 91.7 & 516.44 \\
$\mathrm{PAN}$ & 395 & 62.46 & 71.30 & 162.60 & 186.81 & 0.61 & 96.7 & 185.79 \\
$\mathrm{O}_{3}$ & 506 & 68.23 & 76.00 & 51.06 & 26.10 & 1.31 & 92.8 & 62.54 \\
\hline
\end{tabular}

Table 2. Summary of simulated and observed mixing ratios of different tracers in the Emmons et al. (2000) database. N.points is the number of points used for the statistical estimation. The arithmetic mean of the model simulated mixing ratios (MM), the observed mixing ratios $(\mathrm{OM})$, and the corresponding standard deviations (MSTD, OSTD) in $\mathrm{pmol} / \mathrm{mol}$ are listed in the subsequent columns. For $\mathrm{CO}$ and $\mathrm{O}_{3}$ the units are in nmol/mol. PF2 denotes the percentage of simulated points within a factor of 2 with respect to the observations, and RMSE represents the root mean square error between simulated and observed points.

and spring (MAM). The outflow region around south America in SON is also simulated well. Over land, a good agreement is found for Europe, central and Eastern United States, northern Africa, Australia, Russia, and the Indian subcontinent with a mean bias within $\pm 1 \times 10^{18}$ molecules $\mathrm{cm}^{-2}$. During the biomass burning seasons (JJA in central Africa, north and north-east China and SON in south America), we observe an overestimation of $30 \%$ by EMAC. By comparing EMAC's total CO columns to IASI CO satellite retrievals, Rosanka et al. (2021c) found that EMAC tends to underestimate CO in Indonesia in SON 2015. In 2015, a particularly strong El Niño led to severe peatland fires, which resulted in large CO emissions. Rosanka et al. (2021c) attribute the underestimation to a too low biomass burning emission factor for peatland used by EMAC. Here, we do not find any underestimation of CO in Indonesia in SON (see Fig. 2), since the year 2010 was a year with little biomass burning emissions in Indonesia (van der Werf et al., 2017). Following their analysis, the recent biomass burning emission factor estimate by Andreae (2019) suggests that EMAC underestimates the CO emission factor by about $10 \%$ in Central South America and Africa. It must however be stressed that the uncertainties on biomass burning emissions are substantial, depending on regions and species (Carter et al., 2020). In contrast, in South America the overprediction of EMAC's CO columns can be 

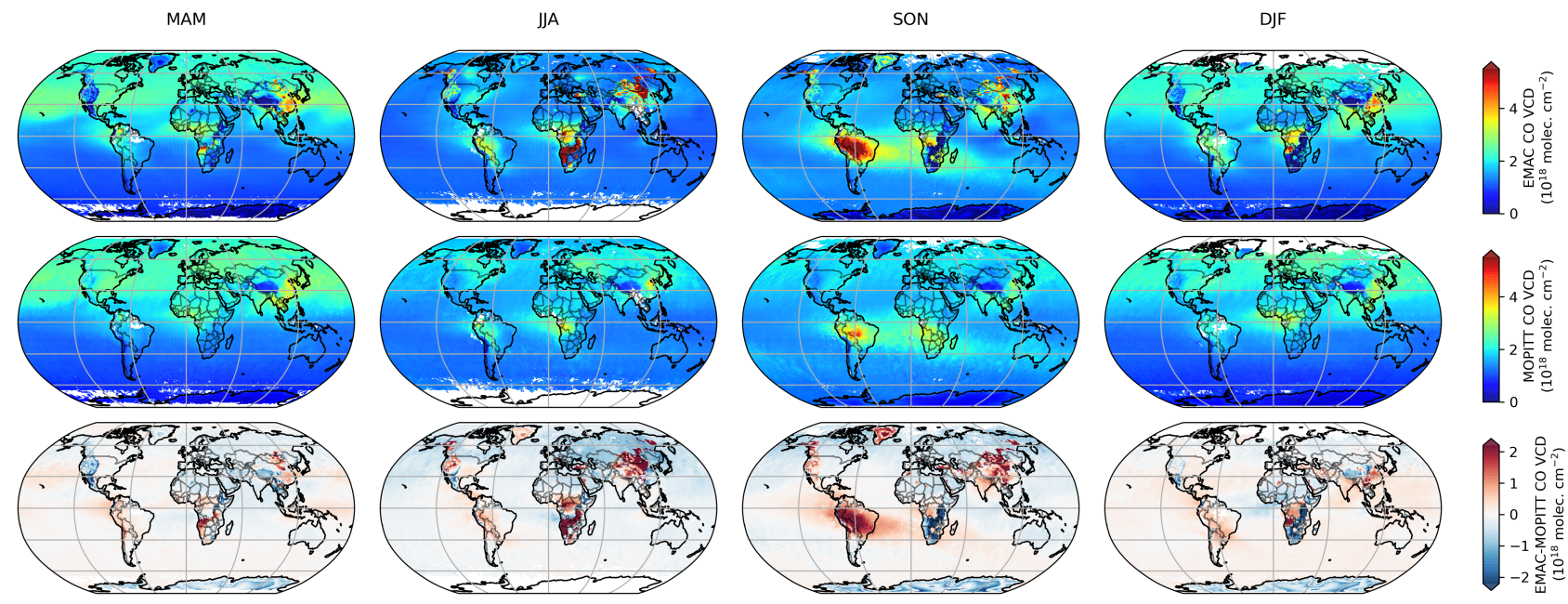

Figure 2. Global seasonal mean maps of CO vertical column densities (VCD) for the year 2010 for EMAC (top), MOPITT (middle), and bias (EMAC - MOPITT), (bottom).

partially attributed to EMAC's tendency to overestimate biogenic emissions of CO precursors in this region (Rosanka et al., $2021 b, c)$.

Figure 3 shows the 2010 annual mean measured and simulated surface CO mixing ratio at the WDCGG stations sorted according to their latitude coordinates. The relative bias at all stations is also shown on a global map in the inset of Figure 3. Similar latitudinal gradients are seen for the measurements and simulations with high values around the mid-latitudes of the northern hemisphere. The measured and simulated CO agree within $1 \sigma$ annual variability for 106 out of 113 stations for which data were available for the year 2010. The bias between model and simulation was found to be less than $20 \%$ of the observations for 96 stations.

\subsection{Volatile Organic Compounds}

\subsection{1 $\mathrm{C}_{2}-\mathrm{C}_{4}$ Alkanes}

Alkanes are VOC ubiquitously present in the atmosphere, mainly emitted from anthropogenic activities. In Figure 4 the scatter plots of model results and in-situ observations from the NOAA/INSTAR database are presented. The statistic for each plot is summarized in Table 3. The model seems to reproduce satisfactorily the mixing ratios of the $\mathrm{C}_{2}-\mathrm{C}_{4}$ alkanes with more than $98,91,84$ and $79 \%$ of the simulated values lying within a factor of two to the observations for $\mathrm{C}_{2} \mathrm{H}_{6}, \mathrm{C}_{3} \mathrm{H}_{8}, \mathrm{i}-\mathrm{C}_{4} \mathrm{H}_{10}$ and $\mathrm{n}-\mathrm{C}_{4} \mathrm{H}_{10}$, respectively. Furthermore, the average ratios show that a slight overestimation is present for i-butane and n-butane, whereas the model tends to underestimate the mixing ratios of ethane and propane. This is confirmed by the comparison with 


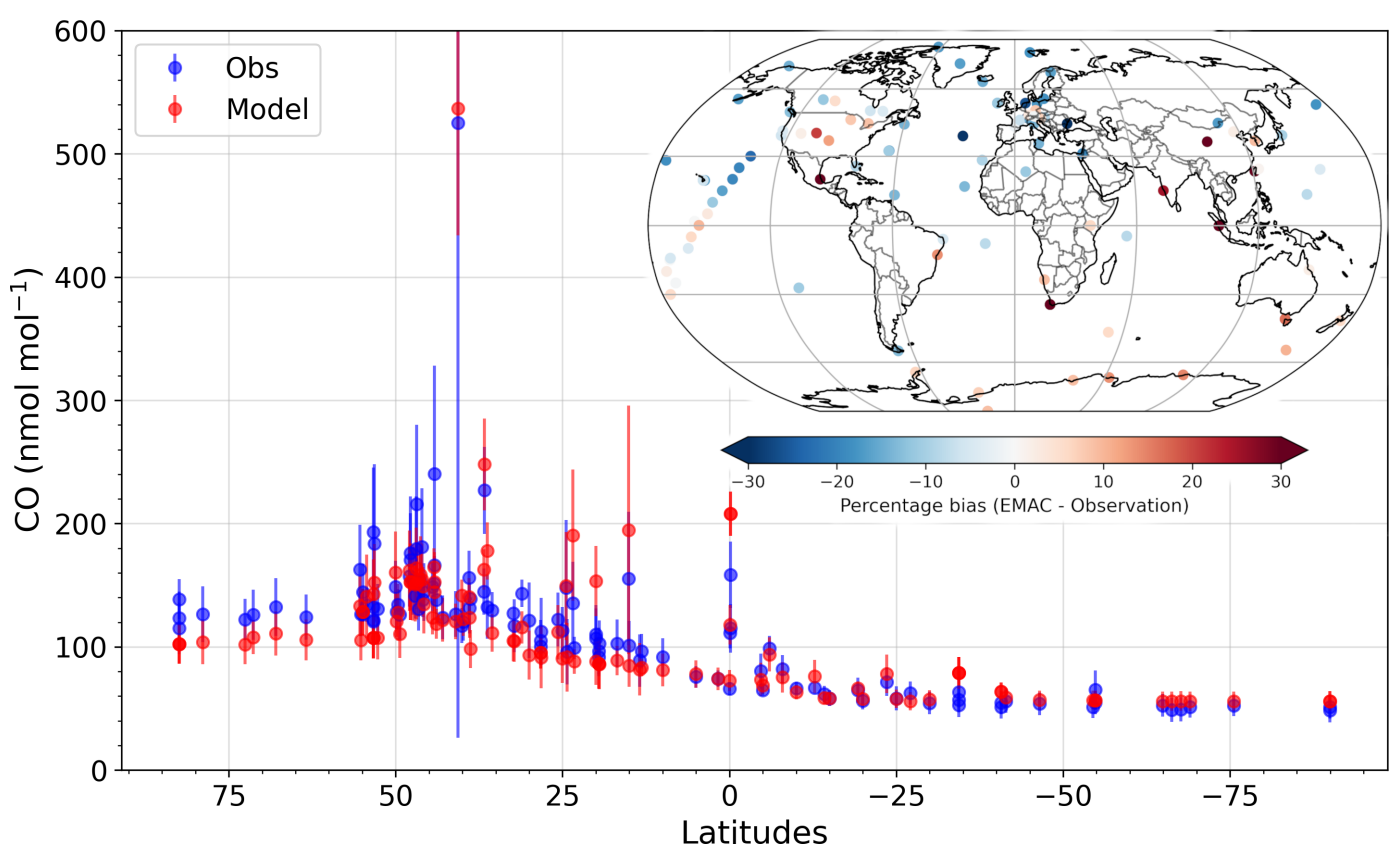

Figure 3. Latitudinal gradient of the annual mean (2010) of the measured and simulated surface CO mixing ratio at the WDCGG measurement stations. The error bars show the $1 \sigma$ standard deviation of the annual mean (based on daily mean output). The map in the inset shows the annual bias between the simulation and measurements at the locations of the WDCGG stations.

the Emmons et al. (2000) database (Table 2), which shows that both, ethane and propane, are underestimated by the model, also with respect to the vertical profile (column $\overline{\mathrm{MM} / \mathrm{OM}}$ ).

Figure 4 shows also a noticeable underestimation of the mixing ratios in the region between $30^{\circ} \mathrm{N}$ and $0^{\circ} \mathrm{N}$, for propane and the butanes. This is clearly due to the underestimation of the oceanic emissions, as these stations (i.e., at Mahe Island, Seychelles (SEY), The American Samoa Observatory (SMO), Ascension Island, UK (ASC), and Easter Iland, Chile (EIC)) are all strongly influenced by oceanic emissions. It must be pointed out that for $\mathrm{i}-\mathrm{C}_{4} \mathrm{H}_{10}$ and $\mathrm{n}-\mathrm{C}_{4} \mathrm{H}_{10}$, no oceanic emissions where included in the simulation, but that these are necessary for a correct representation of butanes, as already shown previously (Pozzer et al., 2010).

\subsection{2 $\mathrm{C}_{2}-\mathrm{C}_{3}$ Alkenes}

Differently from alkanes, the alkenes are mostly emitted by the biosphere. As shown in Table 2, the numerical simulation of alkenes diverges more from the observations than the simulated alkanes do. Both, $\mathrm{C}_{2} \mathrm{H}_{4}$ and $\mathrm{C}_{3} \mathrm{H}_{6}$, are underestimated compared to the observations (see model mean, MM, against observed mean, OM in Tab. 2). Nevertheless, while $\mathrm{C}_{2} \mathrm{H}_{4}$ is overall reasonably reproduced (average of the ratios equal to 1.06, see Table 2), for $\mathrm{C}_{3} \mathrm{H}_{6}$ a strong underestimation is present (average of the ratios equal to 0.4, see Table 2). This is shown in Fig. 5, where examples of the vertical distribution of $\mathrm{C}_{2} \mathrm{H}_{4}$ 
https://doi.org/10.5194/gmd-2021-295

Preprint. Discussion started: 29 September 2021

(c) Author(s) 2021. CC BY 4.0 License.

(c) (1)
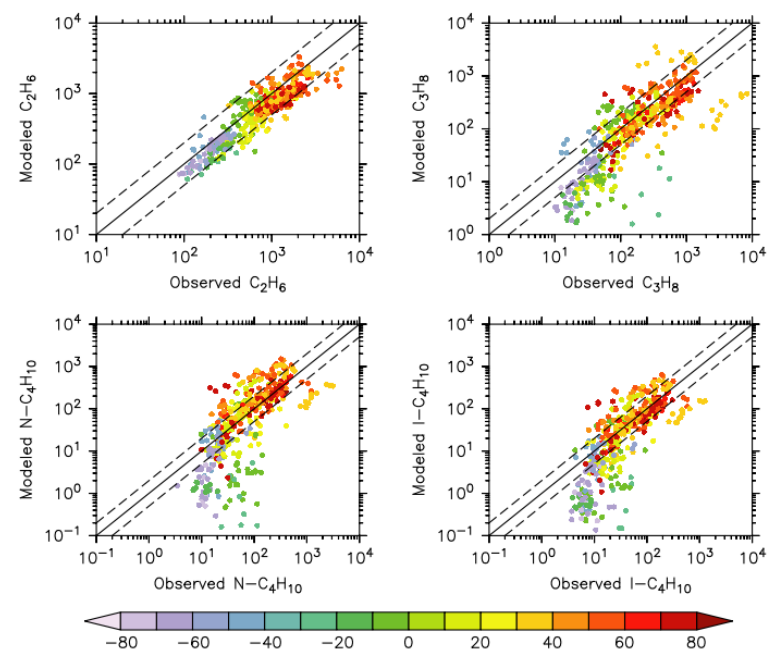

Figure 4. Scatter plot of measured and simulated surface alkanes mixing ratios at the NOAA/INSTAAR measurement stations for the year 2010. The units are in $\mathrm{pmol} \mathrm{mol}{ }^{-1}$. The color code denotes the latitude of the stations.

\begin{tabular}{lcccccccc}
\hline Species & N.points & MM & MSTD & OM & OSTD & $\overline{\text { MM/OM }}$ & PF2 & RMSE \\
\hline $\mathrm{C}_{2} \mathrm{H}_{6}$ & 450 & 742.54 & 551.02 & 1038.32 & 845.09 & 0.77 & 98.4 & 621.54 \\
$\mathrm{C}_{3} \mathrm{H}_{8}$ & 447 & 262.87 & 417.25 & 393.13 & 745.48 & 0.91 & 91.5 & 755.93 \\
$\mathrm{i}-\mathrm{C}_{4} \mathrm{H}_{10}$ & 436 & 70.60 & 97.44 & 73.73 & 126.46 & 1.23 & 84.8 & 124.23 \\
$\mathrm{n}-\mathrm{C}_{4} \mathrm{H}_{10}$ & 423 & 160.49 & 231.75 & 146.89 & 293.97 & 1.46 & 79.6 & 307.80 \\
\hline
\end{tabular}

Table 3. Summary of simulated and observed mixing ratios of different tracers in the NOAA/INSTAAR database (station observations). The columns are as in Table 2

are shown. The issues in simulating $\mathrm{C}_{3} \mathrm{H}_{6}$ have been already pointed out by Pozzer et al. (2006), where similar results were obtained with large underestimation of this tracer.

\subsection{3 $\mathrm{CH}_{3} \mathrm{OH}$}

$\mathrm{CH}_{3} \mathrm{OH}$ is the most abundant oxygenated VOC is the Earth's atmosphere (Singh et al., 2001), primarily emitted by the terrestrial vegetation (Jacob et al., 2005). Other sources include biomass burning, the oceans and secondary formation in the troposphere (e.g., Millet et al., 2008; Stavrakou et al., 2011). The annual global distribution of $\mathrm{CH}_{3} \mathrm{OH}$ total columns obtained from 

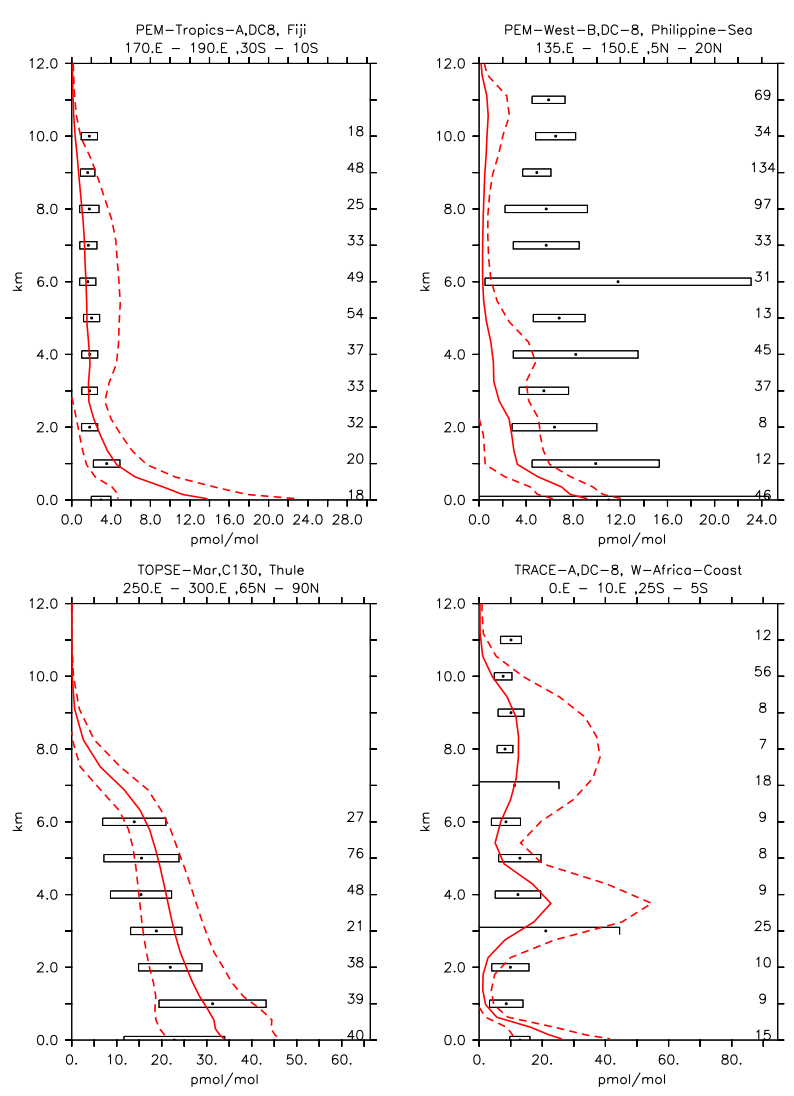

Figure 5. Vertical profiles of $\mathrm{C}_{2} \mathrm{H}_{4}$ in pmol mol ${ }^{-1}$ for some selected campaigns from Emmons et al. (2000). Asterisks and boxes represent the average and the standard deviation (w.r.t. space and time) of the measurements in the region, respectively. The simulated average is indicated by the red line and the corresponding simulated standard deviation w.r.t. time and space by the dashed lines. On the right hand side, the number of measurements is listed.

the IASI measurements and EMAC of the year 2010 as well as their differences are presented in Fig. 6. Over land, the satellite and model spatial distributions of $\mathrm{CH}_{3} \mathrm{OH}$ are relatively consistent, with the main source regions observed within the tropics (mainly over the Amazon Basin and central Africa), in Southeast Asia, and at Northern Hemisphere mid- and high latitudes. However, important differences in terms of column magnitude exist. Over the tropical forests, EMAC indeed simulates annual $\mathrm{CH}_{3} \mathrm{OH}$ columns up to two times larger than those retrieved from the IASI observations (3.0-3.5 $\times 10^{16}$ molecules cm $^{-2}$ ). This can be partly ascribed to the high temperature bias that exists in the model over these areas (Hagemann and Stacke, 2015), which induces an excess of biogenic VOC emissions from the MEGAN submodel. Furthermore, dry deposition of methanol in tropical rainforests is likely under-represented by the Wesely (1989) approach used here (Karl et al., 2004). The potential contribution of an additional non-stomatal pathway favourable under humid conditions (Müller et al., 2018) has been shown by Emmerichs et al. (2021) for a less soluble species. On the other hand, EMAC underestimates the $\mathrm{CH}_{3} \mathrm{OH}$ columns at mid- and 

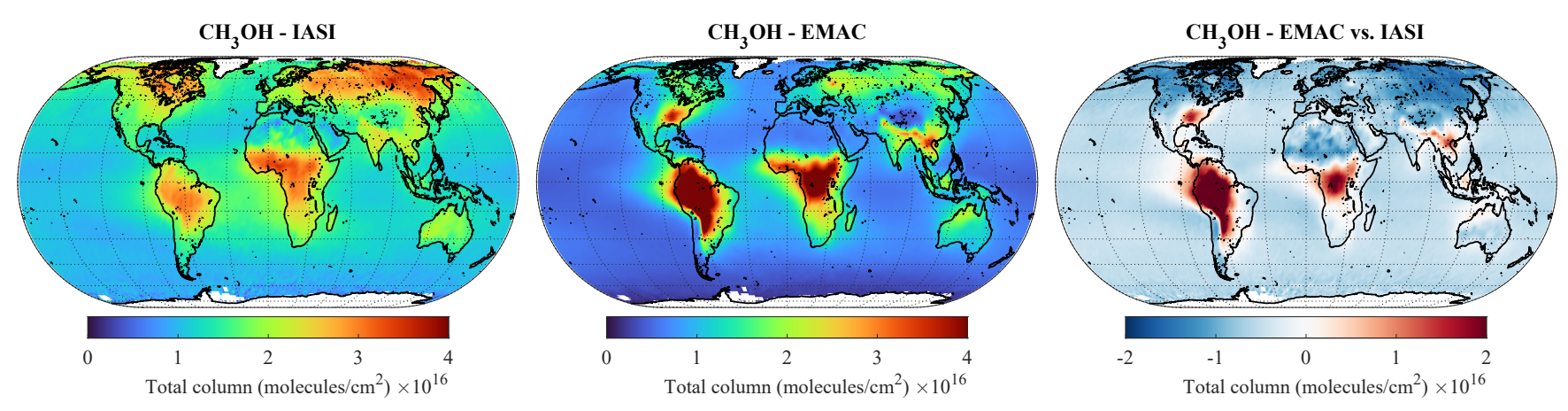

Figure 6. Annually averaged $\mathrm{CH}_{3} \mathrm{OH}$ total columns (in molecules $\mathrm{cm}^{-2}$ ) from IASI satellite observations (left), simulated by EMAC (middle), and the EMAC-to-IASI column differences (right), for the year 2010.

high latitudes of the Northern Hemisphere, indicating that biogenic and/or biomass burning VOC emissions are too low during summertime in these regions. Southeast US is the region in North America where most of the simulated $\mathrm{CH}_{3} \mathrm{OH}$ enhancement exists, driven by substantial biogenic emissions in summertime, while larger columns are measured by IASI during the same season further northwards in the boreal regions. Over the oceans, EMAC underestimates the observed $\mathrm{CH}_{3} \mathrm{OH}$ columns by $\sim 5 \times 10^{15}$ molecules $\mathrm{cm}^{-2}$, which might result from an insufficient transport from the continental source regions and/or from missing secondary source(s) (see e.g., Bates et al., 2021; Müller et al., 2016). This is confirmed by the comparison of model results with the Emmons et al. (2000) database, where the methanol model mean is considerably lower than the observed one.

\subsection{4 $\mathrm{CH}_{3} \mathrm{COCH}_{3}$}

Acetone is the one of the most abundant oxygenated VOCs in the Earth's atmosphere after $\mathrm{CH}_{3} \mathrm{OH}$ (Singh et al., 2001). Its sources include the terrestrial vegetation, the oxidation of hydrocarbon precursors of biogenic and anthropogenic origin, the oceans and biomass burning (e.g., Jacob et al., 2002; Pozzer et al., 2010; Fischer et al., 2012). The acetone total columns obtained from the EMAC simulation and the IASI observations exhibit major discrepancies in terms of global distribution (Figure 7). The satellite instrument detects the largest acetone columns (up to $2 \times 10^{16}$ molecules $\mathrm{cm}^{-2}$ ) at mid- and high latitudes of the boreal hemisphere, ascribed to important emissions of biogenic precursors during summertime (Franco et al., 2019), but a moderate burden at low latitudes and over the tropical forests. It is worth noting that this pattern is in agreement with the global acetone measurements obtained with the ACE-FTS satellite limb sounder (Dufour et al., 2016). Conversely, EMAC simulates strong hotspots of acetone within the tropics, especially over South America and Africa, with annually averaged columns larger than $2 \times 10^{16}$ molecules $\mathrm{cm}^{-2}$, but underestimates the acetone abundance by up to a factor of 2 in the Northern Hemisphere. Such a mismatch between satellite and model distributions points to major deficiencies in the current emission inventories of acetone and its precursors. For example, the extremely large acetone columns simulated by EMAC over the Persian Gulf and the Indo Gangetic Plain can be attributed to the highly elevated emissions of propane - an important precursor of acetone - in these regions. In vegetated regions, an underestimation of acetone dry deposition, accounting globally 

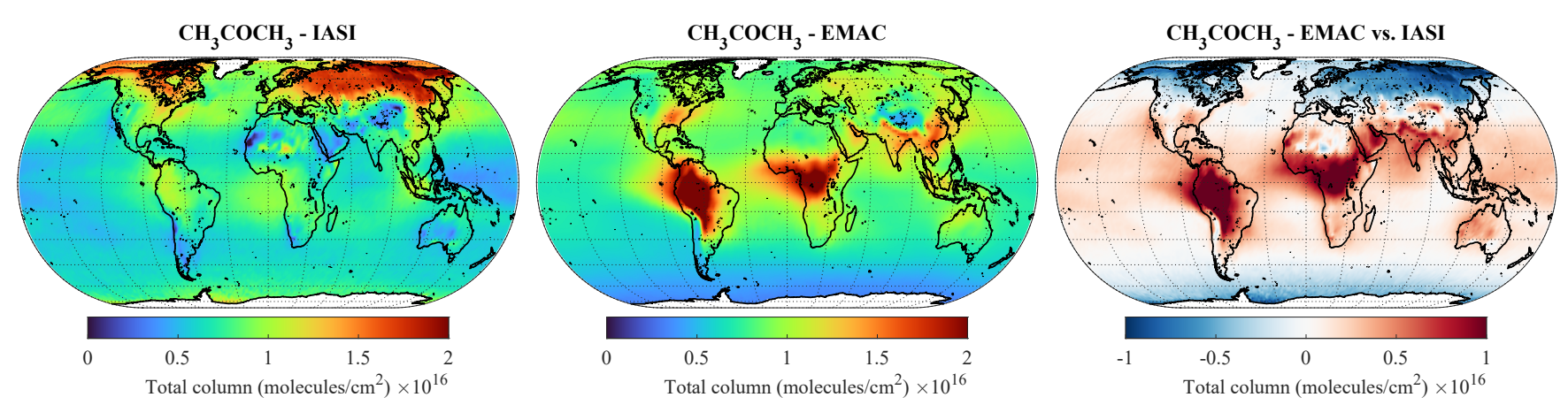

Figure 7. Same as Fig. 6, but for $\mathrm{CH}_{3} \mathrm{COCH}_{3}$.

for $20 \%$ of the total loss (Khan et al., 2015), likely contributes to the mismatch. According to measurements, significant amounts of acetone are removed during night through non-stomatal uptake (Karl et al., 2004; Müller et al., 2018). However, over remote areas and the oceans, the simulated acetone abundance is consistent with the IASI measurements, with vertical column integrals in the range of $0.5-1.0 \times 10^{16}$ molecules $\mathrm{cm}^{-2}$. The model, nevertheless, simulates a slight overestimation over the oceans at low latitudes compared to IASI, especially in the outflows of the tropical hotspots. Compared to the aircraft observations, the model results present a much better agreement than when compared against remote sensed data, with only a somewhat small bias (see Tab. 2). This apparent agreement with the observations is due to the uneven distribution of the field campaign present in the observational dataset (see Emmons et al. (2000), Fig.1 and Huijnen et al. (2019), Fig.1). In fact, most of the campaigns in which acetone was measured took place over the ocean, where the model is correct or slightly overestimating the total column observed by IASI. In contrast, only few campaigns in the Northern Hemisphere are present in the dataset (such as ABLE-3B, and POLINAT-2) for which the model strongly underestimates the observed values. As a result of the sparsity of the aircraft observations used, Table 2 presents a quite fair agreement between model and aircraft observations, an agreement which is, however, not corroborated by the more spatially complete comparison with the IASI total column.

\subsection{5 $\mathrm{HCOOH}$}

Formic acid is the dominant organic acid in the troposphere and a product of the degradation of a large suite of VOC precursors, but its observed abundance is generally severely underestimated by state-of-the-art global models (e.g., Millet et al., 2015; Paulot et al., 2011; Stavrakou et al., 2012). Similarly, in our simulation the EMAC model largely underestimates the HCOOH total columns derived from the IASI observations by up to a factor of 4 , in particular in remote environments (see Fig. 8). Although the two main tropical source regions identified by IASI - the Amazon Basin and central Africa - are reproduced by EMAC, the magnitude of the simulated $\mathrm{HCOOH}$ columns are too low in comparison to the satellite measurements. It also has to be mentioned that the apparent agreement over Amazonia is possibly due to the high temperature bias in the region and the subsequent excess of simulated isoprene emissions during the dry season. Over the other source regions (e.g., Southeast Asia and Southeast US), the model underestimation is more pronounced, in particular in the Northern Hemisphere. 

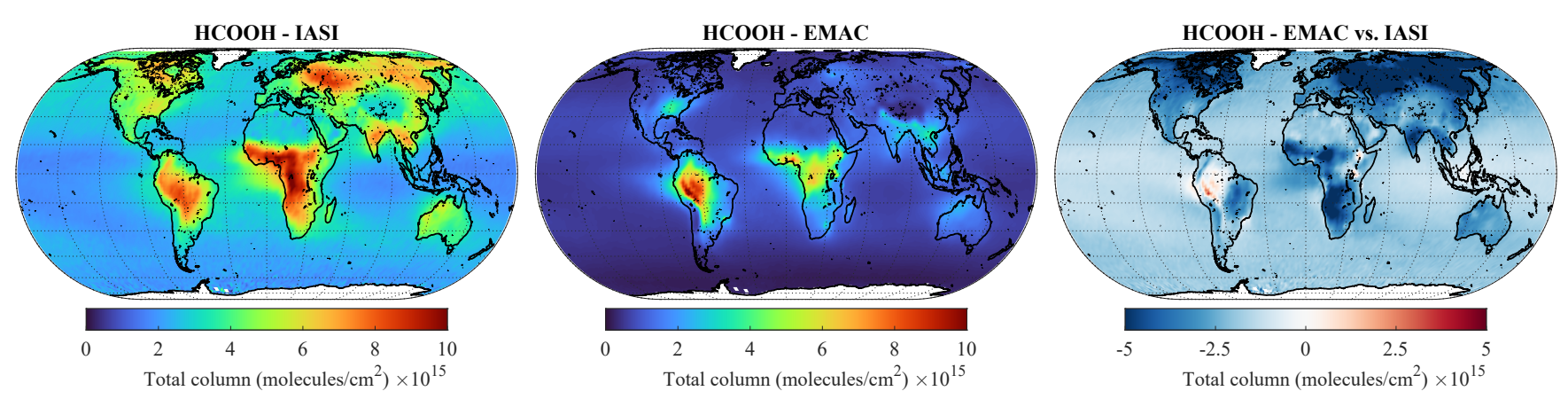

Figure 8. Same as Fig. 6, but for $\mathrm{HCOOH}$.

The large enhancement of $\mathrm{HCOOH}$ columns observed with IASI over western Russia $\left(\sim 8 \times 10^{15} \mathrm{molecules}^{-2}\right)$, attributed to the August 2010 wildfires, is not reproduced by EMAC $\left(<2 \times 10^{15}\right.$ molecules $\left.\mathrm{cm}^{-2}\right)$ and suggests that the biomass burning emissions of VOCs are underestimated.

The general underestimation of simulated versus observational data is also confirmed by the comparison with the aircraft database (Emmons et al., 2000), as shown in Table 2. Although this underestimation of the model results is less apparent compared to that of the total column observations, it must be noted that only a limited number of merged data (53, see Table 2 ) is available for the comparison with aircraft observations and therefore such a comparison provides only an indication rather than a quantitative estimate. It must be stressed that Franco et al. (2021) showed the importance of in-cloud chemistry for this tracer, which is missing in this study. The lack of adequate in-cloud chemistry would therefore explain the almost ubiquitous underestimation of this tracer.

\subsection{6 $\mathrm{CH}_{3} \mathrm{COOH}$}

Acetic acid is the second most abundant carboxylic acid in the troposphere and, based on the IASI retrievals, presents a spatial pattern, regional seasonality, and vertical abundance, which resemble those of HCOOH (Franco et al., 2020). Like the latter, $\mathrm{CH}_{3} \mathrm{COOH}$ is produced from the oxidation of various tropospheric precursors, but has emission factors from biomass burning that are 3 to 10 times larger than those of $\mathrm{HCOOH}$ (Akagi et al., 2011; Andreae, 2019). $\mathrm{CH}_{3} \mathrm{COOH}$ is more difficult to detect in the infrared IASI spectra and its retrievals are subject to larger uncertainties, in particular over the oceans (see Franco et al., 2020). Therefore, we limit here the comparison with EMAC to the continents, excluding measurements over desert areas that are altered by surface emissivity artefacts (Fig. 9). From the comparison, conclusions similar as for HCOOH can be drawn for $\mathrm{CH}_{3} \mathrm{COOH}$ : the two main tropical source regions are relatively well reproduced by EMAC (with a better agreement over Africa in this case), whereas the observed $\mathrm{CH}_{3} \mathrm{COOH}$ levels are underpredicted in the Northern Hemisphere by up to a factor of 4. The comparison with aircraft observations (see Table 2) confirms again this strong underestimation also over the ocean, as the only campaign in the dataset including $\mathrm{CH}_{3} \mathrm{COOH}$ measurements is the PEM-Tropics-A, which was performed over the Pacific ocean. 

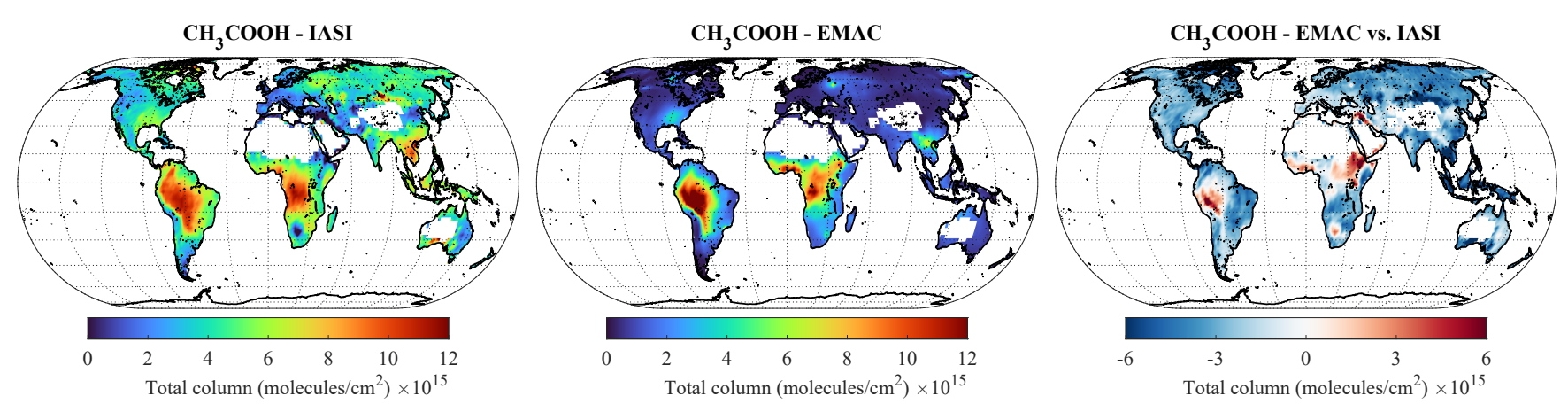

Figure 9. Same as Fig. 6, but for $\mathrm{CH}_{3} \mathrm{COOH}$. In this figure area above the ocean were excluded.

These results confirm that the VOC emissions and oxidation pathways leading to the formation of $\mathrm{CH}_{3} \mathrm{COOH}$ in the troposphere are still poorly understood and constrained (e.g., Khan et al., 2018; Paulot et al., 2011). For example, acetaldehyde - a major $\mathrm{CH}_{3} \mathrm{COOH}$ precursor via its reaction with $\mathrm{OH}$ (Lei et al., 2018) - is well known to be largely underestimated by global models (Millet et al., 2010; Wang et al., 2019). On the other hand, the large model versus observations differences in Southeast Asia also point to missing emissions from biomass burning. Finally, in-cloud chemistry could be important in the $\mathrm{CH}_{3} \mathrm{COOH}$ formation, analogously to formic acid (Franco et al., 2021), and this process could bring model results and observations to a closer agreement.

\subsubsection{PAN}

Owing to its complex photochemical sources and its thermal instability, PAN (Peroxyacetylnitrate), the main tropospheric reservoir species of $\mathrm{NO}_{\mathrm{x}}$, is a very challenging tracer to simulate. The comparison with the IASI data reveals that the model reproduces correctly the main spatial patterns of PAN, with the source regions and main outflows over the oceans being correct. However, the model constantly underestimates the observed PAN columns over the globe. The satellite column values are indeed between two and four times the simulated PAN columns, with the most pronounced negative bias observed at Northern Hemisphere mid- and high latitudes. The same conclusion can be drawn from the comparison with the aircraft emissions (Table 2), for which the model clearly underestimates the osberved mixing ratios. A closer inspection reveals that PAN is especially underestimated in the middle and upper-troposphere. The model-to-observations discrepancies can mostly be attributed to the unsatisfactory representation of different VOCs. For example, we have seen that the model results do not agree with observations for acetone, which is an important precursor of the peroxyacetyl radical in the free troposphere (Fischer et al., 2014). Furthermore, the strongest model's underestimation appears to be exactly where $\mathrm{CH}_{3} \mathrm{COCH}_{3}$ is at most underestimated, confirming that deficiencies of simulated precursor patterns are the main cause of the PAN biases. Additionally, sensitivity simulations suggested that the PAN formation in global models is more sensitive to the representation of VOCs (Fischer et al., 2014). Finally, an insufficient vertical transport of VOCs from the planetary boundary layer to the free troposphere in the model might also reduce the amount of PAN, because PAN is more stable at the lower temperatures of the free troposphere. 

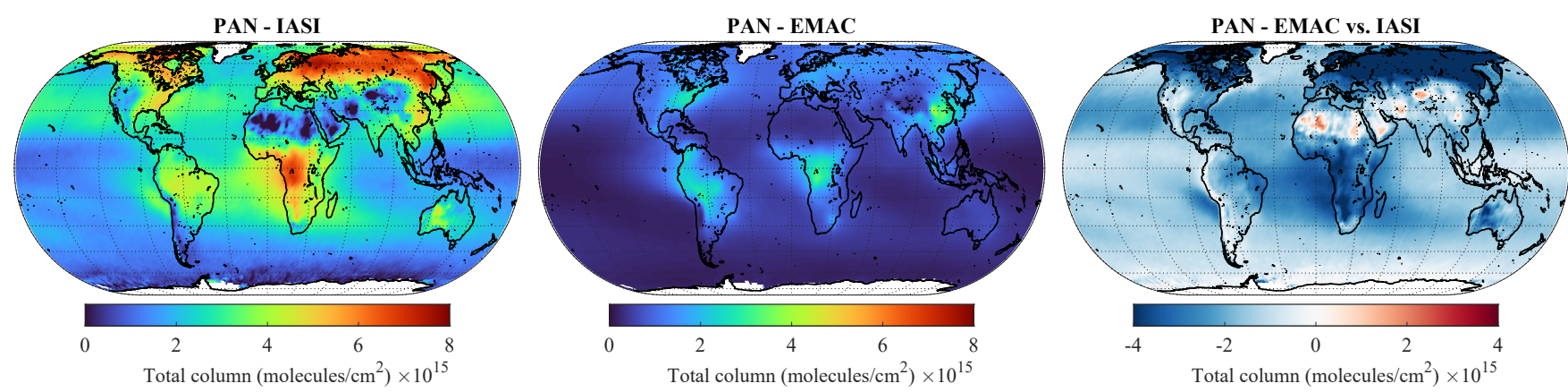

Figure 10. Same as Fig. 6, but for PAN.

\subsection{OH}

The simulated distribution of the hydroxyl radical $(\mathrm{OH})$ is in line with the findings by Lelieveld et al. (2016) (further denoted as L16), who earlier thoroughly analysed the MOM performance in EMAC with a setup featuring a simplified treatment of aerosol microphysics and gas/aerosol partitioning. The total $\mathrm{OH}$ turnover (composition of annual production and loss terms, shown in Fig. 11) of $234 \mathrm{Tmol} \mathrm{yr}^{-1}$ in 2010 is $7 \%$ less than that found by L16 and is consistent with the addition of the explicit treatment of secondary organic formation processes of aerosols and changes in trace gas emission fluxes. The $\mathrm{OH}$ production in the VOC- and ROOH-initiated reactions is $3 \%$ lower in both, the free troposphere (FT), and the boundary layer (BL). This is compensated by the increased share of primary production $\left(P\right.$, via the $\mathrm{O}\left({ }^{1} \mathrm{D}\right)+\mathrm{H}_{2} \mathrm{O}$ pathway), especially in the BL ( $4 \%$ increase vs. $2 \%$ in the FT). Regarding the partitioning of the $\mathrm{OH}$ sinks, however, no substantial changes can be noted (see Fig. 11, right panel). Together with the reduction of the secondary sources $(S)$, the resulting $\mathrm{OH}$ recycling probability $r_{\mathrm{OH}}$ (defined as $1-P /(S+P)$, see details in L16) establishes at $59 \%$ and $62 \%$ in the BL and FT, respectively. Being about $5 \%$ lower than the estimate reckoned by L16, such high $r_{\mathrm{OH}}$ values signify still highly stable (buffered) $\mathrm{OH}$ concentrations and therefore a likewise stable tropospheric oxidative capacity obtained with this model set-up.

The simulated annual air mass-weighted average hydroxyl concentrations are 12.1 (troposphere), 12.0 (FT) and 13.6 (BL) $10^{15}$ molecules $\mathrm{cm}^{-3}$ in the year 2010, which correspond to $\mathrm{OH}$ chemical removal lifetimes of $1.59,1.78$ and $0.53 \mathrm{~s}$, respectively. The diagnosed tropospheric $\mathrm{OH}$ inter-hemispheric gradient ( $\mathrm{NH} / \mathrm{SH}$ ratio) is 1.17 , lower than that estimated by L16 (1.20) due to the increased $\mathrm{OH}$ reactivity via VOC and SOA in the $\mathrm{NH}$ and at the lower end of the model estimates reviewed there. By not being in agreement with the measurement-based estimates suggesting hemispheric symmetry in tropospheric $\mathrm{OH}$ (Patra et al., 2014; Wolfe et al., 2019), the pronounced asymmetry in atmospheric models results from asymmetric $\mathrm{OH}$ production due to skewed distributions of $\mathrm{O}_{3}$ and $\mathrm{NO}_{\mathrm{x}}$ prevailing in the $\mathrm{NH}$, and calls for further studies in this direction.

Overall, the simulated tropospheric hydroxyl radical distribution is comparable to that thoroughly analysed by L16 with a minor increase in reactivity of up to $5 \%$ when calculated from the changes to the $\mathrm{CH}_{4}$ and $\mathrm{MCF}\left(\mathrm{CH}_{3} \mathrm{CCl}_{3}\right)$ lifetimes against removal by $\mathrm{OH}\left(\tau_{\mathrm{OH}}\right)$. The here estimated $\tau_{\mathrm{OH}}\left(\mathrm{CH}_{4}\right)$ values are 8.4 and 4.4 years in the FT and BL, respectively; the tropospheric $\tau_{\mathrm{OH}}(\mathrm{MCF})$ value is obtained to be 4.9 years. 


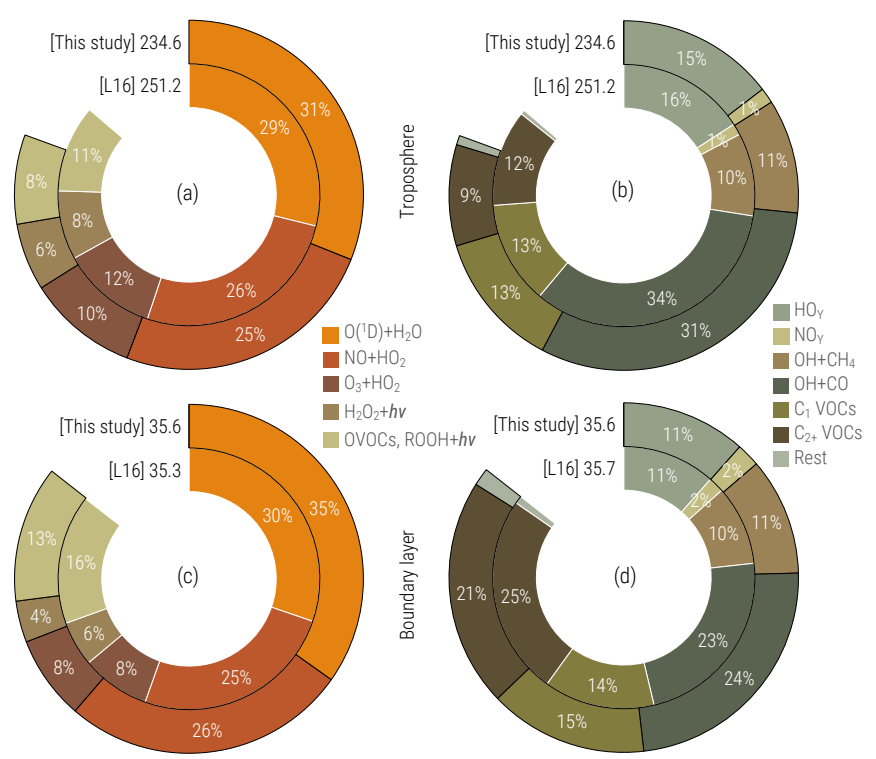

Figure 11. Simulated $\mathrm{OH}$ production (left) and sink (right) by category in the troposphere (top) and boundary layer (bottom) in this study and by Lelieveld et al. (2016) (denoted L16). Values are annual totals in Tmol/yr for 2010. Percentages denote fractions attributed to particular categories (see L16 for for details).

\subsection{Aerosol Optical Depth}

In order to evaluate the overall performance of the model in reproducing aerosol distribution, the AOD at $550 \mathrm{~nm}$ simulated by the model is compared to satellite based and station observations. Figure 12 shows the annual average AOD of the simulation and of the observations (satellite). The distribution is remarkably similar, with the high AOD regions (Northern Africa and Soth Eastern Asia) being well simulated by the model. Open ocean AOD of $\simeq 0.2$ AOD units are reproduced by the model, with slightly underestimated AOD over the central Atlantic (possibly due to slightly underestimated dust outflow from the northern Africa region). To quantify the model capability to reproduce the AOD, in Figure 13, the model daily AODs are compared to the collocated (in space and time) observations from MODIS and the AERONET instruments (middle and bottom row, respectively). For comparison, the same scatter plot has been produced comparing MODIS and AERONET directly (top row). The model has difficulties in reproducing the daily variability of AERONET AOD, with only $58 \%$ of the simulated AOD within a factor of 2 to the observational data. Even the correlation is considerably low, with an $R^{2}$ equal to 0.33 . Very similar results are obtained by comparing the model results to the satellite AOD observations, with again only $57 \%$ of the simulated data within a factor of 2 to the observations. Once monthly averages are used for the inter-comparison, the statistics remain almost unchanged with just a small improvement in the slope of the fitting curve (see Fig. 13, central column). Finally, using the annual averages for the intercomparison, the coefficients of determination $R^{2}$ almost double ( 0.633 and 0.567 for the comparison of the model with MODIS and AERONET data, respectively), while more than $80 \%$ of the model results are 

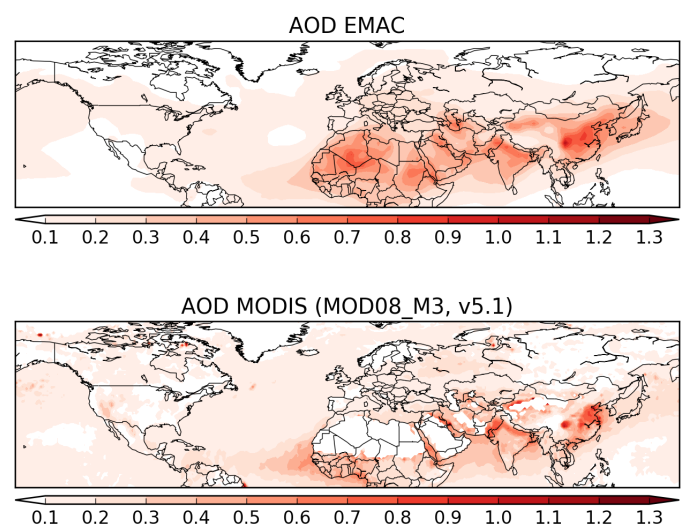

Figure 12. Global map of AOD from model results and the MODIS observations for the year 2010 (annual average).

within a factor of 2 to the observations (either satellite or in-situ). To put these results into context, the same analysis has been performed comparing the MODIS data and AERONET stations. Although the satellite observations outperform (slightly) the model results compared to the AERONET measured AOD in the case of the daily and monthly averages, for the annual averages the model seems to perform equally well, with a similar coefficient of determination and a fraction of values within a factor of 2 to the observations. Due to the intrinsic characteristics of the model (such as its relative coarse resolution) it is not expected to have a good representation of the short term variability.

\subsection{Fine particulate mater $\left(\mathrm{PM}_{2.5}\right)$}

The comparison of model results for $\mathrm{PM}_{2.5}$ (i.e. fine particles with an aerodynamic diameter smaller than $2.5 \mu \mathrm{m}$ ) was performed against the dataset of Hammer et al. (2020). Although this dataset is not a pure observational dataset, it has a global coverage and has been constrained from in-situ measurements. The comparison is done for $\mathrm{PM}_{2.5}$ at $35 \%$ relative humidity, i.e. dry fine particulate mass (in $\mu \mathrm{g} \mathrm{m}^{-3}$ ). In Figure 14, the maps of the annual average of the model results and the pseudoobservation dataset are shown. Although the distribution patterns appear to be similar, the model tends to underestimate the fine particle concentration over northern India and eastern China, on the one hand, while the opposite happens over east Africa and the Middle East. On the other hand side, the model seems to reproduce $\mathrm{PM}_{2.5}$ quite accurately over both Europe and North America, and even the locally enhanced levels of $\mathrm{PM}_{2.5}\left(\sim 30 \mu \mathrm{g} \mathrm{m}^{-3}\right)$ in Canada from Boreal forest biomass burning are nicely reproduced by the model.

In Figure 15, the scatter plot of the two datasets is shown, while in Table 4 the statistics for the different regions presented in the figures are listed. Due to the large grid resolution difference, the pseudo-observations have been aggregated to the grid resolution of the model. As already noted from the global map, the model tends to underestimate $\mathrm{PM}_{2.5}$ over South Asia and East Asia by $\sim 40 \%$ and $\sim 20 \%$, respectively. Nevertheless, in both regions, more than $70 \%$ of the model results are within 

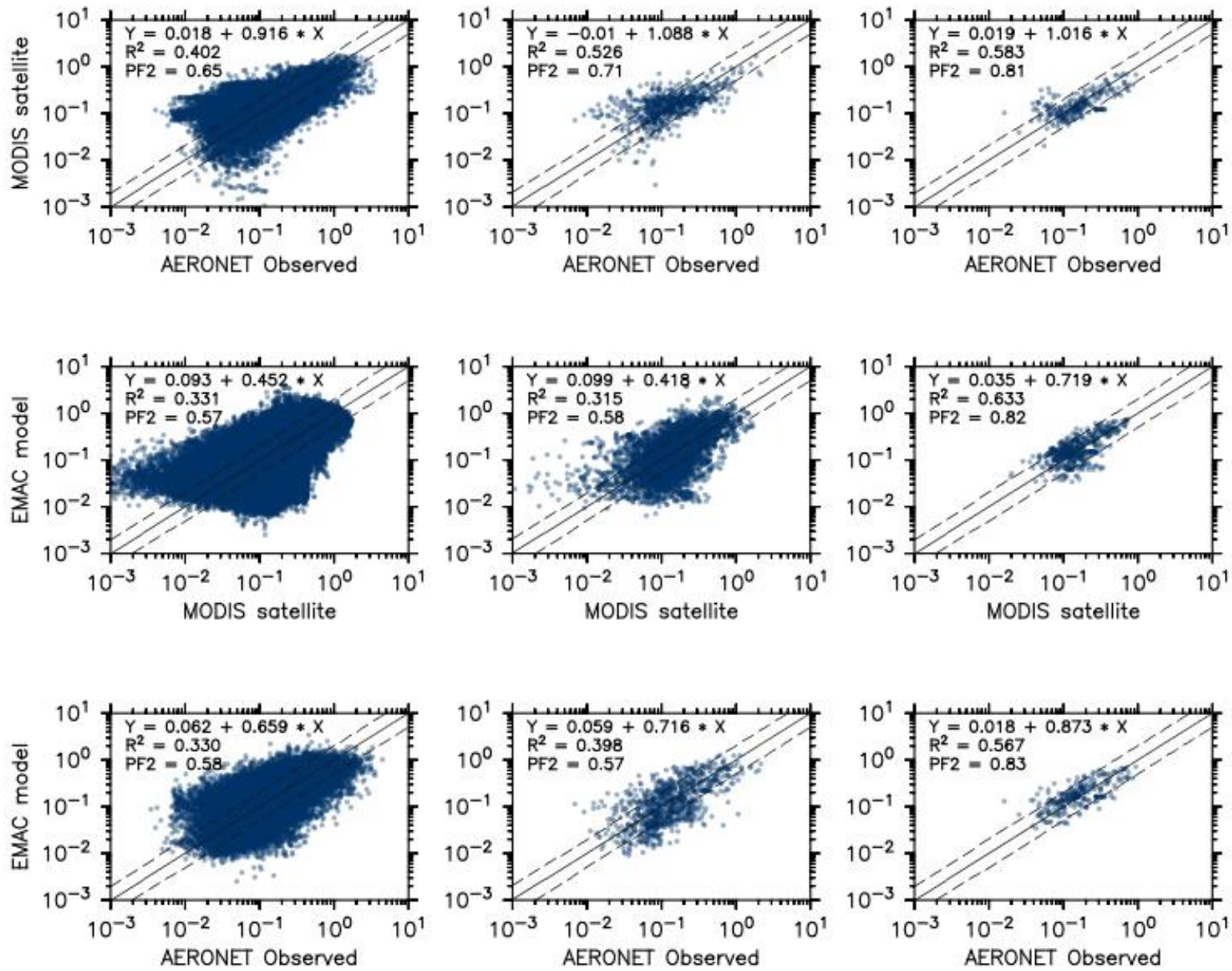

Figure 13. Scatter plots of AOD estimated by the EMAC model in this study versus the MODIS and the AERONET observations. Left, Middle and Right: scatter plots using daily, monthly and annual averages, respectively. Both, model and satellite based observations, were sampled at the AERONET locations. In each plot the coefficients of the linear fit, the coefficient of determination and the fraction of data within a factor of 2 are listed.

a factor of 2 of the pseudo-observations. The model agrees well, however, with data from Europe and North America, with more than $95 \%$ of the model results within a factor of two. The overall comparison indicates that the model agrees well with the pseudo-observations, as the spatial-temporal averages of the two datasets are very close $\left(17.1 \mu \mathrm{g} \mathrm{m}^{-3}\right.$ for the model and 
https://doi.org/10.5194/gmd-2021-295

Preprint. Discussion started: 29 September 2021

(c) Author(s) 2021. CC BY 4.0 License.

(c) (i)
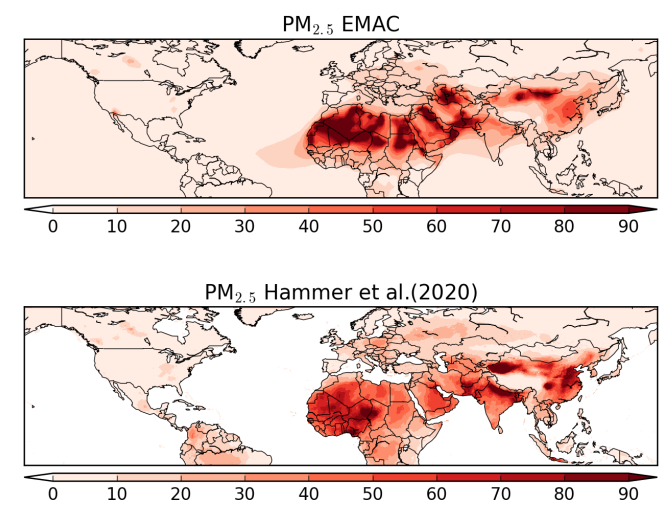

Figure 14. Global map of $\mathrm{PM}_{2.5}$ from model results and the Hammer et al. (2020) dataset for the year 2010 (annual average) in $\mu \mathrm{gr} / \mathrm{m}^{3}$. The data from Hammer et al. (2020) does not contain values over the ocean.

$19.4 \mu \mathrm{g} \mathrm{m}^{-3}$ for the pseudo-observations), with more than $70 \%$ of the model simulated $\mathrm{PM}_{2.5}$ within a factor of two of the pseudo-observed $\mathrm{PM}_{2.5}$.

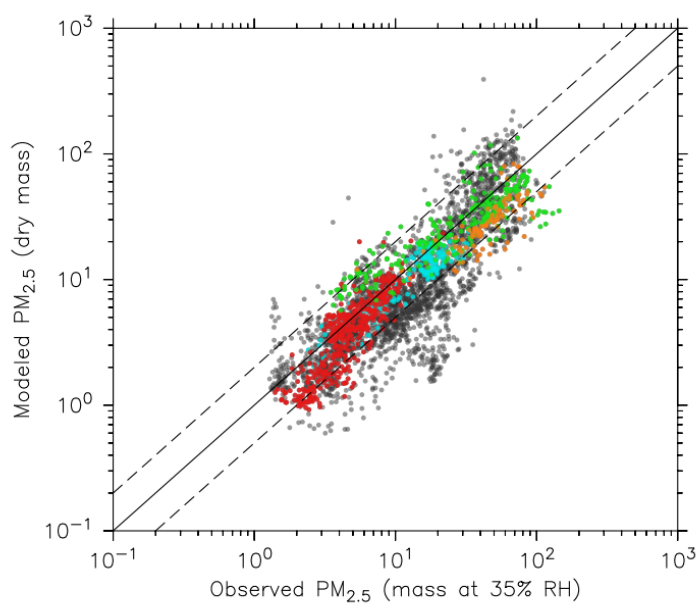

Figure 15. Scatter plots of $\mathrm{PM}_{2.5}$ of model results versus data from Hammer et al. (2020) for the year 2010 (annual average) in $\mu \mathrm{g} \mathrm{m}^{-3}$. Light blue, red, green, and orange colors depict points located in Europe, North America, East Asia, and South Asia, respectively. Grey points indicate the remaining parts of the world. 


\begin{tabular}{lcccc}
\hline Region & MM & OM & MM/OM & PF2 \\
\hline Europe & 11.4 & 14.3 & 0.80 & 98.8 \\
North America & 4.8 & 5.2 & 0.92 & 95.2 \\
South Asia & 31.2 & 50.3 & 0.62 & 72.6 \\
East Asia & 31.2 & 37.1 & 0.84 & 82.1 \\
World & 18.4 & 19.4 & 0.94 & 71.4
\end{tabular}

Table 4. Summary for simulated and pseudo-observed, annually averaged $\mathrm{PM}_{2.5}$. MM and OM denote the arithmetic mean of the simulated and observed concentrations, respectively, in $\mu \mathrm{gm}^{-3}$. PF2 is the percentage of simulated points within a factor of 2 with respect to the observations.

\subsection{Aerosol Composition}

For the evaluation of the simulated mass concentrations of sulfate, nitrate, ammonium, sodium and five species related to sea spray and organic aerosols, we use in-situ measurements from different monitoring networks, as described in Sect. 3.2. Co-located time series of simulated and observed quantities were obtained by bilinear interpolation of the gridded model data at ground level to the respective site location. The analysis is based on monthly mean concentrations, which are derived from daily (model data, EMEP observations) and weekly (EPA) data, with the exception of EANET, which directly provides monthly averages. Note that some monitoring stations are located relatively close to each other, such that the reported concentrations may not be independent from each other, which can lead to an overestimation of the degrees of freedom in the calculation of quantities such as the root mean square error.

\subsubsection{Sulfate $\left(\mathrm{SO}_{4}^{2-}\right)$}

Observed particulate sulfate concentrations are reproduced well by the model. The monthly mean concentration is matched closely for North America (EPA) and slightly underestimated for Europe (EMEP) and East Asia (EANET) (see Table 5). For EPA and EMEP data, more than $80 \%$ of the simulated monthly mean concentrations lie within a factor of two of the observations, and more than $70 \%$ for EANET. The standard deviation of observed monthly mean values is lower than the root mean square error (RMSE) for all monitoring networks, which is an indication for a good quality of the model results (Barna and Lamb, 2000). Also, RMSE is lower in the present study compared to a similar analysis by Pozzer et al. (2012a) in which, however, a longer time period of four years (2005-2008) was investigated. Pozzer et al. (2012a) also report a relatively large spread (observation standard deviation equal to $5.3 \mu \mathrm{gm}^{-3}$ ) of the measured sulfate concentrations in EANET, which is likely to be caused by a comparably low number of stations which cover a large region with strong spatial gradients.

The close overall agreement of average concentrations simulated by the model (MM) with the observations (OM) for EPA can partly be attributed to underestimated high concentrations in summer (composite of June, July and August, "JJA"), which are compensated by overestimated lower concentrations from autumn to spring (see Figure 16). Relative deviations are largest 
https://doi.org/10.5194/gmd-2021-295

Preprint. Discussion started: 29 September 2021

(c) Author(s) 2021. CC BY 4.0 License.

\begin{tabular}{|c|c|c|c|c|c|c|c|c|c|}
\hline Species & Network & $\mathrm{N}_{\text {station }}$ & $\mathrm{MM}$ & MSTD & $\mathrm{OM}$ & OSTD & $\overline{\mathrm{MM} / \mathrm{OM}}$ & PF2 & RMSE \\
\hline $\mathrm{SO}_{4}^{2-}$ & EPA & 81 & 1.92 & 0.99 & 1.88 & 1.20 & 1.35 & 84.3 & 0.93 \\
\hline $\mathrm{SO}_{4}^{2-}$ & EMEP & 42 & 1.68 & 1.05 & 1.79 & 1.21 & 1.37 & 83.7 & 0.95 \\
\hline $\mathrm{SO}_{4}^{2-}$ & EANET & 25 & 2.83 & 1.65 & 3.58 & 4.06 & 1.58 & 71.0 & 3.49 \\
\hline $\mathrm{NO}_{3}^{-}$ & EPA & 81 & 1.89 & 1.97 & 0.77 & 1.07 & 4.29 & 36.9 & 1.88 \\
\hline $\mathrm{NO}_{3}^{-}$ & EMEP & 22 & 3.34 & 2.89 & 1.93 & 2.15 & 3.75 & 55.3 & 2.97 \\
\hline $\mathrm{NO}_{3}^{-}$ & EANET & 23 & 3.34 & 3.34 & 1.45 & 2.43 & 8.36 & 32.6 & 3.47 \\
\hline $\mathrm{NH}_{4}^{+}$ & EPA & 81 & 1.09 & 0.89 & 0.73 & 0.53 & 1.84 & 64.8 & 0.77 \\
\hline $\mathrm{NH}_{4}^{+}$ & EMEP & 27 & 1.31 & 1.17 & 0.92 & 0.86 & 1.69 & 62.0 & 0.92 \\
\hline $\mathrm{NH}_{4}^{+}$ & EANET & 23 & 1.40 & 1.35 & 1.00 & 1.14 & 2.38 & 54.7 & 1.07 \\
\hline $\mathrm{Na}^{+}$ & EPA & 81 & 0.16 & 0.22 & 0.16 & 0.36 & 2.19 & 61.1 & 0.23 \\
\hline $\mathrm{Na}^{+}$ & EMEP & 24 & 0.57 & 0.43 & 0.60 & 0.73 & 2.03 & 53.1 & 0.57 \\
\hline $\mathrm{Na}^{+}$ & EANET & 21 & 0.92 & 0.81 & 1.22 & 1.67 & 2.89 & 46.8 & 1.53 \\
\hline $\mathrm{Mg}^{2+}$ & EPA & 81 & 0.05 & 0.06 & 0.05 & 0.05 & 2.06 & 42.7 & 0.06 \\
\hline $\mathrm{Mg}^{2+}$ & EMEP & 22 & 0.17 & 0.13 & 0.07 & 0.09 & 4.65 & 32.6 & 0.16 \\
\hline $\mathrm{Mg}^{2+}$ & EANET & 15 & 0.29 & 0.21 & 0.24 & 0.26 & 2.38 & 57.8 & 0.27 \\
\hline $\mathrm{Ca}^{2+}$ & EPA & 81 & 0.06 & 0.12 & 0.26 & 0.27 & 0.60 & 16.2 & 0.37 \\
\hline $\mathrm{Ca}^{2+}$ & EMEP & 28 & 0.14 & 0.25 & 0.15 & 0.25 & 1.60 & 51.5 & 0.24 \\
\hline $\mathrm{Ca}^{2+}$ & EANET & 19 & 0.23 & 0.22 & 0.75 & 1.97 & 1.44 & 45.2 & 2.07 \\
\hline $\mathrm{K}^{+}$ & EPA & 81 & 0.03 & 0.05 & 0.07 & 0.04 & 0.83 & 19.8 & 0.08 \\
\hline $\mathrm{K}^{+}$ & EMEP & 25 & 0.09 & 0.13 & 0.08 & 0.07 & 1.42 & 60.0 & 0.14 \\
\hline $\mathrm{K}^{+}$ & EANET & 20 & 0.12 & 0.09 & 0.26 & 0.34 & 0.98 & 47.1 & 0.37 \\
\hline $\mathrm{Cl}^{-}$ & EPA & 81 & 0.35 & 0.65 & 0.14 & 0.51 & 5.92 & 24.7 & 0.53 \\
\hline $\mathrm{Cl}^{-}$ & EMEP & 24 & 2.16 & 1.59 & 0.86 & 1.05 & 37.24 & 29.5 & 1.82 \\
\hline $\mathrm{Cl}^{-}$ & EANET & 17 & 2.63 & 2.55 & 1.90 & 2.88 & 4.38 & 39.2 & 2.62 \\
\hline $\mathrm{OA}$ & IMPROVE & 155 & 1.32 & 1.11 & 0.92 & 0.73 & 1.73 & 0.65 & 1.01 \\
\hline $\mathrm{OA}$ & EMEP & 12 & 1.43 & 0.77 & 2.55 & 2.27 & 0.83 & 0.60 & 2.35 \\
\hline OA & EASIA & 9 & 9.20 & 9.91 & 16.07 & 11.41 & 0.51 & 0.42 & 9.25 \\
\hline
\end{tabular}

Table 5. Summary of simulated and observed monthly averaged aerosol concentrations for $\mathrm{SO}_{4}^{2-}, \mathrm{NO}_{3}^{-}, \mathrm{NH}_{4}^{+}, \mathrm{Na}^{+}, \mathrm{Mg}^{2+}, \mathrm{Ca}^{2+}, \mathrm{K}^{+}$, $\mathrm{Cl}^{-}$and organic aerosols (OA) and different observational networks (second column). $\mathrm{N}_{\text {station }}$ is the number of stations providing data for the respective species and network; note that this is not the sample size for the shown statistics. The next columns provide the arithmetic mean of the simulated (MM) and observed concentrations (OM), and the respective standard deviations (MSTD, OSTD) in $\mu \mathrm{gm}^{-3}$. PF2 denotes the percentage of simulated points within a factor of 2 with respect to the observations, and RMSE represents the root mean square error between simulated and observed points. 
in winter and autumn, when observed concentrations are much lower than simulated concentrations. In Europe (EMEP), the highest concentrations are observed during the winter months, which is captured by the model.

The East-West gradient of observed annual mean concentrations in North America is represented well in the model, although the amplitude is underestimated: lower values in the West are overestimated while higher concentrations in the East are underestimated (Figure 17). This feature also lead to a good agreement between observed and simulated mean concentrations in Table 5. The North-South gradient over Europe is also captured by the model. Despite the less dense spatial distribution of monitoring stations providing data for particulate sulfate, one can observe a correspondence between simulated and observed annual mean concentrations, especially over Japan. One outlier in Japan with a very low observed annual mean concentration is located at a relatively high altitude ("Happo", $1850 \mathrm{~m}$ ), so that the comparison to model data on ground level may not be appropriate for this station. The same holds for two EMEP stations, namely Jungfraujoch (Switzerland) at $3578 \mathrm{~m}$, and Chopok (Slovakia) at $2008 \mathrm{~m}$, where annual mean concentrations are largely overestimated.
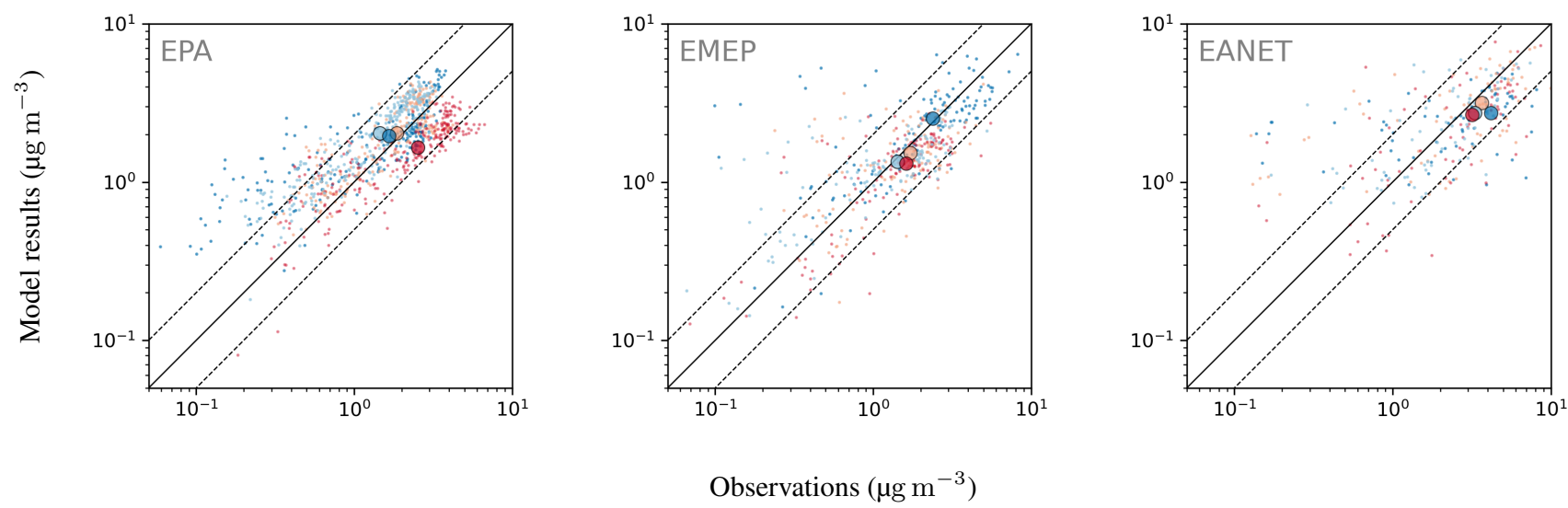

Figure 16. Scatter plots of observed and simulated monthly average $\mathrm{SO}_{4}^{2-}$ concentrations for the year 2010 and three observational networks: EPA, EMEP, and EANET (left to right). The coloring of the points represents a categorization into seasons (dark blue: DJF, orange: MAM, red: JJA, light blue: SON), the respective seasonal averages of monthly concentrations are depicted as large circles. Dashed lines denote the interval of a factor of 2 of the observations. The simulated concentrations were obtained by sampling the modeled data at the respective station locations using bilinear interpolation over neighbouring grid points.

\subsubsection{Nitrate $\left(\mathrm{NO}_{3}^{-}\right)$}

475 Nitrate is less well represented than sulfate, showing a general overestimation of observed concentrations with an average ratio of simulated to observed concentrations by at least 3.75 . This comparably large ratio is dominated by a few stations with small concentrations, where the median ratios lie between 1.70 and 2.84. About half (EMEP) to two thirds (EPA, EANET) of the simulated monthly mean concentrations exceed a factor of 2 with respect to the observations. For EANET and EMEP, the number of monitoring stations is substantially lower than for EPA, which may partly explain the larger spread in both, the 


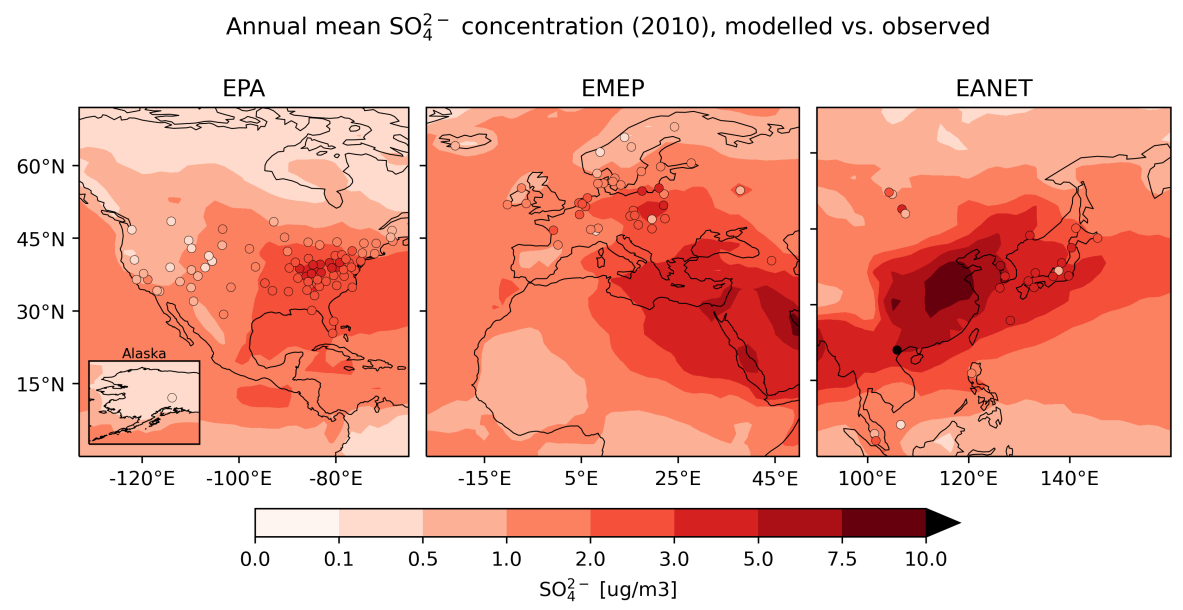

Figure 17. Annual mean $\mathrm{SO}_{4}^{2-}$ concentrations for the year 2010 for the model and three observational networks: EPA, EMEP, and EANET (left to right). Simulated data are shown as shaded contours, while the observational data are depicted as circles.

model results and observations (OSTD, MSTD). The RMSE is larger than the observed standard deviations for all considered networks, suggesting a less faithful representation of this species. This overestimation may be attributed to the usage of Teflon filters, as nitrate can evaporate from the filters under warm and dry conditions (Ames and Malm, 2001). Schaap (2003), Schaap et al. (2004) and de Meij et al. (2006) showed that particulate ammonium and nitrate partially evaporate from the filters at temperatures between 15 to $20^{\circ} \mathrm{C}$ and can evaporate completely at temperatures above $20^{\circ} \mathrm{C}$. Therefore, this effect predominantly affects measurements during the warmer seasons, when nitrate concentrations are close to the annual minimum. An indication for overestimation due to evaporation would then be a closer agreement between model and observation in the colder winter months. However, both in relative and absolute terms, the overestimation of monthly mean nitrate concentrations is more pronounced in winter than in summer for the three considered networks (Figure 18). All regions show the same seasonal cycle with respect to averaged monthly mean concentrations; a maximum in winter and a minimum in summer, both for model results and observations. The spatial gradient of annual mean concentrations is captured well for North America (EPA), although the concentrations towards the East coast are generally overestimated. The low number of monitoring stations for EANET and EMEP does not allow us to draw solid conclusions; yet we can report that the North-South gradient of nitrate over Europe is reproduced by the model, except for an outlier at high altitude in Central Europe (Figure 19). The region with highest simulated annual mean concentrations and strong spatial gradients is East Asia, however it is scarcely covered by monitoring stations reporting full coverage for the considered year 2010.

\subsubsection{Ammonium $\left(\mathrm{NH}_{4}^{+}\right)$}

Considering the ratio of averaged monthly mean ammonium concentrations, the model overestimates the observed concentrations, yet to a lower degree than for nitrate (Table 5). This feature is also apparent in the fraction of simulated monthly 

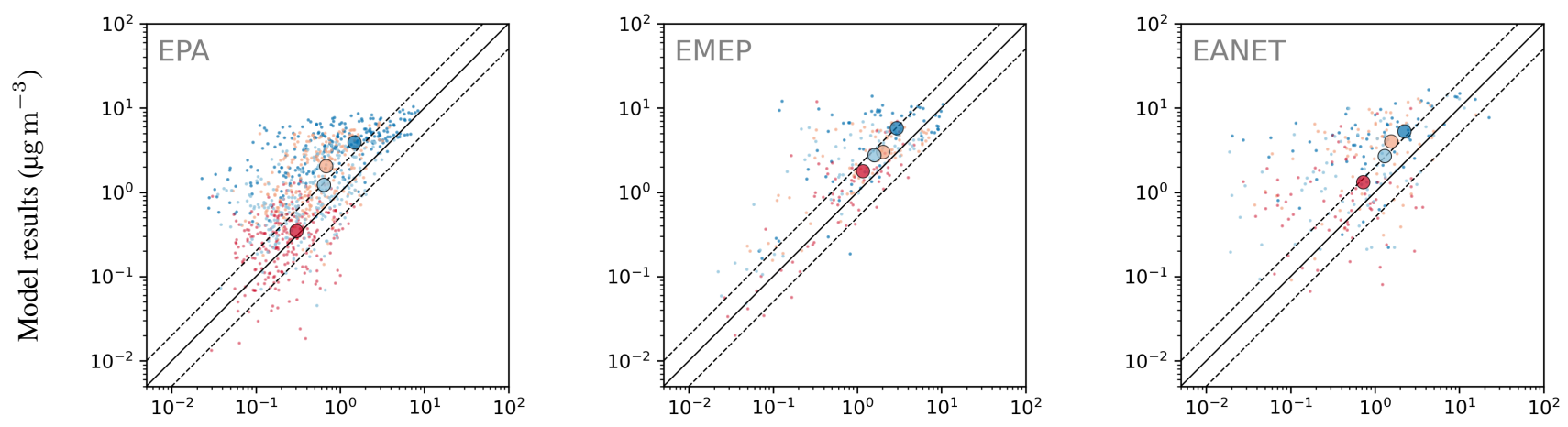

Observations $\left(\mu \mathrm{gm}^{-3}\right)$

Figure 18. As in Figure 16, but for $\mathrm{NO}_{3}^{-}$.

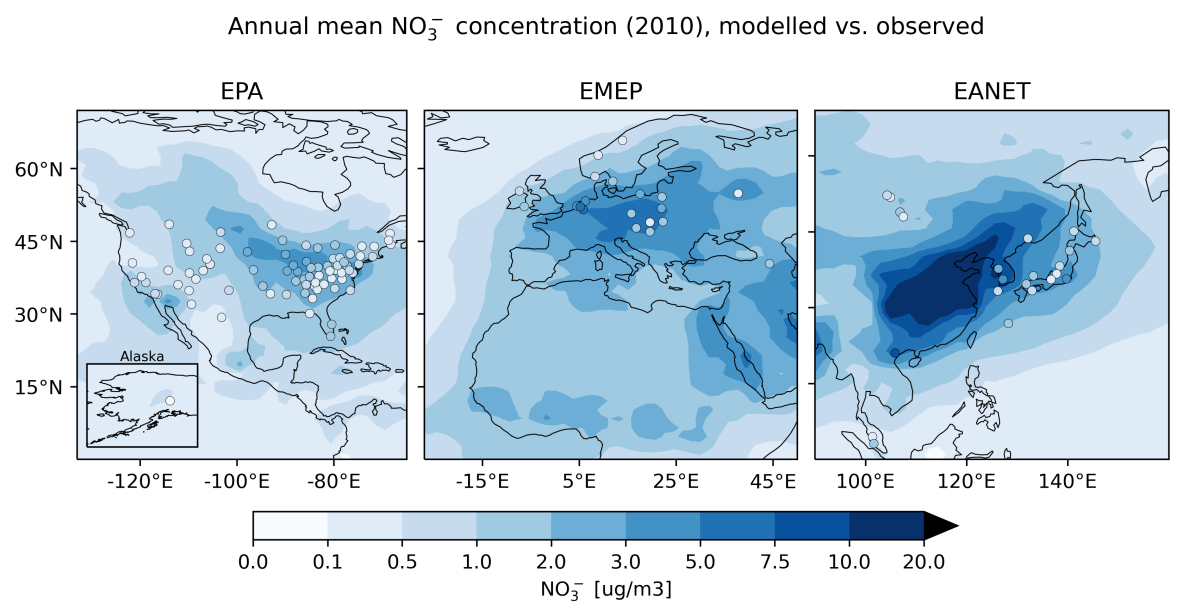

Figure 19. As in Figure 17, but for $\mathrm{NO}_{3}^{-}$.

mean values within a factor of two of the observations: $54.7 \%$ for the network in East Asia and more than $60 \%$ for Europe and North America. The magnitude of overestimation is similar for the three networks, ranging from $40 \%$ to $50 \%$. RMSE values are close to the standard deviation of observations in all networks, again indicating a good representation by the model. The largest concentrations occur during the winter months (Figure 20). While the degree of overestimation is similar for the different seasons in EMEP and EANET, this does not hold for EPA: summer concentrations are systematically underestimated, whereas autumn to spring concentrations are generally overestimated. The monthly mean concentrations for winter and spring constitute most of the values outside the factor of 2 regarding the observations for all considered regions. Both the observed North-South and East-West gradients of annual mean concentrations are represented well for the EPA network ((Figure 21), though the simulated gradient is less pronounced. 
The North-South gradient of observations over Europe is also captured by the model, although the number of stations is again comparably low. The simulated spatial patterns in East Asia also match the observations arguably well.

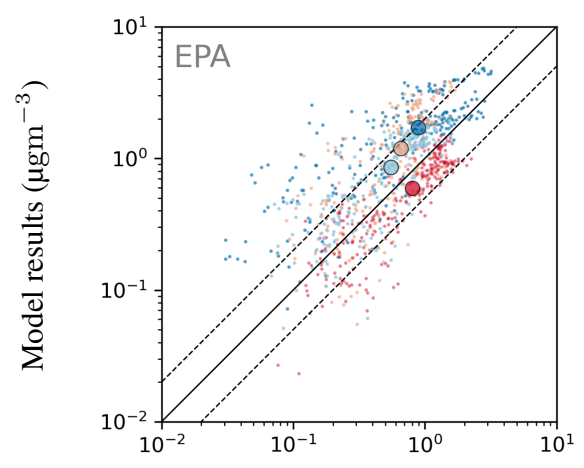

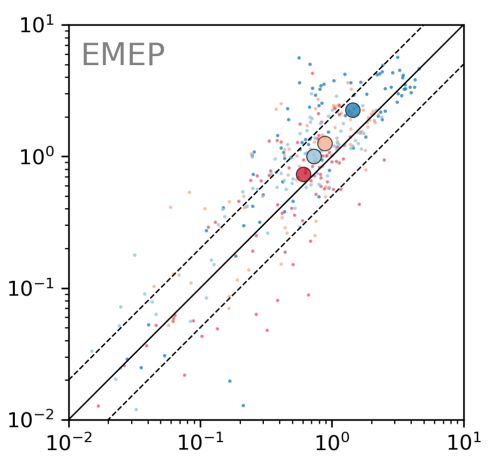

Observations $\left(\mu \mathrm{g} \mathrm{m}^{-3}\right)$

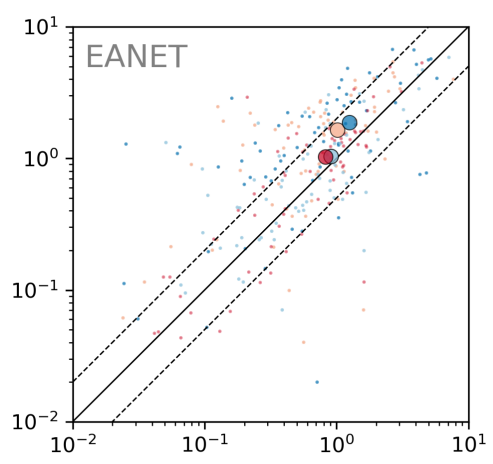

Figure 20. As in Figure 16, but for $\mathrm{NH}_{4}^{+}$.

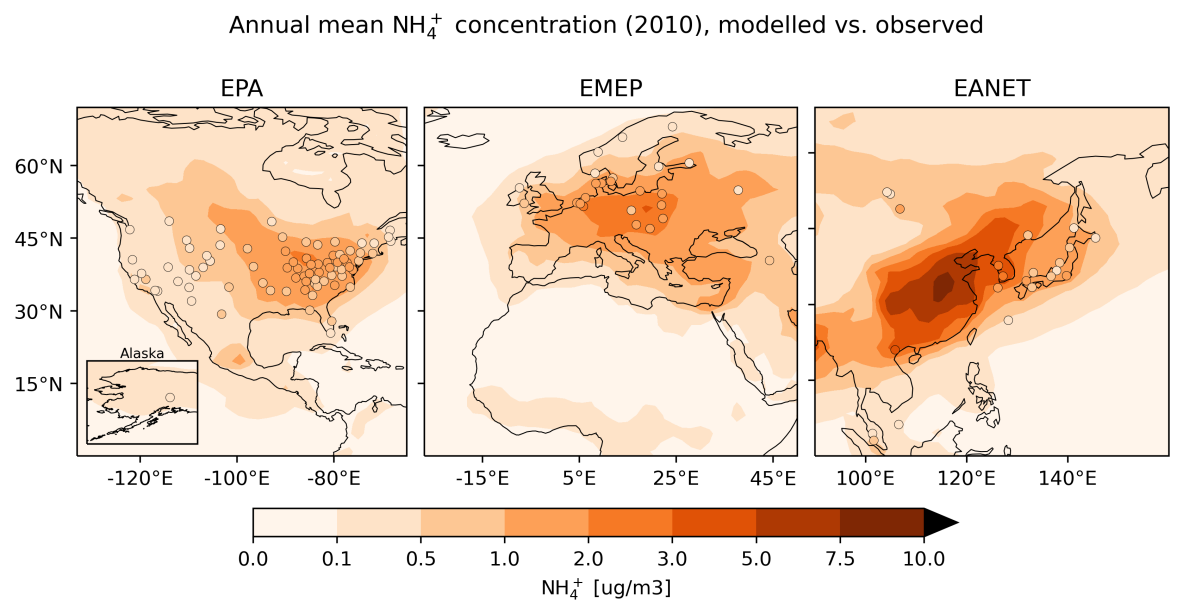

Figure 21. As in Figure 17, but for $\mathrm{NH}_{4}^{+}$.

\subsubsection{Dust and sea spray}

This section provides an overview for species frequently found in dust and sea spray aerosol: sodium, calcium, magnesium, potassium and chloride. As the ocean is a large source of these water-soluble species, concentrations over the sea and coastal areas are large, as opposed to lower concentrations over the continents. Sodium, potassium, magnesium and calcium can also be found in desert dust, for instance in the Sahara, as reported by Reid et al. (2003) and Moreno et al. (2006). However, most 
of the monitoring locations except for those in coastal areas are sampling quite remote sites far from the source regions, and thus can not be expected to display the full range of concentrations. In the following, we present the results for sodium in more detail, followed by a brief overview of the remaining species.

Sodium is represented well by the model, as averaged monthly mean concentrations from model and observations agree in general, particularly for EPA (Table 5). The mean ratio MM/OM, however, shows an average overestimation by a factor of at least 2. The observational standard deviation OSTD for all regions is smaller than the RMSE, the latter being reduced compared to the results from a previous study by Pozzer et al. (2012a). For EMEP, more than 3 out of 5 simulated monthly mean values lie within a factor of 2 of the observations and more than 53\% and $46 \%$ for EMEP and EANET, respectively, which is a substantial improvement compared to Pozzer et al. (2012a). The latter two networks offer again only a small number of stations. Considering the average of monthly mean concentrations separated by season, one can observe an underestimation of summer concentrations for all networks (Figure 22).

As mentioned before, the regional distribution of stations does not cover those regions with high concentrations. However, including the information of all networks at once, one can observe that continental stations exhibit low annual mean concentrations, while high concentrations can be observed for instance at stations close to the coast (i.e. Japan, Florida, Denmark, Sweden), indicating that spatial features of the global sodium distribution are qualitatively captured (Figure 23).

Potassium, magnesium and calcium ions share spatial features with sodium in the model, exhibiting elevated values over the ocean, as well as over the Sahara and Gobi desert, and reduced concentrations over other continental areas.

The number of stations in EANET is quite low for all sea spray species which, on the one hand, allows for a few outliers to dominate mean values and errors. On the other hand, EPA offers a large number of stations, yet the correspondence of model and observations is also quite low for sea spray and dust species. Average monthly mean concentrations for magnesium are represented well in the model, which is caused by a large overestimation of concentrations in winter months balancing an underestimation of summer concentrations (not shown).

Chloride concentrations are widely overestimated with respect to all three networks. The exceptionally high ratio $\overline{\mathrm{MM} / \mathrm{OM}}$ for EMEP is caused by two outliers with MM/OM $>1000$ due to very low observed concentrations. Without these, $\overline{\mathrm{MM} / \mathrm{OM}}$ is better, with a value of 13.08 .

\subsubsection{Organic Aerosols (OA)}

Figure 25 shows the comparison of model calculated OA concentrations with measurements from the EMEP observational network over Europe, the IMPROVE network over rural North American locations, as well as short-term measurement data collected over East Asia as summarized by Jo et al. (2013). The comparison statistic is presented in Fig. 5. The model captures relatively well the monthly average concentrations of OA over these highly populated regions of the Northern Hemisphere.

545 This is rather encouraging, given the expected uncertainties of the emission inventory and the complex chemistry involved to simulate the secondary organic aerosol formation. It is worth emphasizing that the model considers the formation of SOA solely from the homogeneous gas-phase photochemical oxidation of its precursors. Therefore, the omission of other SOA formation pathways (e.g., from aqueous-phase and heterogeneous reactions) can add to the model bias. This is mostly evident during 

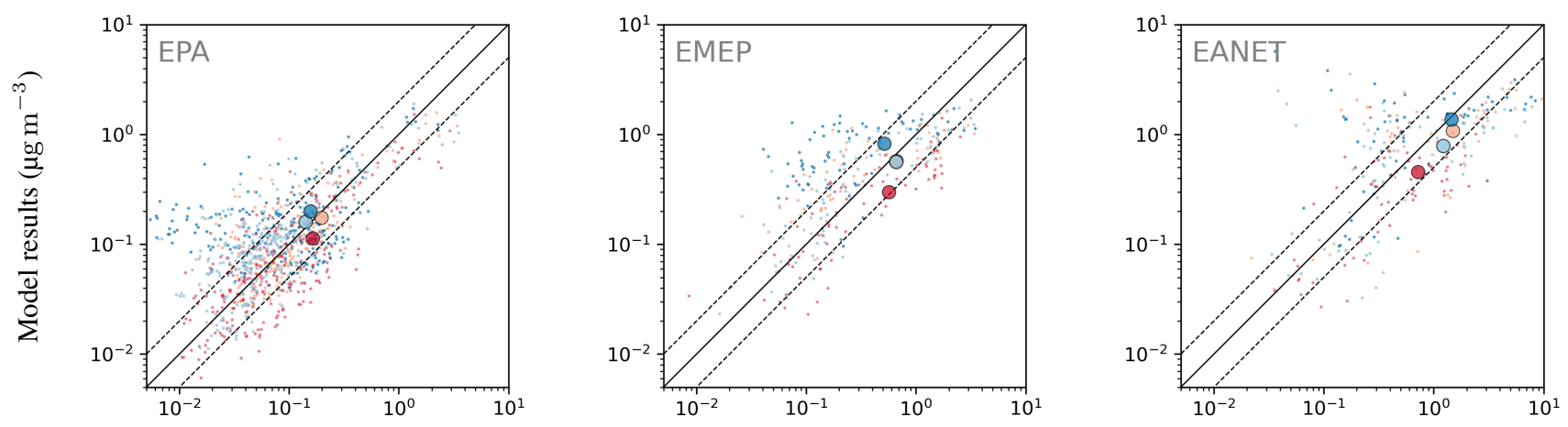

Observations $\left(\mu \mathrm{g} \mathrm{m}^{-3}\right)$

Figure 22. As in Figure 16, but for $\mathrm{Na}^{+}$.

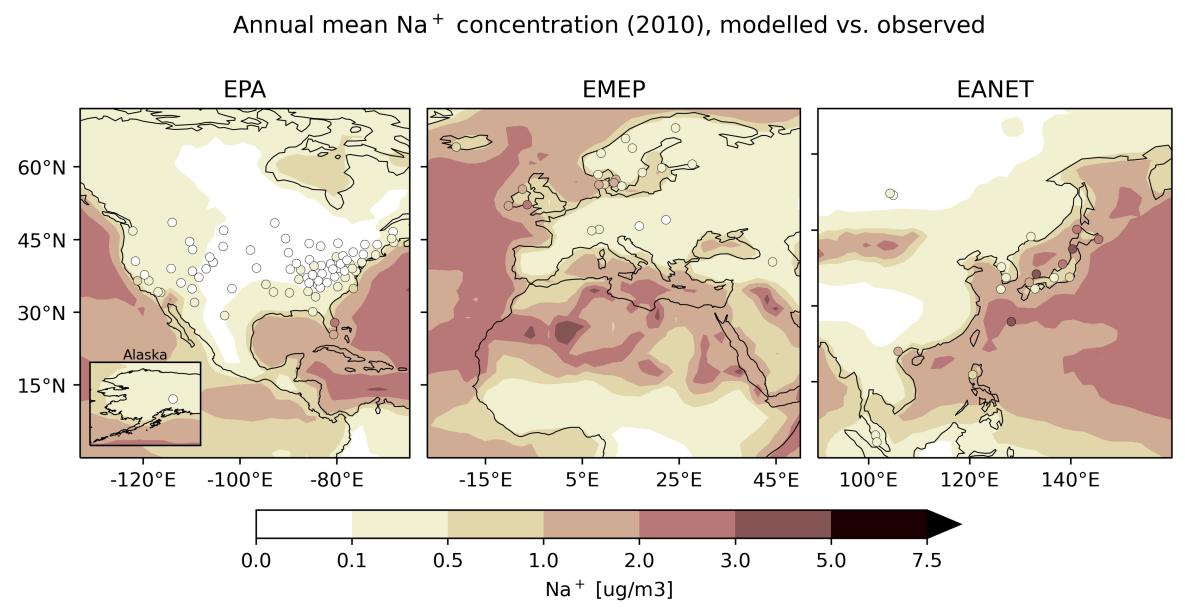

Figure 23. As in Figure 17, but for $\mathrm{Na}^{+}$.

winter (e.g., over Europe), when the relative importance of these processes on SOA formation is increasing due to the lower photochemical activity and the limited conversion of gas phase organic precursors to SOA. In addition, recent studies have provided strong evidence that the uptake of water-soluble gas-phase oxidation products (even small carbonyls like formaldehyde and acetic acid) can be the main driver of SOA pollution during haze events over Eastern Asia (Gkatzelis et al., 2020). Given the coarse resolution of the model and its inability to simulate these SOA formation pathways, the observed total OA concentrations are expected to be systematically underestimated by the model over Eastern Asia. Nevertheless, model results are in general in reasonable agreement with observations with the exception of the strong underestimation over Beijing and Shijiazhuang, which brings the $\overline{\mathrm{MM} / \mathrm{OM}}$ to very low value (i.e. 0.51). Over Europe, the model also tends to underestimates OA, with $\overline{\mathrm{MM} / \mathrm{OM}}$ of 0.83 (see Tab. 5). The model performs worst during winter. Tsimpidi et al. (2016) has identified the lack 

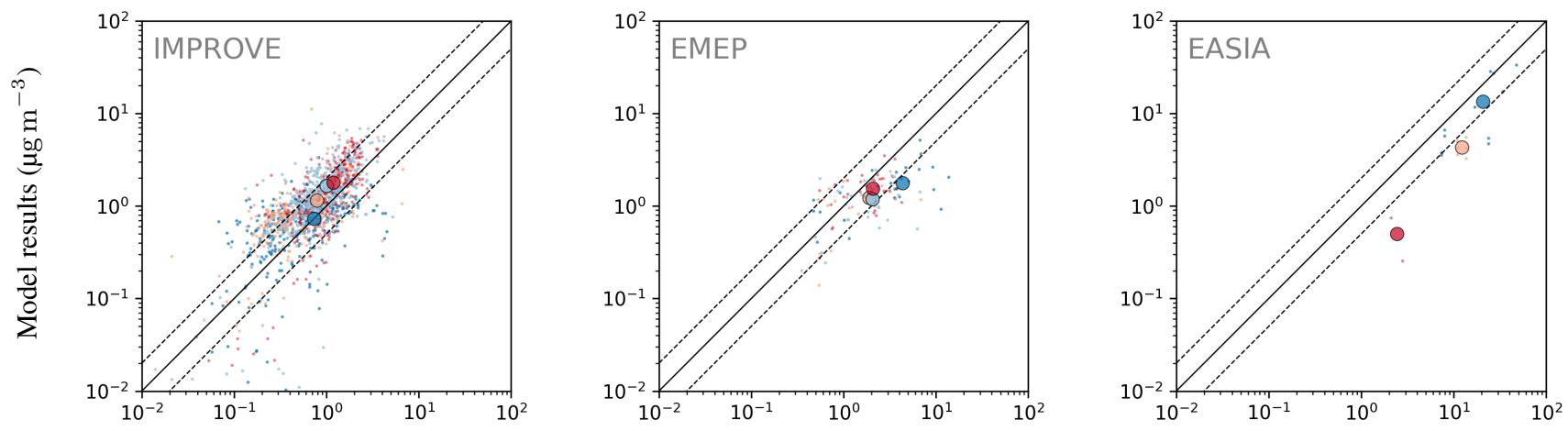

Observations $\left(\mu \mathrm{g} \mathrm{m}{ }^{-3}\right)$

Figure 24. As in Figure 16, but for OA.

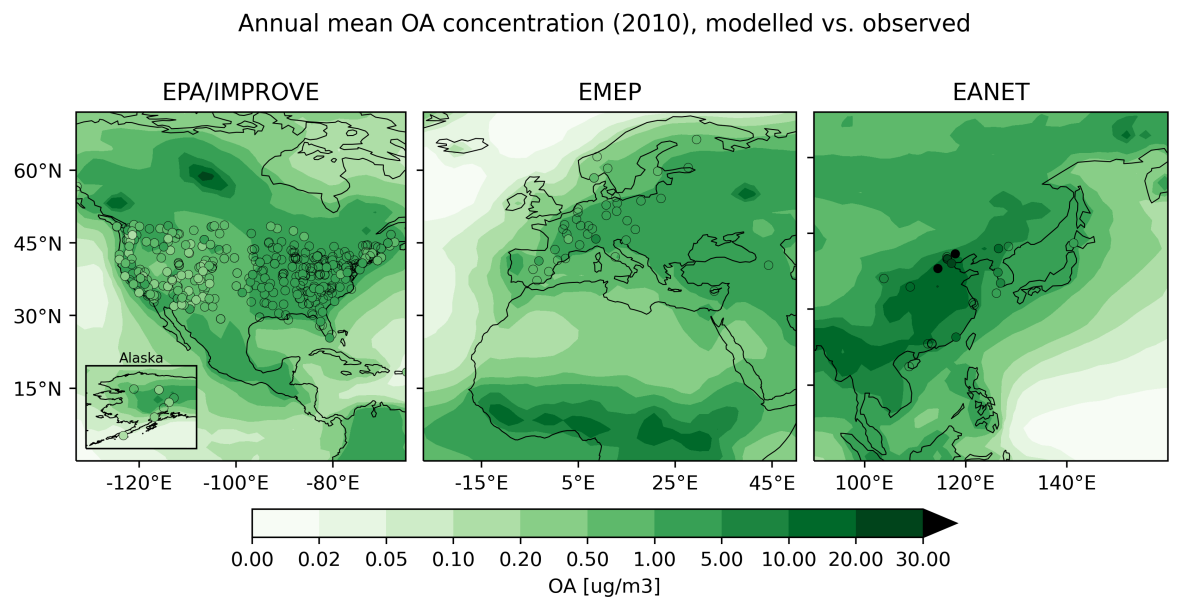

Figure 25. As in Figure 17, but for OA.

of biomass burning emissions as the main source of this discrepancy. Later, Kodros et al. (2020) and Paglione et al. (2020) have shown evidence that biomass burning also contributes significantly to SOA formation during wintertime following its oxidation by the $\mathrm{NO}_{3}$ radical in the dark. Over North America, the model tends to overestimate OA over rural areas with a $\overline{\mathrm{MM} / \mathrm{OM}}$ equal to 1.73 . However, as shown in Fig. 24, part of this discrepancy is explained by the low values of OA over the US national parks.

Despite the agreement of the surface OA concentrations between model results and observations, the OA are strongly underestimated in the free troposphere. In Fig. 26, the model is compared with 12 field campaign measurements (Heald et al., 2011). Our results show similar agreement to the one obtained by Heald et al. (2011), with the simulated values below the observed one. 

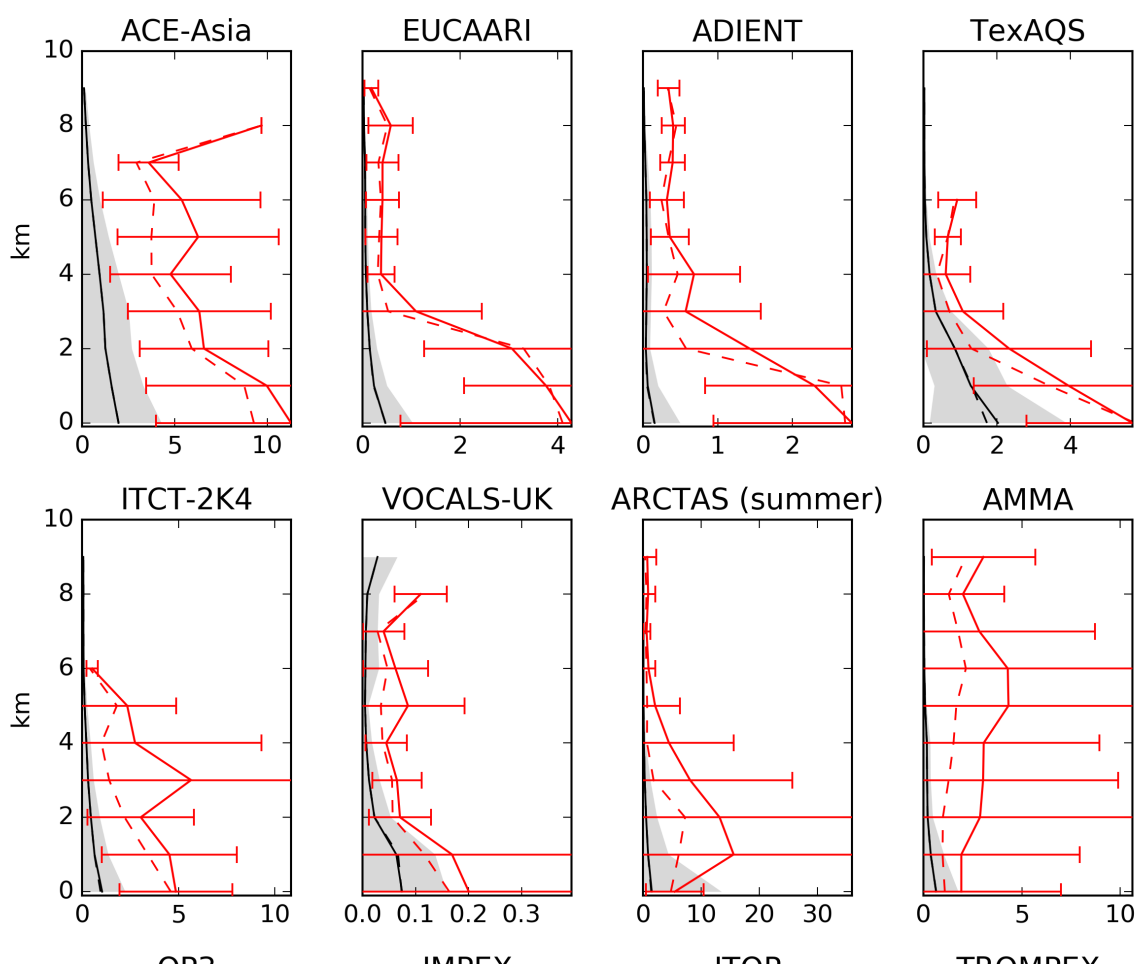

ARCTAS (summer)
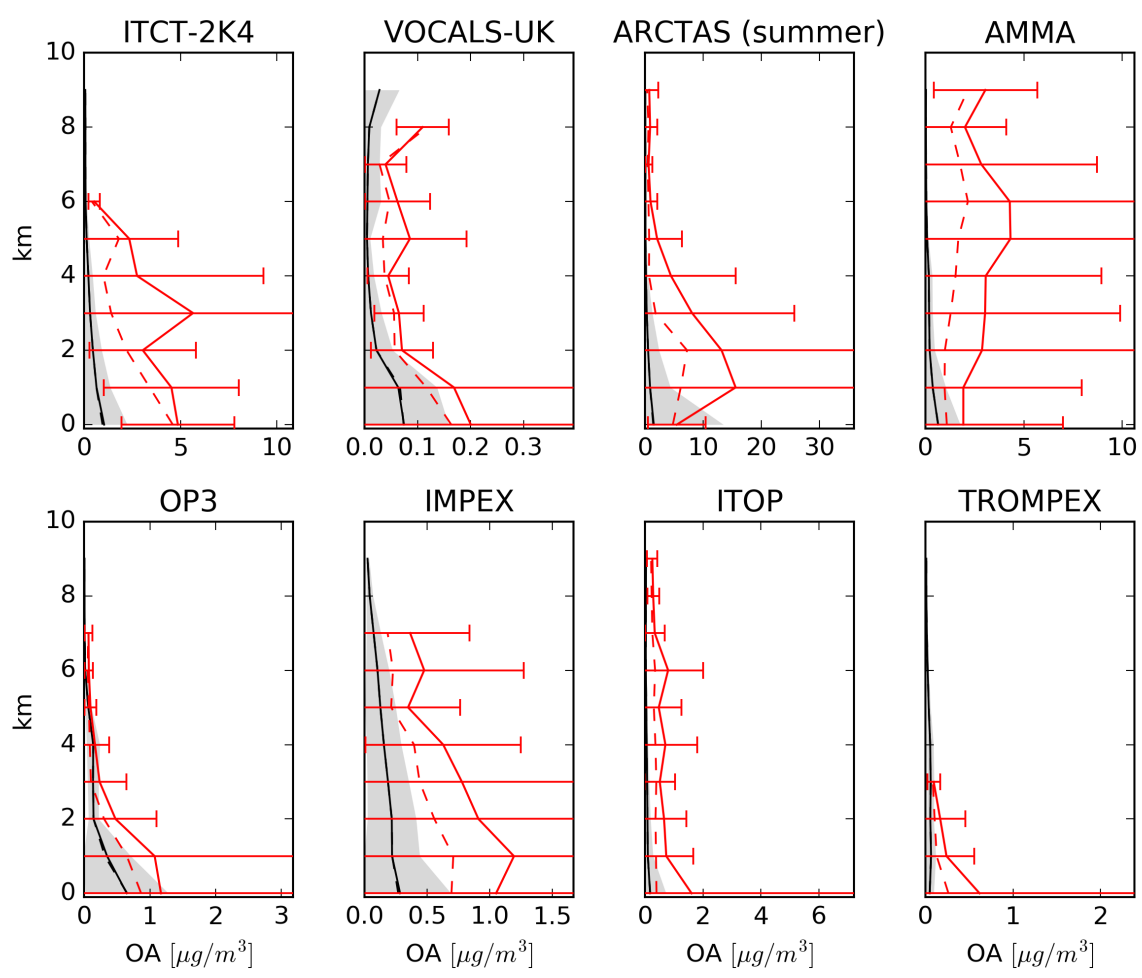

Figure 26. Model results of mean vertical profile of organic aerosol for selected field campaigns in black, and spatio-temporal standard deviation as grey area. The observed mean values are depicted in solid red, with the bars representing the standard deviation of the observations. The observed median is presented as red dashed line.

\section{Conclusions}

We have presented an evaluation of EMAC with a comprehensive degradation scheme for organics (MOM) in the MECCA chemistry submodel, combined with an explicit estimation of the organic tracers' condensation on aerosols with a VBS approach (ORACLE submodel). We have compared the model results with a large number of in-situ and satellite based remote 
sensing observations. The evaluation focuses on carbon monoxide (CO), simple organics and aerosols, which are most influenced by the new scheme. CO is correctly reproduced compared with station measurements, with the correct north-south gradient. Nevertheless, once the model results are compared with the satellite observations from MOPITT, an overestimation of $\mathrm{CO}$ over the Amazon basin is apparent, especially in autumn, possibly due to an overestimation of the biomass burning emissions simulated by the model. For alkanes the comparison shows a good agreement, although an oceanic source for the butanes is missing. In contrast, the model underestimates alkenes, and especially $\mathrm{C}_{3} \mathrm{H}_{6}$, which shows large differences compared to the observations. Model results of oxygenated species show an indifferent picture when compared to observations, depending on the tracer: while methanol is well reproduced, simulated acetone shows large spatial discrepancies compared to the remotely sensed observations. In fact, for the latter, the model misses strong emissions over the boreal forests, while it predicts instead too high total columns over tropical forests (i.e., Amazonia and Central Africa). Formic and acetic acid show similar agreements to the observations, with the main tropical sources well reproduced, but with a strong underestimation elsewhere.

The aerosols at the surface are well reproduced by the model, both with respect to composition and total amount. The annually averaged simulated AODs show a very good agreement with the AERONET station observations, but with some deficiencies in the representation of the short term variability. The agreement of the fine particulate mass $\left(\mathrm{PM}_{2.5}\right)$ near the surface is also quite good, with most of the simulated values within a factor of 2 to the observations. The evaluation of the aerosol chemical composition shows a high level of agreement for near-surface sulphate and some more deviations for $\mathrm{NH}_{4}^{+}$ and nitrate, which are both overestimated by the model, especially the latter (even though the observations are characterized with a high level of uncertainty). The mechanically produced primary aerosol species (dust and seasalt) show a reasonable agreement with the observations with some substantial overestimation of the simulated chloride concentrations indicating a too weak acid displacement process over the continents.

Finally, the comparison of OA shows a good agreement with station observations, while the vertical distribution of the simulated values are largely underestimated, when compared with aircraft measurements, analogously to other global atmospheric chemistry models of similar complexity, although significant improvement in this direction has been recently published (Pai et al., 2020).

\section{Outlook}

The presented model evaluation is useful for identifying areas for further model improvements. A few possible directions are discussed next.

Emissions have always been a critical point for simulating tropospheric chemistry. It has already shown in many studies that even anthropogenic emissions of alkanes need to be improved as severely underestimated in many inventories (e.g. Emmons et al., 2015; Tilmes et al., 2016), mostly coming from erroneous speciation of the total VOC emissions (Dalsøren et al., 2018)

Residential wood burning and/or biofuel use (e.g., for heating) that often contribute significantly to both POA and SOA formation over urban areas are strongly underestimated in the emission inventories (Tsimpidi et al., 2016; Denier Van Der Gon 
et al., 2015). In addition, global models lack OA emissions from residential and commercial cooking activities that can be an important source of OA (Mohr et al., 2012; Sun et al., 2011; Ge et al., 2012; Hayes et al., 2013). Underestimation of cold-start vehicle emissions (Weilenmann et al., 2009) can also lead to significant underestimation of OA formation from the transport sector (e.g., during wintertime).

As seen in this study, the model results underestimate selected VOCs in boreal regions. The thawing of permafrost is potentially an additional emission source of organic compounds at high latitudes in the northern hemisphere (Li et al., 2020), which has not been considered yet. However, an estimate with global data sets is still missing. Furthermore, the emission of VOCs from biomass burning is likely strongly underestimated. In fact, overwintering fires in boreal forest (Scholten et al., 2021), which smoulder through the non-fire season, are normally not detected by satellite observations and therefore are missing in our used emissions dataset. Moreover, peat fires are not easily detected from space, but are characterized by larger emission factors for many VOCs. They are important for simulating air composition during peat fires in Indonesia (Rosanka et al., 2021c) and likely critical for resolving the model biases at high latitudes, where most of peatland is located and could be further released by permafrost thawing. Ramo et al. (2021) also found that small undetected fires enhance the estimated amount of emitted carbon from biomass burning in sub-Saharan Africa by 31-101\%. Finally, soil temperature and soil wetness play an important role in the estimation of the online emissions of biogenic VOCs, and it is therefore important to have a correct simulation of the surface properties by the underlying climate model.

Furthermore, dry deposition is a relevant process also affecting VOCs in the lower troposphere (Khan et al., 2015). The inclusion of the additional uptake at the plant cuticle leads to a better representation (Karl et al., 2004; Müller et al., 2018; Emmerichs et al., 2021) and would likely reduce the overestimation of species like acetaldehyde in the Tropics, as shown here. In the Amazon forest, the missing storage capacity of soil water leading to too high temperatures (Hagemann and Stacke, 2015) additionally causes an underestimation of dry deposition (Emmerichs et al., 2021), while temperature-dependent processes like VOC emissions are overestimated.

Another source of uncertainty is related to the scavenging efficiency of gas-phase OA precursors. The water solubility of these oxidized organic vapors is largely unknown and is typically considered uniform for all organic compounds in modeling studies even though they become increasingly more hydrophilic during their atmospheric lifetime (Hodzic et al., 2014; Tsimpidi et al., 2017).

The extension of MOM for the oxidation of additional VOCs has the potential to reduce the negative model biases for some oxygenated volatile organic compounds (OVOCs) and enhance the predicted OA levels. For instance, with an emission strength of more than $40 \mathrm{Tg} \mathrm{yr}^{-1}$, anthropogenic $\mathrm{C}_{5^{-}}$and higher hydrocarbons can be a significant source of OVOCs like acetaldehyde and acetone (Pozzer et al., 2010). Further improvements are expected from an extended representation of the emission and oxidation of known biogenic VOCs with more than 5 carbon atoms. Moreover, the emissions of aromatic compounds from biogenic sources could be as large as $40 \mathrm{Tg} \mathrm{yr}^{-1}$ (Misztal et al., 2015). So far only a small emission of toluene is considered and a more comprehensive representation of biogenic aromatics would likely lead to further improvements.

The formation of SOA in most models relies on the reaction of its gas-phase precursors with reactive atmospheric radicals (e.g., $\mathrm{OH}, \mathrm{O}_{3}, \mathrm{NO}_{3}$ ) and their chemical aging is usually considered by the further photo-oxidation of the semivolatile products 
solely in the gas phase. However, SOA is also subject to oxidation in the aqueous phase through superficial and bulk interactions with gas-phase oxidants (George and Abbatt, 2010). Therefore, fundamental processes of SOA formation in the aqueous phase (e.g., from isoprene epoxydiols (Nguyen et al., 2009) and glyoxal (Fu et al., 2008)) are typically missing from the conventionally used parameterizations. In addition, the uptake of small carbonyls (e.g., aldehydes and acids) to the aqueous phase and their subsequent oxidation and oligomerization has been recently linked to significant increases of SOA mass during pollution events (Gkatzelis et al., 2021).

Recently, MOM has been coupled to the detailed Jülich Aqueous-phase Mechanism of Organic Chemistry (JAMOC, Rosanka et al., 2021a) for cloud droplets. An explicit treatment of multiphase chemistry of OVOC has already been used for assessing the global role of clouds as a sink of ozone (Rosanka et al., 2021b). By comparing EMAC's prediction of total methanol columns to IASI satellite retrievals (comparable to Sect. 4.2.3 and Fig. 6), they find that EMAC's tendency to overestimate methanol is partially reduced by the additional cloud sink. This suggests that the missing representation of in-cloud OVOC chemistry introduces a significant bias in the present study, and therefore a more detailed multi-phase chemistry should be included for future studies. Furthermore, JAMOC is limited to the oxidation of OVOCs containing up to four carbon atoms (Rosanka et al., 2021a), and an expansion to larger species (i.e. containing more than four carbon atoms) is thus desirable, in order to improve the representation of these OVOCs in EMAC when using MOM. Finally, based on the results of Franco et al. (2021), more detailed in-cloud chemistry could improve the representation of acids (such as acetic and formic acid), which is clearly underestimated here where cloud chemistry is important.

Code and data availability. The Modular Earth Submodel System (MESSy) is continuously further developed and applied by a consortium of institutions. The usage of MESSy and access to the source code is licensed to all affiliates of institutions which are members of the MESSy Consortium. Institutions can become a member of the MESSy Consortium by signing the MESSy Memorandum of Understanding. More information can be found on the MESSy Consortium Website (http://www.messy-interface.org). The code presented here has been based on MESSy version 2.54 and is available in the official release of version 2.55.

Author contributions. A.P., A.P.T. and V.A.K. planned the research. A.P. designed, coded, prepared the input files and performed the model simulation. A.P., V.K., S.G., S.F.R., B.F. S.R., T.E., D.T., H.T., V.F. and A.P.T. wrote the manuscript. D.T. developed MOM and integrated it into MECCA. S.G. implemented extended budgeting of species turnover. A.P.T and V.A.K. modified ORACLE to accommodate the organic tracers from the MOM chemical mechanism. M.C., D.G. and J.K. provided the emissions for the simulations. A.P., S.F.R, V.K and D.A. have contributed to the evaluation. C.H. provided observational data for the comparison. P.J. and H.T. contributed to model development of the here applied system. B.F., L.C. and P-F.C. developed the IASI VOC products and performed the comparisons with EMAC.

Competing interests. No competing interests are present. 
https://doi.org/10.5194/gmd-2021-295

Preprint. Discussion started: 29 September 2021

(c) Author(s) 2021. CC BY 4.0 License.

(c) (1)

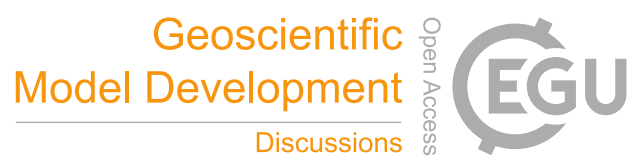

Acknowledgements. IASI is a joint mission of Eumetsat and the Centre National d'Etudes Spatiales (CNES, France). The IASI Level-1C data are distributed in near real-time by Eumetsat through the EumetCast distribution system. The authors acknowledge the AERIS data infrastructure (https://www.aeris-data.fr/, last access on September 21, 2021) for providing access to the IASI Level-1C data and Level2 temperature data. IASI activities have been supported by the Belgian State Federal Office for Scientific, Technical and Cultural Affairs (Prodex arrangement IASI.FLOW). L. Clarisse is a research associate supported by the F.R.S.-FNRS. H.T. acknowledges funding from the Carl-Zeiss foundation. We are grateful to Colette Heald for providing the aircraft data and for her support and suggestions to improve the manuscript. 
https://doi.org/10.5194/gmd-2021-295

Preprint. Discussion started: 29 September 2021

(c) Author(s) 2021. CC BY 4.0 License.

(c) (i)

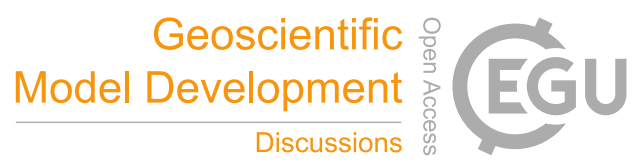

References

Akagi, S., Yokelson, R. J., Wiedinmyer, C., Alvarado, M., Reid, J., Karl, T., Crounse, J., and Wennberg, P.: Emission factors for open and domestic biomass burning for use in atmospheric models, Atmospheric Chemistry and Physics, 11, 4039-4072, 2011.

Ames, R. B. and Malm, W. C.: Comparison of sulfate and nitrate particle mass concentrations measured by IMPROVE and the CDN, Atmospheric Environment, 35, 905 - 916, https://doi.org/https://doi.org/10.1016/S1352-2310(00)00369-1, http://www.sciencedirect.com/ science/article/pii/S1352231000003691, 2001.

Andreae, M. O.: Emission of trace gases and aerosols from biomass burning-an updated assessment, Atmospheric Chemistry and Physics, $19,8523-8546,2019$.

Astitha, M., Lelieveld, J., Abdel Kader, M., Pozzer, A., and de Meij, A.: Parameterization of dust emissions in the global atmospheric chemistry-climate model EMAC: impact of nudging and soil properties, Atmospheric Chemistry and Physics, 12, 11057-11083, https://doi.org/10.5194/acp-12-11057-2012, https://acp.copernicus.org/articles/12/11057/2012/, 2012.

Barna, M. and Lamb, B.: Improving ozone modeling in regions of complex terrain using observational nudging in a prognostic meteorological model, Atmospheric Environment, 34, 4889 - 4906, https://doi.org/https://doi.org/10.1016/S1352-2310(00)00231-4, http: //www.sciencedirect.com/science/article/pii/S1352231000002314, 2000.

Bates, K. H., Jacob, D. J., Wang, S., Hornbrook, R. S., Apel, E. C., Kim, M. J., Millet, D. B., Wells, K. C., Chen, X., Brewer, J. F., Ray, E. A., Commane, R., Diskin, G. S., and Wofsy, S. C.: The Global Budget of Atmospheric Methanol: New Constraints on Secondary, Oceanic, and Terrestrial Sources, Journal of Geophysical Research: Atmospheres, 126, https://doi.org/10.1029/2020jd033439, 2021.

Berrisford, P., Dee, D., Poli, P., Brugge, R., Fielding, M., Fuentes, M., Kållberg, P., Kobayashi, S., Uppala, S., and Simmons, A.: The ERA-Interim archive Version 2.0, p. 23, https://www.ecmwf.int/node/8174, 2011.

Bloss, C., Wagner, V., Jenkin, M. E., Volkamer, R., Bloss, W. J., Lee, J. D., Heard, D. E., Wirtz, K., Martin-Reviejo, M., Rea, G., Wenger, J. C., and Pilling, M. J.: Development of a detailed chemical mechanism (MCMv3.1) for the atmospheric oxidation of aromatic hydrocarbons, Atmospheric Chemistry and Physics, 5, 641-664, https://doi.org/10.5194/acp-5-641-2005, https://acp.copernicus.org/articles/5/641/2005/, 2005.

Cabrera-Perez, D., Taraborrelli, D., Sander, R., and Pozzer, A.: Global atmospheric budget of simple monocyclic aromatic compounds., Atmospheric Chemistry \& Physics, 16, 2016.

700 Capouet, M., Müller, J.-F., Ceulemans, K., Compernolle, S., Vereecken, L., and Peeters, J.: Modeling aerosol formation in alpha-pinene photo-oxidation experiments, Journal of Geophysical Research: Atmospheres, 113, https://doi.org/https://doi.org/10.1029/2007JD008995, 2008.

Carter, T. S., Heald, C. L., Jimenez, J. L., Campuzano-Jost, P., Kondo, Y., Moteki, N., Schwarz, J. P., Wiedinmyer, C., Darmenov, A. S., Silva, A. M. d., et al.: How emissions uncertainty influences the distribution and radiative impacts of smoke from fires in North America, Atmospheric Chemistry and Physics, 20, 2073-2097, 2020.

Clerbaux, C., Boynard, A., Clarisse, L., George, M., Hadji-Lazaro, J., Herbin, H., Hurtmans, D., Pommier, M., Razavi, A., Turquety, S., Wespes, C., and Coheur, P.-F.: Monitoring of atmospheric composition using the thermal infrared IASI/MetOp sounder, Atmospheric Chemistry and Physics, 9, 6041-6054, https://doi.org/10.5194/acp-9-6041-2009, 2009.

Crippa, M., Guizzardi, D., Muntean, M., Schaaf, E., Dentener, F., van Aardenne, J. A., Monni, S., Doering, U., Olivier, J. G. J., Pagliari, V., and Janssens-Maenhout, G.: Gridded emissions of air pollutants for the period 1970-2012 within EDGAR v4.3.2, Earth Syst. Sci. Data, 10, 1987-2013, https://doi.org/10.5194/essd-10-1987-2018, https://www.earth-syst-sci-data.net/10/1987/2018/, 2018. 
https://doi.org/10.5194/gmd-2021-295

Preprint. Discussion started: 29 September 2021

(c) Author(s) 2021. CC BY 4.0 License.

(c) (i)

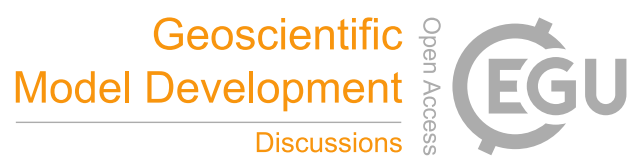

Crutzen, P. J. and Lawrence, M. G.: The impact of precipitation scavenging on the transport of trace gases: A 3-dimensional model sensitivity study, Journal of Atmospheric Chemistry, 37, 81-112, 2000.

Dalsøren, S. B., Myhre, G., Hodnebrog, Ø., Myhre, C. L., Stohl, A., Pisso, I., Schwietzke, S., Höglund-Isaksson, L., Helmig, D., Reimann,

S., et al.: Discrepancy between simulated and observed ethane and propane levels explained by underestimated fossil emissions, Nature Geoscience, 11, 178-184, 2018.

de Meij, A., Krol, M., Dentener, F., Vignati, E., Cuvelier, C., and Thunis, P.: The sensitivity of aerosol in Europe to two different emission inventories and temporal distribution of emissions, Atmospheric Chemistry and Physics, 6, 4287-4309, https://doi.org/10.5194/acp-64287-2006, https://acp.copernicus.org/articles/6/4287/2006/, 2006.

Deeter, M. N., Edwards, D. P., Francis, G. L., Gille, J. C., Mao, D., Martínez-Alonso, S., Worden, H. M., Ziskin, D., and Andreae, M. O.: Radiance-based retrieval bias mitigation for the MOPITT instrument: the version 8 product, Atmospheric Measurement Techniques, 12, 4561-4580, https://doi.org/10.5194/amt-12-4561-2019, https://amt.copernicus.org/articles/12/4561/2019/, 2019.

Denier Van Der Gon, H., Bergström, R., Fountoukis, C., Johansson, C., Pandis, S., Simpson, D., and Visschedijk, A. J.: Particulate emissions from residential wood combustion in Europe-revised estimates and an evaluation, Atmospheric Chemistry and Physics, 15, 6503-6519, 2015.

Dietmüller, S., Jöckel, P., Tost, H., Kunze, M., Gellhorn, C., Brinkop, S., Frömming, C., Ponater, M., Steil, B., Lauer, A., and Hendricks, J.: A new radiation infrastructure for the Modular Earth Submodel System (MESSy, based on version 2.51), Geoscientific Model Development, 9, 2209-2222, https://doi.org/10.5194/gmd-9-2209-2016, https://gmd.copernicus.org/articles/9/2209/2016/, 2016.

Donahue, N. M., Epstein, S., Pandis, S. N., and Robinson, A. L.: A two-dimensional volatility basis set: 1. organic-aerosol mixing thermodynamics, Atmospheric Chemistry and Physics, 11, 3303-3318, 2011.

Dubovik, O., Smirnov, A., Holben, B., King, M., Kaufman, Y., Eck, T., and Slutsker, I.: Accuracy assessments of aerosol optical properties retrieved from Aerosol Robotic Network (AERONET) Sun and sky radiance measurements, J. Geophys. Res, 105, 9791-9806, 2000.

Dufour, G., Szopa, S., Harrison, J. J., Boone, C. D., and Bernath, P. F.: Seasonal variations of acetone in the upper troposphere-lower stratosphere of the northern midlatitudes as observed by ACE-FTS, Journal of Molecular Spectroscopy, 323, 67-77, https://doi.org/10.1016/j.jms.2016.02.006, 2016.

E. Jenkin, M., Shallcross, D. E., and Harvey, J. N.: Development and application of a possible mechanism for the generation of cis-pinic acid from the ozonolysis of $\alpha$ and $\beta$ - pinene, Atmospheric Environment, 34, 2837 - 2850, http://www.sciencedirect.com/science/article/pii/ S135223100000087X, 2000.

Emmerichs, T., Kerkweg, A., Ouwersloot, H., Fares, S., Mammarella, I., and Taraborrelli, D.: A revised dry deposition scheme for land-atmosphere exchange of trace gases in ECHAM/MESSy v2.54, Geoscientific Model Development, 14, 495-519, https://doi.org/10.5194/gmd-14-495-2021, https://gmd.copernicus.org/articles/14/495/2021/, 2021.

Emmons, L., Arnold, S., Monks, S., Huijnen, V., Tilmes, S., Law, K. S., Thomas, J. L., Raut, J.-C., Bouarar, I., Turquety, S., et al.: The POLARCAT Model Intercomparison Project (POLMIP): overview and evaluation with observations, Atmospheric Chemistry and Physics, $15,6721-6744,2015$.

Emmons, L. K., Hauglustaine, D. A., Müller, J.-F., Carroll, M. A., Brasseur, G. P., Brunner, D., Staehelin, J., Thouret, V., and Marenco, A.: Data composites of airborne observations of tropospheric ozone and its precursors, J. Geophys. Res., 105, $20497-20538,2000$.

Epstein, S. A., Riipinen, I., and Donahue, N. M.: A semiempirical correlation between enthalpy of vaporization and saturation concentration for organic aerosol, Environmental science \& technology, 44, 743-748, 2010. 
https://doi.org/10.5194/gmd-2021-295

Preprint. Discussion started: 29 September 2021

(c) Author(s) 2021. CC BY 4.0 License.

(c) (i)

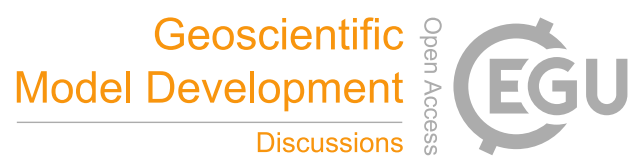

Farina, S. C., Adams, P. J., and Pandis, S. N.: Modeling global secondary organic aerosol formation and processing with the volatility basis set: Implications for anthropogenic secondary organic aerosol, Journal of Geophysical Research: Atmospheres, 115, https://doi.org/https://doi.org/10.1029/2009JD013046, https://agupubs.onlinelibrary.wiley.com/doi/abs/10.1029/2009JD013046, 2010.

Fischer, E., Jacob, D. J., Millet, D. B., Yantosca, R. M., and Mao, J.: The role of the ocean in the global atmospheric budget of acetone, Geophysical Research Letters, 39, 2012.

Fischer, E. V., Jacob, D. J., Yantosca, R. M., Sulprizio, M. P., Millet, D. B., Mao, J., Paulot, F., Singh, H. B., Roiger, A., Ries, L., Talbot,

R. W., Dzepina, K., and Deolal, S. P.: Atmospheric peroxyacetyl nitrate (PAN): a global budget and source attribution, Atmospheric Chemistry and Physics, 14, 2679-2698, https://doi.org/10.5194/acp-14-2679-2014, 2014.

Franco, B., Clarisse, L., Stavrakou, T., Müller, J.-F., Van Damme, M., Whitburn, S., Hadji-Lazaro, J., Hurtmans, D., Taraborrelli, D., Clerbaux, C., and Coheur, P.-F.: A General Framework for Global Retrievals of Trace Gases From IASI: Application to Methanol, Formic Acid, and PAN, Journal of Geophysical Research: Atmospheres, 123, 13,963-13,984, https://doi.org/10.1029/2018jd029633, 2018.

Franco, B., Clarisse, L., Stavrakou, T., Müller, J.-F., Pozzer, A., Hadji-Lazaro, J., Hurtmans, D., Clerbaux, C., and Coheur, P.-F.: Acetone Atmospheric Distribution Retrieved From Space, Geophysical Research Letters, 46, 2884-2893, https://doi.org/10.1029/2019g1082052, 2019.

Franco, B., Clarisse, L., Stavrakou, T., Müller, J.-F., Taraborrelli, D., Hadji-Lazaro, J., Hannigan, J. W., Hase, F., Hurtmans, D., Jones, N., Lutsch, E., Mahieu, E., Ortega, I., Schneider, M., Strong, K., Vigouroux, C., Clerbaux, C., and Coheur, P.-F.: Spaceborne Measurements of Formic and Acetic Acids: A Global View of the Regional Sources, Geophysical Research Letters, 47, e2019GL086239, https://doi.org/10.1029/2019g1086239, 2020.

Franco, B., Blumenstock, T., Cho, C., Clerbaux, C., Coheur, P.-F., Maziére, M., Smedt, I. D., Dorn, H.-P., T.Emmerichs, Fuchs, H., Gkatzelis, G., Grigffith, D., Gromov, S., Hannigan, J., Hase, F., Hohaus, T., Jones, N., Kerkweg, A., Kiendler-Scharr, A., Lutsch, E., Mahieu, E., Noveli, A., Ortega, I., Paton-Walsh, C., Pommier, M., Pozzer, A., Reimer, D., Rosanka, S., Sander, R., Schneider, M., Strong, K., Tillmann, R., Roozendael, M. V., Vereecken, L., Vigouroux, C., Wahner, A., and Taraborrelli, D.: Ubiquitous atmospheric production of organic acids mediated by cloud droplets, Nature, 593, 233-237, https://doi.org/10.1038/s41586-021-03462-x, 2021.

Fu, T.-M., Jacob, D. J., Wittrock, F., Burrows, J. P., Vrekoussis, M., and Henze, D. K.: Global budgets of atmospheric glyoxal and methylglyoxal, and implications for formation of secondary organic aerosols, Journal of geophysical research: atmospheres, $113,2008$.

Ge, X., Setyan, A., Sun, Y., and Zhang, Q.: Primary and secondary organic aerosols in Fresno, California during wintertime: Results from high resolution aerosol mass spectrometry, Journal of Geophysical Research: Atmospheres, 117, 2012.

George, I. and Abbatt, J.: Heterogeneous oxidation of atmospheric aerosol particles by gas-phase radicals, Nature Chemistry, 2, 713-722, 2010.

Gkatzelis, G. I., Papanastasiou, D. K., Karydis, V. A., Hohaus, T., Liu, Y., Schmitt, S. H., Schlag, P., Fuchs, H., Novelli, A., Chen, Q., et al.: Uptake of water-soluble gas-phase oxidation products drives organic particulate pollution in Beijing, Geophysical Research Letters, p. e2020GL091351, 2020

Gkatzelis, G. I., Papanastasiou, D. K., Karydis, V. A., Hohaus, T., Liu, Y., Schmitt, S. H., Schlag, P., Fuchs, H., Novelli, A., Chen, Q., et al.: Uptake of Water-soluble Gas-phase Oxidation Products Drives Organic Particulate Pollution in Beijing, Geophysical Research Letters, 48, e2020GL091 351, 2021.

Grewe, V., Brunner, D., Dameris, M., Grenfell, J., Hein, R., Shindell, D., and Staehelin, J.: Origin and variability of upper tropospheric nitrogen oxides and ozone at northern mid-latitudes, Atmospheric Environment, 35, 3421-3433, 2001. 
https://doi.org/10.5194/gmd-2021-295

Preprint. Discussion started: 29 September 2021

(c) Author(s) 2021. CC BY 4.0 License.

(c) (i)

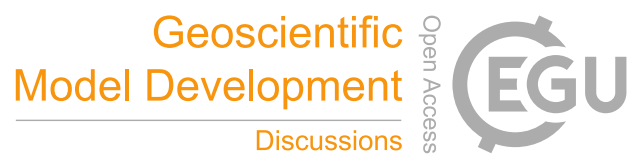

Guelle, W., Schulz, M., Balkanski, Y., and Dentener, F.: Influence of the source formulation on modeling the atmospheric global distribution of sea salt aerosol, Journal of Geophysical Research: Atmospheres, 106, 27 509-27 524, 2001.

Guenther, A., Karl, T., Harley, P., Wiedinmyer, C., Palmer, P. I., and Geron, C.: Estimates of global terrestrial isoprene emissions using MEGAN (Model of Emissions of Gases and Aerosols from Nature), Atmospheric Chemistry and Physics, 6, 3181-3210, https://doi.org/10.5194/acp-6-3181-2006, https://acp.copernicus.org/articles/6/3181/2006/, 2006.

Guenther, A. B., Jiang, X., Heald, C. L., Sakulyanontvittaya, T., Duhl, T., Emmons, L. K., and Wang, X.: The Model of Emissions of Gases and Aerosols from Nature version 2.1 (MEGAN2.1): an extended and updated framework for modeling biogenic emissions, Geoscientific Model Development, 5, 1471-1492, https://doi.org/10.5194/gmd-5-1471-2012, https://gmd.copernicus.org/articles/5/1471/2012/, 2012.

Hagemann, S. and Stacke, T.: Impact of the soil hydrology scheme on simulated soil moisture memory, Climate Dynamics, 44, 1731-1750, https://doi.org/10.1007/s00382-014-2221-6, 2015.

Hammer, M. S., van Donkelaar, A., Li, C., Lyapustin, A., Sayer, A. M., Hsu, N. C., Levy, R. C., Garay, M., Kalashnikova, O., Kahn, R. A., et al.: Global Estimates and Long-Term Trends of Fine Particulate Matter Concentrations (1998-2018), Environmental Science \& Technology, 13, 7879-7890, 2020.

Hayes, P., Ortega, A., Cubison, M., Froyd, K., Zhao, Y., Cliff, S., Hu, W., Toohey, D., Flynn, J., Lefer, B., et al.: Organic aerosol composition and sources in Pasadena, California, during the 2010 CalNex campaign, Journal of Geophysical Research: Atmospheres, 118, 9233-9257, 2013.

Heald, C., Coe, H., Jimenez, J., Weber, R., Bahreini, R., Middlebrook, A., Russell, L., Jolleys, M., Fu, T.-M., Allan, J., et al.: Exploring the vertical profile of atmospheric organic aerosol: comparing 17 aircraft field campaigns with a global model, Atmospheric Chemistry and Physics, 11, 12 673-12 696, 2011.

Heald, C. L. and Kroll, J. H.: The fuel of atmospheric chemistry: Toward a complete description of reactive organic carbon, Science Advances, 6, https://doi.org/10.1126/sciadv.aay8967, https://advances.sciencemag.org/content/6/6/eaay8967, 2020.

Heald, C. L., Jacob, D. J., Park, R. J., Russell, L. M., Huebert, B. J., Seinfeld, J. H., Liao, H., and Weber, R. J.: A large organic aerosol source in the free troposphere missing from current models, Geophysical Research Letters, 32, https://doi.org/10.1029/2005GL023831, https://agupubs.onlinelibrary.wiley.com/doi/abs/10.1029/2005GL023831, 2005.

810 Hens, K., Novelli, A., Martinez, M., Auld, J., Axinte, R., Bohn, B., Fischer, H., Keronen, P., Kubistin, D., Nölscher, A. C., Oswald, R., Paasonen, P., Petäjä, T., Regelin, E., Sander, R., Sinha, V., Sipilä, M., Taraborrelli, D., Tatum Ernest, C., Williams, J., Lelieveld, J., and Harder, H.: Observation and modelling of $\mathrm{HO}_{x}$ radicals in a boreal forest, Atmospheric Chemistry and Physics, 14, 8723-8747, https://doi.org/10.5194/acp-14-8723-2014, https://acp.copernicus.org/articles/14/8723/2014/, 2014.

Holben, B., Eck, T., Slutsker, I., Tanre, D., Buis, J., Setzer, A., Vermote, E., Reagan, J., Kaufman, Y., Nakajima, T., et al.: AERONET: federated instrument network and data archive for aerosol characterization, Remote Sensing of Environment, 66, 1-16, 1998.

Hsu, N., Tsay, S.-C., King, M., and Herman, J.: Aerosol properties over bright-reflecting source regions, IEEE Transactions on Geoscience and Remote Sensing, 42, 557-569, https://doi.org/10.1109/TGRS.2004.824067, 2004.

Huijnen, V., Pozzer, A., Arteta, J., Brasseur, G., Bouarar, I., Chabrillat, S., Christophe, Y., Doumbia, T., Flemming, J., Guth, J., Josse, B., Karydis, V. A., Marécal, V., and Pelletier, S.: Quantifying uncertainties due to chemistry modelling - evaluation of tropospheric composition simulations in the CAMS model (cycle 43R1), Geoscientific Model Development, 12, 1725-1752, https://doi.org/10.5194/gmd-121725-2019, https://gmd.copernicus.org/articles/12/1725/2019/, 2019.

Inness, A., Baier, F., Benedetti, A., Bouarar, I., Chabrillat, S., Clark, H., Clerbaux, C., Coheur, P., Engelen, R., Errera, Q., et al.: The MACC reanalysis: an 8-yr data set of atmospheric composition., Atmospheric Chemistry \& Physics Discussions, 12, 2012. 
https://doi.org/10.5194/gmd-2021-295

Preprint. Discussion started: 29 September 2021

(c) Author(s) 2021. CC BY 4.0 License.

(c) (i)

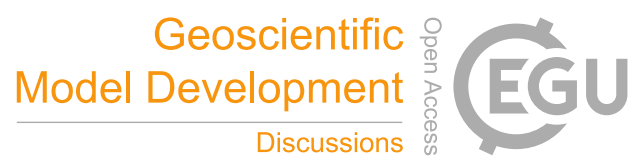

Jacob, D., Field, B., Jin, E., Bey, I., Li, Q., Logan, J., and Yantosca, R.: Atmospheric budget of acetone, J. Geophys. Res., 107, 4100, doi:10.1029/2001JD000 694, 2002.

Jacob, D. J., Field, B. D., Li, Q., Blake, D. R., de Gouw, J., Warneke, C., Hansel, A., Wisthaler, A., Singh, H. B., and Guenther, A.: Global budget of methanol: Constraints from atmospheric observations, J. Geophys. Res., 110, doi:10.1029/2004JD005 172, 2005.

Jenkin, M. E., Saunders, S. M., Wagner, V., and Pilling, M. J.: Protocol for the development of the Master Chemical Mechanism, MCM v3 (Part B): tropospheric degradation of aromatic volatile organic compounds, Atmospheric Chemistry and Physics, 3, 181-193, https://doi.org/10.5194/acp-3-181-2003, https://acp.copernicus.org/articles/3/181/2003/, 2003.

Jeuken, A., Siegmund, P., Heijboer, L., Feichter, J., and Bengtsson, L.: On the potential assimilating meteorological analyses in a global model for the purpose of model validation, J. Geophys. Res., 101, 16939-16950, 1996.

Jo, D., Park, R., Kim, M., and Spracklen, D.: Effects of chemical aging on global secondary organic aerosol using the volatility basis set approach, Atmospheric Environment, 81, 230-244, 2013.

Jöckel, P., Tost, H., Pozzer, A., Brühl, C., Bucholz, J., L., G., Hoor, P., Kerkweg, A., Lawrence, M., Sander, R., Steil, B., Stiller, G., Tanarhte, M., Taraborrelli, D., van Aardenne, J., and Lelieveld, J.: Evaluation of the atmospheric chemistry GCM ECHAM5/MESSy: Consistent simulation of ozone in the stratosphere and troposphere, Atmos. Chem. Phys., 6, 5067-5104, 2006.

Jöckel, P., Kerkweg, A., Pozzer, A., Sander, R., Tost, H., Riede, H., Baumgaertner, A., Gromov, S., and Kern, B.: Development cycle 2 of the Modular Earth Submodel System (MESSy2), Geoscientific Model Development, 3, 717-752, https://doi.org/10.5194/gmd-3-717-2010, https://gmd.copernicus.org/articles/3/717/2010/, 2010.

Jöckel, P., Tost, H., Pozzer, A., Kunze, M., Kirner, O., Brenninkmeijer, C. A. M., Brinkop, S., Cai, D. S., Dyroff, C., Eckstein, J., Frank, F., Garny, H., Gottschaldt, K.-D., Graf, P., Grewe, V., Kerkweg, A., Kern, B., Matthes, S., Mertens, M., Meul, S., Neumaier, M., Nützel, M., Oberländer-Hayn, S., Ruhnke, R., Runde, T., Sander, R., Scharffe, D., and Zahn, A.: Earth System Chemistry integrated Modelling (ESCiMo) with the Modular Earth Submodel System (MESSy) version 2.51, Geoscientific Model Development, 9, 1153-1200, https://doi.org/10.5194/gmd-9-1153-2016, https://gmd.copernicus.org/articles/9/1153/2016/, 2016.

Kaiser, J., Heil, A., Andreae, M., Benedetti, A., Chubarova, N., Jones, L., Morcrette, J.-J., Razinger, M., Schultz, M., Suttie, M., et al.: Biomass burning emissions estimated with a global fire assimilation system based on observed fire radiative power, Biogeosciences, 9 , $527,2012$.

Karl, T., Potosnak, M., Guenther, A., Clark, D., Walker, J., Herrick, J. D., and Geron, C.: Exchange processes of volatile organic compounds above a tropical rain forest: Implications for modeling tropospheric chemistry above dense vegetation, Journal of Geophysical Research: Atmospheres, 109, https://doi.org/https://doi.org/10.1029/2004JD004738, https://agupubs.onlinelibrary.wiley.com/doi/abs/10. 1029/2004JD004738, 2004.

Karydis, V., Tsimpidi, A., Pozzer, A., Astitha, M., and Lelieveld, J.: Effects of mineral dust on global atmospheric nitrate concentrations, Atmospheric Chemistry and Physics, 16, 1491-1509, 2016.

Kerkweg, A., Buchholz, J., Ganzeveld, L., Pozzer, A., Tost, H., and Jöckel, P.: Technical Note: An implementation of the dry removal processes DRY DEPosition and SEDImentation in the Modular Earth Submodel System (MESSy), Atmos. Chem. Phys., 6, 4617-4632, https://doi.org/https://doi.org/10.5194/gmd-14-495-2021, 2006a.

Kerkweg, A., Sander, R., Tost, H., and Jöckel, P.: Technical note: Implementation of prescribed (OFFLEM), calculated (ONLEM), and pseudo-emissions (TNUDGE) of chemical species in the Modular Earth Submodel System (MESSy), Atmos. Chem. Phys., 6, 36033609, https://doi.org/10.5194/acp-6-3603-2006, https://www.atmos-chem-phys.net/6/3603/2006/, 2006b. 
https://doi.org/10.5194/gmd-2021-295

Preprint. Discussion started: 29 September 2021

(c) Author(s) 2021. CC BY 4.0 License.

(c) (i)

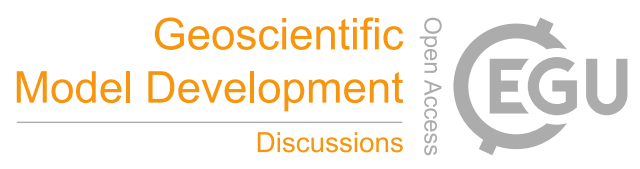

Khan, M., Cooke, M., Utembe, S., Archibald, A., Maxwell, P., Morris, W., Xiao, P., Derwent, R., Jenkin, M., Percival, C., Walsh, R., Young, T., Simmonds, P., Nickless, G., O’Doherty, S., and Shallcross, D.: A study of global atmospheric budget and distribution of acetone using global atmospheric model STOCHEM-CRI, Atmospheric Environment, 112, 269-277, https://doi.org/https://doi.org/10.1016/j.atmosenv.2015.04.056, https://www.sciencedirect.com/science/article/pii/ S1352231015300595, 2015.

Khan, M. A. H., Lyons, K., Chhantyal-Pun, R., McGillen, M. R., Caravan, R. L., Taatjes, C. A., Orr-Ewing, A. J., Percival, C. J., and Shallcross, D. E.: Investigating the Tropospheric Chemistry of Acetic Acid Using the Global 3-D Chemistry Transport Model, STOCHEM-CRI, Journal of Geophysical Research: Atmospheres, 123, 6267-6281, https://doi.org/10.1029/2018jd028529, 2018.

Klingmüller, K., Metzger, S., Abdelkader, M., Karydis, V. A., Stenchikov, G. L., Pozzer, A., and Lelieveld, J.: Revised mineral dust emissions in the atmospheric chemistry-climate model EMAC (MESSy 2.52 DU_Astitha1 KKDU2017 patch), Geoscientific Model Development, 11, 989-1008, https://doi.org/10.5194/gmd-11-989-2018, https://www.geosci-model-dev.net/11/989/2018/, 2018.

Kodros, J. K., Papanastasiou, D. K., Paglione, M., Masiol, M., Squizzato, S., Florou, K., Skyllakou, K., Kaltsonoudis, C., Nenes, A., and Pandis, S. N.: Rapid dark aging of biomass burning as an overlooked source of oxidized organic aerosol, Proceedings of the National Academy of Sciences, 117, 33 028-33 033, 2020.

Lana, A., Bell, T., Simó, R., Vallina, S., Ballabrera-Poy, J., Kettle, A., Dachs, J., Bopp, L., Saltzman, E., Stefels, J., et al.: An updated climatology of surface dimethlysulfide concentrations and emission fluxes in the global ocean, Global Biogeochemical Cycles, $25,2011$.

Lauer, A., Eyring, V., Hendricks, J., Jöckel, P., and Lohmann, U.: Global model simulations of the impact of ocean-going ships on aerosols, clouds, and the radiation budget, Atmos. Chem. Phys., 7, 5061-5079, https://doi.org/10.5194/acp-7-5061-2007, http://www. atmos-chem-phys.net/7/5061/2007/, 2007.

Lei, X., Chen, D., Wang, W., Liu, F., and Wang, W.: Quantum chemical studies of the OH-initiated oxidation reactions of propenols in the presence of O2, Molecular Physics, 117, 682-692, https://doi.org/10.1080/00268976.2018.1537527, 2018.

Lelieveld, J., Gromov, S., Pozzer, A., and Taraborrelli, D.: Global tropospheric hydroxyl distribution, budget and reactivity, Atmospheric Chemistry and Physics, 16, 12 477-12 493, https://doi.org/10.5194/acp-16-12477-2016, 2016.

Li, H., Väliranta, M., Mäki, M., Kohl, L., Sannel, A. B. K., Pumpanen, J., Koskinen, M., Bäck, J., and Bianchi, F.: Overlooked organic vapor emissions from thawing Arctic permafrost, Environmental Research Letters, 15, 104 097, https://doi.org/10.1088/1748-9326/abb62d, https://doi.org/10.1088/1748-9326/abb62d, 2020.

Li, Y., Pöschl, U., and Shiraiwa, M.: Molecular corridors and parameterizations of volatility in the chemical evolution of organic aerosols, Atmos. Chem. Phys, 16, 3327-3344, 2016.

Mallik, C., Tomsche, L., Bourtsoukidis, E., Crowley, J. N., Derstroff, B., Fischer, H., Hafermann, S., Hüser, I., Javed, U., Keßel, S., Lelieveld, J., Martinez, M., Meusel, H., Novelli, A., Phillips, G. J., Pozzer, A., Reiffs, A., Sander, R., Taraborrelli, D., Sauvage, C., Schuladen, J., Su, H., Williams, J., and Harder, H.: Oxidation processes in the eastern Mediterranean atmosphere: evidence from the modelling of $\mathrm{HO}_{x}$ measurements over Cyprus, Atmospheric Chemistry and Physics, 18, 10 825-10 847, https://doi.org/10.5194/acp-18-10825-2018, https://acp.copernicus.org/articles/18/10825/2018/, 2018.

Mann, G. W., Carslaw, K. S., Spracklen, D. V., Ridley, D. A., Manktelow, P. T., Chipperfield, M. P., Pickering, S. J., and Johnson, C. E.: Description and evaluation of GLOMAP-mode: a modal global aerosol microphysics model for the UKCA composition-climate model, Geosci. Model Dev., 3, 519-551, https://doi.org/10.5194/gmd-3-519-2010, http://www.geosci-model-dev.net/3/519/2010/, 2010. 
https://doi.org/10.5194/gmd-2021-295

Preprint. Discussion started: 29 September 2021

(c) Author(s) 2021. CC BY 4.0 License.

(c) (i)

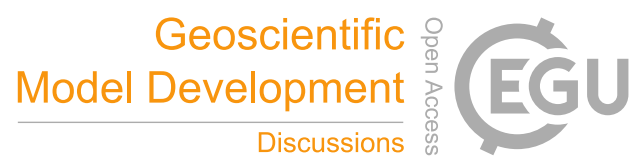

Millet, D. B., Jacob, D. J., Custer, T. G., de Gouw, J. A., Goldstein, A. H., Karl, T., Singh, H. B., Sive, B. C., Talbot, R. W., Warneke, C., and Williams, J.: New constraints on terrestrial and oceanic sources of atmospheric methanol, Atmospheric Chemistry and Physics, 8 , 6887-6905, https://doi.org/10.5194/acp-8-6887-2008, 2008.

Millet, D. B., Guenther, A., Siegel, D. A., Nelson, N. B., Singh, H. B., de Gouw, J. A., Warneke, C., Williams, J., Eerdekens, G., Sinha, V., Karl, T., Flocke, F., Apel, E., Riemer, D. D., Palmer, P. I., and Barkley, M.: Global atmospheric budget of acetaldehyde: 3-D model analysis and constraints from in-situ and satellite observations, Atmospheric Chemistry and Physics, 10, 3405-3425, https://doi.org/10.5194/acp10-3405-2010, 2010.

Millet, D. B., Baasandorj, M., Farmer, D. K., Thornton, J. A., Baumann, K., Brophy, P., Chaliyakunnel, S., de Gouw, J. A., Graus, M., Hu, L., Koss, A., Lee, B. H., Lopez-Hilfiker, F. D., Neuman, J. A., Paulot, F., Peischl, J., Pollack, I. B., Ryerson, T. B., Warneke, C., Williams, B. J., and Xu, J.: A large and ubiquitous source of atmospheric formic acid, Atmospheric Chemistry and Physics, 15, 62836304, https://doi.org/10.5194/acp-15-6283-2015, 2015.

Misztal, P. K., Hewitt, C. N., Wildt, J., Blande, J. D., Eller, A. S., Fares, S., Gentner, D. R., Gilman, J., Graus, M., Greenberg, J., et al.: Atmospheric benzenoid emissions from plants rival those from fossil fuels, Scientific reports, 5, 1-10, 2015.

Mohr, C., DeCarlo, P., Heringa, M., Chirico, R., Slowik, J., Richter, R., Reche, C., Alastuey, A., Querol, X., Seco, R., et al.: Identification and quantification of organic aerosol from cooking and other sources in Barcelona using aerosol mass spectrometer data, Atmospheric Chemistry and Physics, 12, 1649-1665, 2012.

Moreno, T., Querol, X., Castillo, S., Alastuey, A., Cuevas, E., Herrmann, L., Mounkaila, M., Elvira, J., and Gibbons, W.: Geochemical variations in aeolian mineral particles from the Sahara-Sahel Dust Corridor, Chemosphere, 65, 261 - 270, https://doi.org/https://doi.org/10.1016/j.chemosphere.2006.02.052,

http://www.sciencedirect.com/science/article/pii/ S0045653506002529, 2006.

Müller, J.-F., Liu, Z., Nguyen, V. S., Stavrakou, T., Harvey, J. N., and Peeters, J.: The reaction of methyl peroxy and hydroxyl radicals as a major source of atmospheric methanol, Nature Communications, 7, 13 213, https://doi.org/10.1038/ncomms13213, 2016.

Müller, J.-F., Stavrakou, T., Bauwens, M., Compernolle, S., and Peeters, J.: Chemistry and deposition in the Model of Atmospheric composition at Global and Regional scales using Inversion Techniques for Trace gas Emissions (MAGRITTE v1.0). Part B. Dry deposition, Geoscientific Model Development Discussions, 2018, 1-49, https://doi.org/10.5194/gmd-2018-317, https://gmd.copernicus.org/preprints/ gmd-2018-317/, 2018.

Ng, N. L., Canagaratna, M. R., Zhang, Q., Jimenez, J. L., Tian, J., Ulbrich, I. M., Kroll, J. H., Docherty, K. S., Chhabra, P. S., Bahreini, R., Murphy, S. M., Seinfeld, J. H., Hildebrandt, L., Donahue, N. M., DeCarlo, P. F., Lanz, V. A., Prévôt, A. S. H., Dinar, E., Rudich, Y., and Worsnop, D. R.: Organic aerosol components observed in Northern Hemispheric datasets from Aerosol Mass Spectrometry, Atmospheric Chemistry and Physics, 10, 4625-4641, https://doi.org/10.5194/acp-10-4625-2010, https://acp.copernicus.org/articles/10/ 4625/2010/, 2010.

Nguyen, T. L., Peeters, J., and Vereecken, L.: Theoretical study of the gas-phase ozonolysis of $\beta$-pinene (C10H16), Phys. Chem. Chem. Phys., 11, 5643-5656, https://doi.org/10.1039/B822984H, http://dx.doi.org/10.1039/B822984H, 2009.

Nölscher, A., Butler, T., Auld, J., Veres, P., Muñoz, A., Taraborrelli, D., Vereecken, L., Lelieveld, J., and Williams, J.: Using total $\mathrm{OH}$ reactivity to assess isoprene photooxidation via measurement and model, Atmospheric Environment, 89, 453-463, https://doi.org/10.1016/j.atmosenv.2014.02.024, 2014.

Novelli, A., Vereecken, L., Bohn, B., Dorn, H.-P., Gkatzelis, G. I., Hofzumahaus, A., Holland, F., Reimer, D., Rohrer, F., Rosanka, S., Taraborrelli, D., Tillmann, R., Wegener, R., Yu, Z., Kiendler-Scharr, A., Wahner, A., and Fuchs, H.: Importance of isomerization reactions for OH 
https://doi.org/10.5194/gmd-2021-295

Preprint. Discussion started: 29 September 2021

(c) Author(s) 2021. CC BY 4.0 License.

(c) (i)

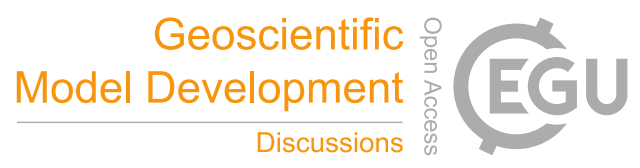

radical regeneration from the photo-oxidation of isoprene investigated in the atmospheric simulation chamber SAPHIR, Atmospheric Chemistry and Physics, 20, 3333-3355, https://doi.org/10.5194/acp-20-3333-2020, https://acp.copernicus.org/articles/20/3333/2020/, 2020.

Paglione, M., Gilardoni, S., Rinaldi, M., Decesari, S., Zanca, N., Sandrini, S., Giulianelli, L., Bacco, D., Ferrari, S., Poluzzi, V., et al.: The impact of biomass burning and aqueous-phase processing on air quality: a multi-year source apportionment study in the Po Valley, Italy, Atmospheric Chemistry and Physics, 20, 1233-1254, 2020.

Pai, S. J., Heald, C. L., Pierce, J. R., Farina, S. C., Marais, E. A., Jimenez, J. L., Campuzano-Jost, P., Nault, B. A., Middlebrook, A. M., Coe, H., et al:: An evaluation of global organic aerosol schemes using airborne observations, Atmospheric Chemistry and Physics, 20, 2637-2665, 2020.

Patra, P. K., Krol, M. C., Montzka, S. A., Arnold, T., Atlas, E. L., Lintner, B. R., Stephens, B. B., Xiang, B., Elkins, J. W., Fraser, P. J., Ghosh, A., Hintsa, E. J., Hurst, D. F., Ishijima, K., Krummel, P. B., Miller, B. R., Miyazaki, K., Moore, F. L., Mühle, J., O’Doherty, S., Prinn, R. G., Steele, L. P., Takigawa, M., Wang, H. J., Weiss, R. F., Wofsy, S. C., and Young, D.: Observational evidence for interhemispheric hydroxyl-radical parity, Nature, 513, 219-223, https://doi.org/10.1038/nature13721, 2014.

Paulot, F., Wunch, D., Crounse, J. D., Toon, G. C., Millet, D. B., DeCarlo, P. F., Vigouroux, C., Deutscher, N. M., Abad, G. G., Notholt, J., Warneke, T., Hannigan, J. W., Warneke, C., de Gouw, J. A., Dunlea, E. J., Mazière, M. D., Griffith, D. W. T., Bernath, P., Jimenez, J. L., and Wennberg, P. O.: Importance of secondary sources in the atmospheric budgets of formic and acetic acids, Atmospheric Chemistry and Physics, 11, 1989-2013, https://doi.org/10.5194/acp-11-1989-2011, 2011.

Pollmann, J., Helmig, D., Hueber, J., Plass-Dülmer, C., and Tans, P.: Sampling, storage, and analysis of C2-C7 non-methane hydrocarbons from the US National Oceanic and Atmospheric Administration Cooperative Air Sampling Network glass flasks, Journal of Chromatography A, 1188, 75-87, 2008.

Pöschl, U., Von Kuhlmann, R., Poisson, N., and Crutzen, P. J.: Development and intercomparison of condensed isoprene oxidation mechanisms for global atmospheric modeling, Journal of Atmospheric Chemistry, 37, 29-52, https://doi.org/10.1023/A:1006391009798, 2000.

Pozzer, A., Jöckel, P., Sander, R., Williams, J., Ganzeveld, L., and Lelieveld, J.: Technical Note: The MESSy-submodel AIRSEA calculating the air-sea exchange of chemical species, Atmos. Chem. Phys., 6, 5435-5444, https://doi.org/10.5194/acp-6-5435-2006, http: //www.atmos-chem-phys.net/6/5435/2006/, 2006.

Pozzer, A., Jöckel, P., Tost, H., Sander, R., Ganzeveld, L., Kerkweg, A., and Lelieveld, J.: Simulating organic species with the global atmospheric chemistry general circulation model ECHAM5/MESSy1: a comparison of model results with observations, Atmospheric Chemistry and Physics, 7, 2527-2550, https://doi.org/10.5194/acp-7-2527-2007, https://acp.copernicus.org/articles/7/2527/2007/, 2007.

Pozzer, A., Jöckel, P., and Van Aardenne, J.: The influence of the vertical distribution of emissions on tropospheric chemistry, Atmospheric Chemistry and Physics, 9, 9417-9432, https://doi.org/10.5194/acp-9-9417-2009, https://www.atmos-chem-phys.net/9/9417/2009/, 2009.

Pozzer, A., Pollmann, J., Taraborrelli, D., Jöckel, P., Helmig, D., Tans, P., Hueber, J., and Lelieveld, J.: Observed and simulated global distribution and budget of atmospheric $\mathrm{C}_{2}-\mathrm{C}_{5}$ alkanes, Atmos. Chem. Phys., 10, 4403-4422, https://doi.org/10.5194/acp-10-4403-2010, http://www.atmos-chem-phys.net/10/4403/2010/, 2010.

Pozzer, A., de Meij, A., Pringle, K. J., Tost, H., Doering, U. M., van Aardenne, J., and Lelieveld, J.: Distributions and regional budgets of aerosols and their precursors simulated with the EMAC chemistry-climate model, Atmos. Chem. Phys., 12, 961-987, https://doi.org/10.5194/acp-12-961-2012, http://www.atmos-chem-phys.net/12/961/2012/, 2012a. 
https://doi.org/10.5194/gmd-2021-295

Preprint. Discussion started: 29 September 2021

(c) Author(s) 2021. CC BY 4.0 License.

(c) (i)

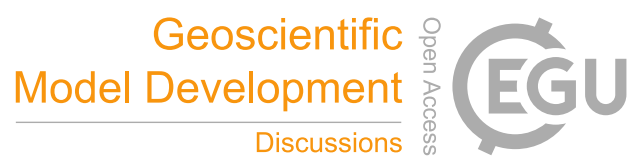

Pozzer, A., Zimmermann, P., Doering, U., van Aardenne, J., Tost, H., Dentener, F., Janssens-Maenhout, G., and Lelieveld, J.: Effects of business-as-usual anthropogenic emissions on air quality, Atmos. Chem. Phys., 12, 6915-6937, https://doi.org/10.5194/acp-12-69152012, http://www.atmos-chem-phys.net/12/6915/2012/, 2012b.

Pringle, K. J., Tost, H., Metzger, S., Steil, B., Giannadaki, D., Nenes, A., Fountoukis, C., Stier, P., Vignati, E., and Lelieveld, J.: Description and evaluation of GMXe: a new aerosol submodel for global simulations (v1), Geosci. Model Dev., 3, 391-412, https://doi.org/10.5194/gmd-3-391-2010, http://www.geosci-model-dev.net/3/391/2010/, 2010a.

Pringle, K. J., Tost, H., Pozzer, A., Pöschl, U., and Lelieveld, J.: Global distribution of the effective aerosol hygroscopicity parameter for CCN activation, Atmos. Chem. Phys., 10, 5241-5255, https://doi.org/10.5194/acp-10-5241-2010, http://www.atmos-chem-phys.net/10/ $5241 / 2010 /, 2010 b$.

Ramo, R., Roteta, E., Bistinas, I., van Wees, D., Bastarrika, A., Chuvieco, E., and van der Werf, G. R.: African burned area and fire carbon emissions are strongly impacted by small fires undetected by coarse resolution satellite data, Proceedings of the National Academy of Sciences, 118, https://doi.org/10.1073/pnas.2011160118, https://www.pnas.org/content/118/9/e2011160118, 2021.

Reid, E. A., Reid, J. S., Meier, M. M., Dunlap, M. R., Cliff, S. S., Broumas, A., Perry, K., and Maring, H.: Characterization of African dust transported to Puerto Rico by individual particle and size segregated bulk analysis, Journal of Geophysical Research: Atmospheres, 108, https://doi.org/https://doi.org/10.1029/2002JD002935, https://agupubs.onlinelibrary.wiley.com/doi/abs/10.1029/2002JD002935, 2003.

Roeckner, E., Brokopf, R., Esch, M., Giorgetta, M., Hagemann, S., Kornblueh, L., Manzini, E., Schlese, U., and Schulzweida, U.: Sensitivity of simulated climate to horizontal and vertical resolution in the ECHAM5 atmosphere model, Journal of Climate, 19, 3771-3791, 2006.

Rosanka, S., Vu, G. H. T., Nguyen, H. M. T., Pham, T. V., Javed, U., Taraborrelli, D., and Vereecken, L.: Atmospheric chemical loss processes of isocyanic acid (HNCO): a combined theoretical kinetic and global modelling study, Atmospheric Chemistry and Physics, 20, 66716686, https://doi.org/10.5194/acp-20-6671-2020, https://acp.copernicus.org/articles/20/6671/2020/, 2020.

Rosanka, S., Sander, R., Wahner, A., and Taraborrelli, D.: Oxidation of low-molecular-weight organic compounds in cloud droplets: development of the Jülich Aqueous-phase Mechanism of Organic Chemistry (JAMOC) in CAABA/MECCA (version 4.5.0), Geoscientific Model Development, 14, 4103-4115, https://doi.org/10.5194/gmd-14-4103-2021, https://gmd.copernicus.org/articles/14/4103/2021/, 2021a.

Rosanka, S., Sander, R., Franco, B., Wespes, C., Wahner, A., and Taraborrelli, D.: Oxidation of low-molecular-weight organic compounds in cloud droplets: global impact on tropospheric oxidants, Atmospheric Chemistry and Physics, 21, 9909-9930, https://doi.org/10.5194/acp21-9909-2021, https://acp.copernicus.org/articles/21/9909/2021/, 2021b.

Rosanka, S., Franco, B., Clarisse, L., Coheur, P.-F., Pozzer, A., Wahner, A., and Taraborrelli, D.: The impact of organic pollutants from Indonesian peatland fires on the tropospheric and lower stratospheric composition, Atmospheric Chemistry and Physics, 21, 1125711 288, https://doi.org/10.5194/acp-21-11257-2021, https://acp.copernicus.org/articles/21/11257/2021/, 2021c.

Sander, R.: Compilation of Henry's law constants (version 4.0) for water as solvent, Atmospheric Chemistry and Physics, 15, 4399-4981, https://doi.org/10.5194/acp-15-4399-2015, https://acp.copernicus.org/articles/15/4399/2015/, 2015.

Sander, R., Baumgaertner, A., Cabrera-Perez, D., Frank, F., Gromov, S., Grooß, J.-U., Harder, H., Huijnen, V., Jöckel, P., Karydis, V. A., Niemeyer, K. E., Pozzer, A., Riede, H., Schultz, M. G., Taraborrelli, D., and Tauer, S.: The community atmospheric chemistry box model CAABA/MECCA-4.0, Geoscientific Model Development, 12, 1365-1385, https://doi.org/10.5194/gmd-12-1365-2019, https://gmd.copernicus.org/articles/12/1365/2019/, 2019.

Schaap, M.: On the importance of aerosol nitrate over Europe : data analysis and modelling, Ph.D. thesis, Universiteit Utrecht, Nederland, https://dspace.library.uu.nl/handle/1874/708, 2003. 
Schaap, M., van Loon, M., ten Brink, H. M., Dentener, F. J., and Builtjes, P. J. H.: Secondary inorganic aerosol simulations for Europe with special attention to nitrate, Atmospheric Chemistry and Physics, 4, 857-874, https://doi.org/10.5194/acp-4-857-2004, https://acp. copernicus.org/articles/4/857/2004/, 2004.

Scholten, R. C., Jandt, R., Miller, E. A., Rogers, B. M., and Veraverbeke, S.: Overwintering fires in boreal forests, Nature, 593, 399-404, 2021.

Singh, H. B., Chen, Y., Staudt, A., Jacob, D., Blake, D., Heikes, B., and Snow, J.: Evidence from the Pacific troposphere for large global sources of oxygenated organic compounds, Nature, 410, 1078-1081, https://doi.org/10.1038/35074067, 2001.

Stavrakou, T., Guenther, A., Razavi, A., Clarisse, L., Clerbaux, C., Coheur, P.-F., Hurtmans, D., Karagulian, F., Mazière, M. D., Vigouroux, C., Amelynck, C., Schoon, N., Laffineur, Q., Heinesch, B., Aubinet, M., Rinsland, C., and Müller, J.-F.: First space-based derivation of the global atmospheric methanol emission fluxes, Atmospheric Chemistry and Physics, 11, 4873-4898, https://doi.org/10.5194/acp-114873-2011, 2011.

Stavrakou, T., Müller, J.-F., Peeters, J., Razavi, A., Clarisse, L., Clerbaux, C., Coheur, P.-F., Hurtmans, D., Mazière, M. D., Vigouroux, C., Deutscher, N. M., Griffith, D. W. T., Jones, N., and Paton-Walsh, C.: Satellite evidence for a large source of formic acid from boreal and tropical forests, Nature Geoscience, 5, 26-30, https://doi.org/10.1038/ngeo1354, 2012.

Sun, Y.-L., Zhang, Q., Schwab, J., Demerjian, K., Chen, W.-N., Bae, M.-S., Hung, H.-M., Hogrefe, O., Frank, B., Rattigan, O., et al.: Characterization of the sources and processes of organic and inorganic aerosols in New York city with a high-resolution time-of-flight aerosol mass apectrometer, Atmospheric Chemistry and Physics, 11, 1581-1602, 2011.

Taraborrelli, D., Lawrence, M. G., Butler, T. M., Sander, R., and Lelieveld, J.: Mainz Isoprene Mechanism 2 (MIM2): an isoprene oxidation mechanism for regional and global atmospheric modelling, Atmospheric Chemistry and Physics, 9, 2751-2777, https://doi.org/10.5194/acp-9-2751-2009, https://acp.copernicus.org/articles/9/2751/2009/, 2009.

Taraborrelli, D., Lawrence, M. G., Crowley, J. N., Dillon, T. J., Gromov, S., Groß, C. B. M., Vereecken, L., and Lelieveld, J.: Hydroxyl radical buffered by isoprene oxidation over tropical forests, Nature Geoscience, 5, 190-193, https://doi.org/10.1038/ngeo1405, 2012.

Taraborrelli, D., Cabrera-Perez, D., Bacer, S., Gromov, S., Lelieveld, J., Sander, R., and Pozzer, A.: Influence of aromatics on tropospheric gas-phase composition, Atmospheric Chemistry and Physics, 21, 2615-2636, https://doi.org/10.5194/acp-21-2615-2021, https: //acp.copernicus.org/articles/21/2615/2021/, 2021.

Tilmes, S., Lamarque, J.-F., Emmons, L. K., Kinnison, D. E., Marsh, D., Garcia, R. R., Smith, A. K., Neely, R. R., Conley, A., Vitt, F., et al.: Representation of the community earth system model (CESM1) CAM4-chem within the chemistry-climate model initiative (CCMI), Geoscientific Model Development, 9, 1853-1890, 2016.

Tost, H. and Pringle, K. J.: Improvements of organic aerosol representations and their effects in large-scale atmospheric models, Atmospheric Chemistry and Physics, 12, 8687-8709, https://doi.org/10.5194/acp-12-8687-2012, https://acp.copernicus.org/articles/12/8687/2012/, 2012.

Tost, H., Jöckel, P., Kerkweg, A., Sander, R., and Lelieveld, J.: Technical Note: A new comprehensive SCAVenging submodel for global atmospheric chemistry modelling, Atmos. Chem. Phys., 6, 565-574, 2006.

Tsimpidi, A. P., Karydis, V. A., Pozzer, A., Pandis, S. N., and Lelieveld, J.: ORACLE (v1.0): module to simulate the organic aerosol composition and evolution in the atmosphere, Geoscientific Model Development, 7, 3153-3172, https://doi.org/10.5194/gmd-7-31532014, https://gmd.copernicus.org/articles/7/3153/2014/, 2014. 
https://doi.org/10.5194/gmd-2021-295

Preprint. Discussion started: 29 September 2021

(c) Author(s) 2021. CC BY 4.0 License.

(c) (i)

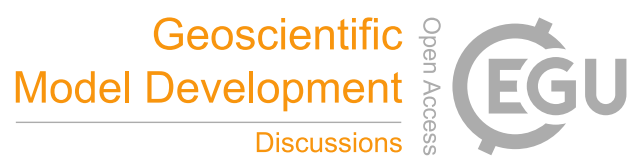

Tsimpidi, A. P., Karydis, V. A., Pandis, S. N., and Lelieveld, J.: Global combustion sources of organic aerosols: model comparison with

84 AMS factor-analysis data sets, Atmospheric Chemistry and Physics, 16, 8939-8962, https://doi.org/10.5194/acp-16-8939-2016, https: //acp.copernicus.org/articles/16/8939/2016/, 2016.

van der Werf, G. R., Randerson, J. T., Giglio, L., van Leeuwen, T. T., Chen, Y., Rogers, B. M., Mu, M., van Marle, M. J. E., Morton, D. C., Collatz, G. J., Yokelson, R. J., and Kasibhatla, P. S.: Global fire emissions estimates during 1997-2016, Earth System Science Data, 9, 697-720, https://doi.org/10.5194/essd-9-697-2017, 2017.

van Eijck, A., Opatz, T., Taraborrelli, D., Sander, R., and Hoffmann, T.: New tracer compounds for secondary organic aerosol formation from $\beta$-caryophyllene oxidation, Atmospheric Environment, 80, 122-130, https://doi.org/10.1016/J.ATMOSENV.2013.07.060, 2013.

Vereecken, L. and Peeters, J.: A theoretical study of the OH-initiated gas-phase oxidation mechanism of $\beta$-pinene (C10H16): first generation products, Phys. Chem. Chem. Phys., 14, 3802-3815, https://doi.org/10.1039/C2CP23711C, http://dx.doi.org/10.1039/C2CP23711C, 2012.

Vereecken, L., Müller, J.-F., and Peeters, J.: Low-volatility poly-oxygenates in the OH-initiated atmospheric oxidation of $\alpha$-pinene: impact of non-traditional peroxyl radical chemistry, Phys. Chem. Chem. Phys., 9, 5241-5248, https://doi.org/10.1039/B708023A, http://dx.doi. org/10.1039/B708023A, 2007.

Vereecken, L., Novelli, A., and Taraborrelli, D.: Unimolecular decay strongly limits the atmospheric impact of Criegee intermediates, Phys. Chem. Chem. Phys., 19, 31 599-31 612, https://doi.org/10.1039/C7CP05541B, http://dx.doi.org/10.1039/C7CP05541B, 2017.

Vignati, E., Wilson, J., and Stier, P.: M7: An efficient size-resolved aerosol microphysics module for large-scale aerosol transport models, J. Geophys. Res., 109, https://doi.org/10.1029/2003JD004485, 2004.

Wang, C., Yuan, T., Wood, S. A., Goss, K.-U., Li, J., Ying, Q., and Wania, F.: Uncertain Henry's law constants compromise equilibrium partitioning calculations of atmospheric oxidation products, Atmospheric Chemistry and Physics, 17, 7529-7540, https://doi.org/10.5194/acp17-7529-2017, https://acp.copernicus.org/articles/17/7529/2017/, 2017.

Wang, S., Hornbrook, R. S., Hills, A., Emmons, L. K., Tilmes, S., Lamarque, J.-F., Jimenez, J. L., Campuzano-Jost, P., Nault, B. A., Crounse, J. D., Wennberg, P. O., Kim, M., Allen, H., Ryerson, T. B., Thompson, C. R., Peischl, J., Moore, F., Nance, D., Hall, B., Elkins, J., Tanner, D., Huey, L. G., Hall, S. R., Ullmann, K., Orlando, J. J., Tyndall, G. S., Flocke, F. M., Ray, E., Hanisco, T. F., Wolfe, G. M., Clair, J. S., Commane, R., Daube, B., Barletta, B., Blake, D. R., Weinzierl, B., Dollner, M., Conley, A., Vitt, F., Wofsy, S. C., Riemer, D. D., and Apel, E. C.: Atmospheric Acetaldehyde: Importance of Air-Sea Exchange and a Missing Source in the Remote Troposphere, Geophysical Research Letters, https://doi.org/10.1029/2019g1082034, 2019.

Weilenmann, M., Favez, J.-Y., and Alvarez, R.: Cold-start emissions of modern passenger cars at different low ambient temperatures and their evolution over vehicle legislation categories, Atmospheric environment, 43, 2419-2429, 2009.

Wesely, M.: Parameterization of surface resistances to gaseous dry deposition in regional-scale numerical models, Atmospheric Environment (1967), 23, 1293-1304, 1989.

Whitburn, S., Van Damme, M., Clarisse, L., Bauduin, S., Heald, C. L., Hadji-Lazaro, J., Hurtmans, D., Zondlo, M. A., Clerbaux, C., and Coheur, P.-F.: A flexible and robust neural network IASI-NH3 retrieval algorithm, Journal of Geophysical Research: Atmospheres, 121, 6581-6599, https://doi.org/10.1002/2016jd024828, 2016.

Wolfe, G. M., Nicely, J. M., St. Clair, J. M., Hanisco, T. F., Liao, J., Oman, L. D., Brune, W. B., Miller, D., Thames, A., González Abad, G., Ryerson, T. B., Thompson, C. R., Peischl, J., McKain, K., Sweeney, C., Wennberg, P. O., Kim, M., Crounse, J. D., Hall, S. R., Ullmann, K., Diskin, G., Bui, P., Chang, C., and Dean-Day, J.: Mapping hydroxyl variability throughout the global remote troposphere 
https://doi.org/10.5194/gmd-2021-295

Preprint. Discussion started: 29 September 2021

(C) Author(s) 2021. CC BY 4.0 License.

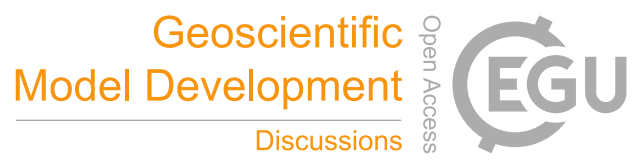

via synthesis of airborne and satellite formaldehyde observations, Proceedings of the National Academy of Sciences, 116, 11 171-11 180, https://doi.org/10.1073/pnas.1821661116, 2019.

Yienger, J.: Empirical model of global soil-biogenic NOx emissions, J. Geophys. Res., 100, 464, 1995. 